Juliana de ARaújo Melo

\title{
Adesão medicamentosa e complexidade do regime terapêutico em idosos com polifarmácia atendidos em hospital dia
}

Tese apresentada à Faculdade de Medicina da Universidade de São Paulo para obtenção do título de Doutor em Ciências

Programa de Ciências Médicas

Área de concentração: Educação e Saúde

Orientador: Prof. Dr. José Marcelo Farfel

São Paulo

2019 
Dados Internacionais de Catalogação na Publicação (CIP)

Preparada pela Biblioteca da

Faculdade de Medicina da Universidade de São Paulo

Creprodução autorizada pelo autor

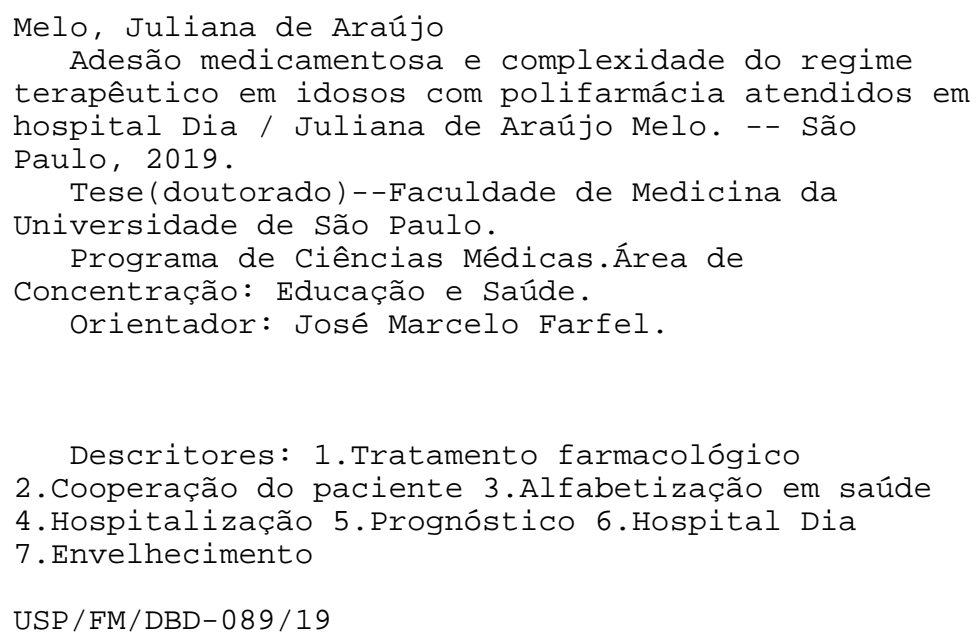

Responsável: Erinalva da Conceição Batista, CRB-8 6755 


\title{
Dedicatória
}

\begin{abstract}
À minha família.
Aos meus pais, Hildérico e Angela, que sempre colocaram minha educação acima de tudo. Por todo o amor e dedicação.
\end{abstract}

À minha irmã, Polyana, pelo amor e incentivo constantes.

À Maria das Neves, que sempre se dedicou a cuidar de mim como uma filha.

Ao meu esposo, Sileno, que além do amor e felicidade plantados diariamente na minha vida, me incentivou na execução esse projeto.

À minha pequena Maria, que me inspira a vida. 


\section{Agradecimentos}

Ao meu orientador, Professor Dr. José Marcelo Farfel, por todo o auxílio e disponibilidade demostrados desde o início do projeto. Minha eterna gratidão.

Ao Dr. Márlon Juliano Romero Aliberti por todo o empenho e dedicação apostados nesse projeto. Serei eternamente grata por ter acreditado que seria possível transformar o Hospital Dia Geriátrico num ambiente de pesquisa capaz de gerar nossas teses de doutorado.

Ao Dr. Sileno de Queiroz Fortes Filho, pelo enorme incentivo e auxílio na finalização desse projeto.

Ao Prof. Dr. Wilson Jacob Filho, por todo o aprendizado durante minha formação em geriatria e pela grandiosa contribuição no exame de qualificação.

Ao Dr. Daniel Apolinário que, desde o início sempre se mostrou muito solícito e disposto a auxiliar nas inúmeras dúvidas que tivemos na execução do projeto. Pela grandiosa e fundamental contribuição no exame de qualificação.

À Dra. Maria do Carmo Sitta pela valiosa contribuição na minha formação médica e por todo o incentivo no exame de qualificação. Sempre será um grande exemplo de profissional para mim.

À Dra. Solange Bricola pelos ensinamentos sobre farmácia clínica durante a residência de clínica médica e pela contribuição no exame de qualificação.

A Thaís Peretti, Christian Douradinho, Laís Silva, Camila Barros, Fernanda Dusilek, Stéphanie Viana e Natália Souza pela enorme dedicação na coleta e tabulação de dados. Sem a ajuda de vocês, a realização desse projeto não seria possível.

Ao Dr. Jonas Gordilho pela generosidade em partilhar seu projeto e me auxiliar nos primeiros passos junto ao serviço de Pós Graduação.

A TODA equipe do Hospital Dia Geriátrico da FMUSP pela compreensão e apoio durante a coleta de dados. 


\section{Normatização}

Esta tese está de acordo com as seguintes normas, em vigor no momento desta publicação:

Referências: adaptado de International Committee of Medical Journals Editors (Vancouver).

Universidade de São Paulo. Faculdade de Medicina. Divisão de Biblioteca e Documentação. Guia de apresentação de dissertações, teses e monografias. Elaborado por Anneliese Carneiro da Cunha, Maria Julia de A. L. Freddi, Maria F. Crestana, Marinalva de Souza Aragão, Suely Campos Cardoso, Valéria Vilhena. 3a ed. São Paulo: Divisão de Biblioteca e Documentação; 2011.

Abreviaturas dos títulos dos periódicos de acordo com List of Journals Indexed in Index Medicus. 


\section{Sumário}

Lista de Siglas e Abreviaturas

Lista de símbolos

Lista de Tabelas

Lista de Quadros

Lista de Figuras

Resumo

Abstract

1 INTRODUÇÃO E RELEVÂNCIA DO TEMA.............................................. 1

1.1 Envehecimento e polifarmácia ......................................................... 2

1.2 Adesão ao tratamento medicamentoso ............................................. 5

1.3 Alfabetismo em saúde e adesão medicamentosa ........................... 10

1.4 Complexidade do regime terapêutico ........................................... 14

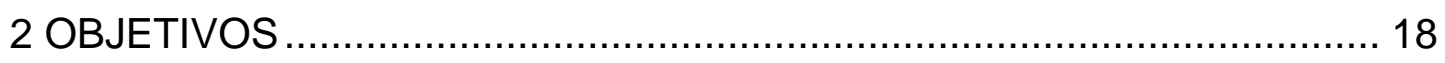

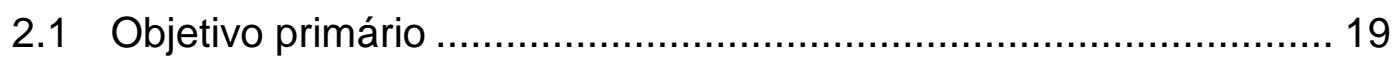

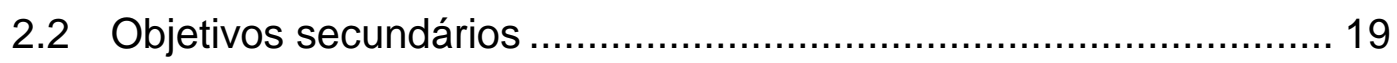

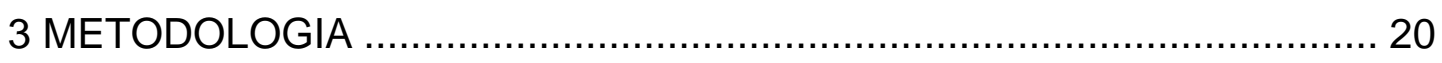

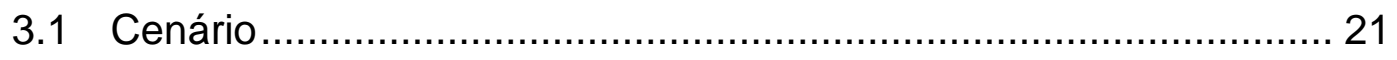

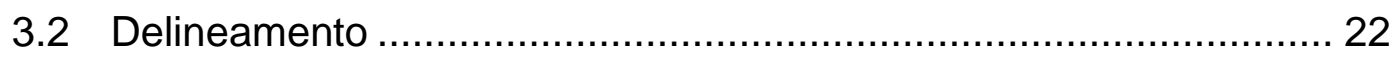

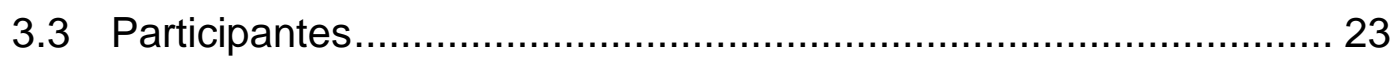

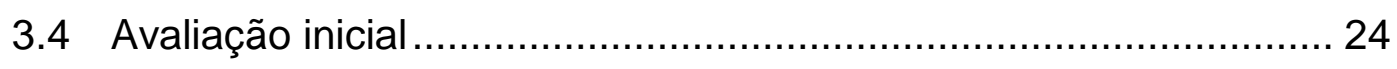

3.4.1 Características sociodemográficas .................................... 25

3.4.2 Suporte social .............................................................. 26

3.4.3 Uso recente do Sistema de Saúde .................................... 27

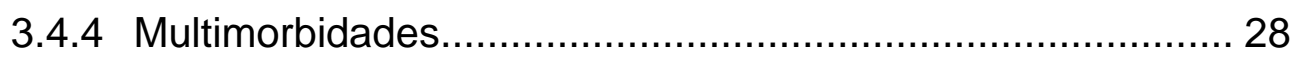

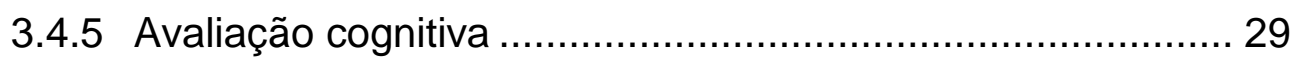

3.4.6 Avaliação de sintomas depressivos ................................... 30

3.4.7 Avaliação de funcionalidade ............................................ 31

3.4.8 Uso de medicamentos .................................................... 32

3.4.9 Avaliação de déficits sensoriais (visão e audição) ................. 33

3.4.10 Avaliação de analfabetismo em saúde ............................... 33

3.5 Avaliação da adesão medicamentosa .......................................... 34 
3.5.1 The Monsky Medicatio Adherence Scale: MMAS-6

3.5.2 Conhecimento do regime terapêutico .................................. 36

3.5.3 Teste da Caixa Orgnizadora de Medicamentos.................... 38

3.6 Avaliação da complexidade do regime terapêutico ......................... 41

3.7 Ténica de amostragem e recrutamento ........................................ 42

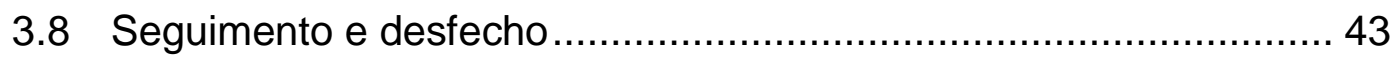

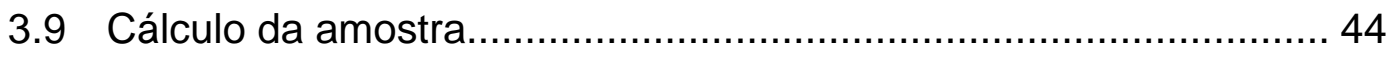

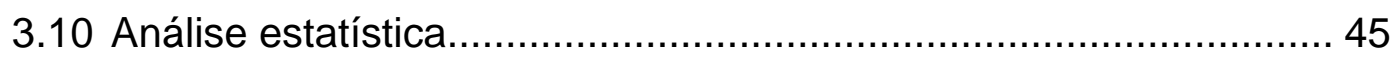

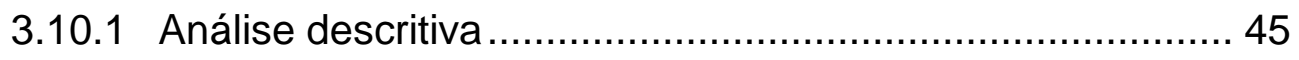

3.10.1.1 Escala do Conhecimento do Regime Terapêutico ....................................................... 46

3.10.1.2 Teste da Caixa de Medicamentos........................ 46

3.10.1.3 Escala de Morisky ............................................. 47

3.10.1.4 Índice de Complexidade do Regime Terapêutico ........................................................ 47

3.10.2 Análise transversal ........................................................ 47

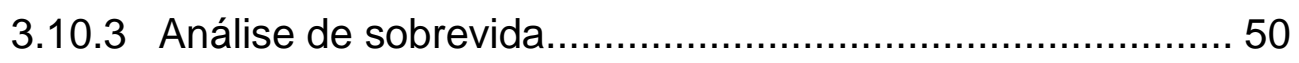

4 QUESTÕES ÉTICAS, PROJETO "GUARDA-CHUVA" E

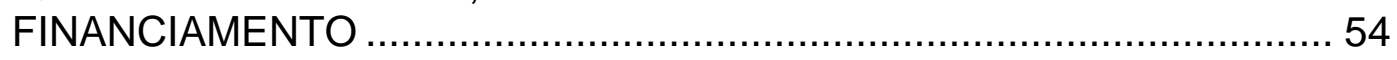

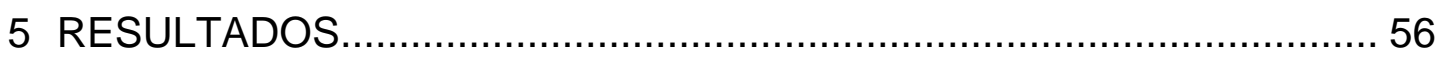

5.1 Associação das características sociodemográficas e clinicas

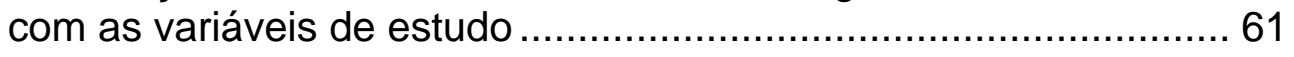

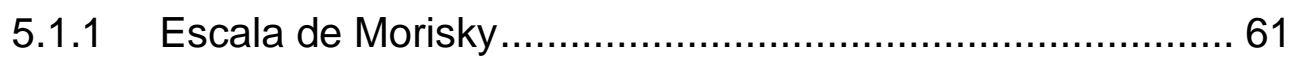

5.1.2 Escala do Conhecimento do Regime Terapêutico ............... 64

5.1.3 Teste da Caixa Organizadora de Medicamentos ................. 69

5.1.4 Índice de Complexidade do Regime Terapêutico ............... 73

5.1.5 Interação entre o Conhecimento do Regime Terapêutico e alfabetismo em saúde através do ICFT ....... 76

5.1.6 Interação entre a escala de Morisky e o GDS-15 ……....... 77

5.1.7 Interação entre o Teste da Caixa de Medicamentos e SAHLPA.................................................................. 77

5.2 Predição das variáveis de estudo para hospitalização .................... 78

5.2.1 Escala de Morisky e Hospitalização ………….................. 78

5.2.2 Conhecimento do regime terapêutico e hospitalização ...... 80

5.2.3 Teste da Caixa de Medicamentos e Hospitalização ............ 82

5.2.4 Complexidade do Regime Terapêutico e Hospitalização ... 84 
5.3 Predição das variáveis de estudo para visita ao pronto socorro ..... 86

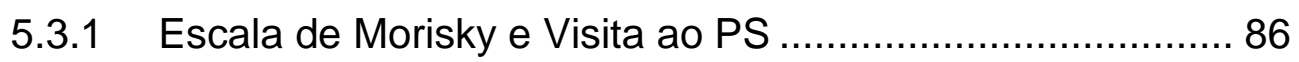

5.3.2 Conhecimento do Regime Terapêutico e Visita ao PS ....... 88

5.3.3 Teste da Caixa de Medicamentos e Visitas ao PS ............. 90

5.3.4 Complexidade do Regime Terapêutico e Visita ao PS ....... 92

5.4 Interação dos testes de adesão terapêutica e o índice de complexidade do regime terapêutico na predição de hospitalização e visita ao PS.

5.4.1 Interação da Escala de Morisky na predição de hospitalização e visita ao PS

5.4.2 Interação da escala do conhecimento do Regime Terapêutico na predição de hospitalização e visita ao PS

5.4.3 Interação do Teste da Caixa de Medicamentos na predição de hospitalização e visita ao PS.

5.4.4 Interação do Índice de Complexidade do Regime Terapêutico na predição de hospitalização e visita ao PS....

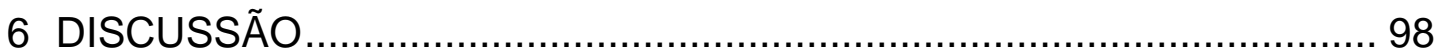

7 PONTOS FORTES EM RELAÇÃO À LITERATURA …........................ 110

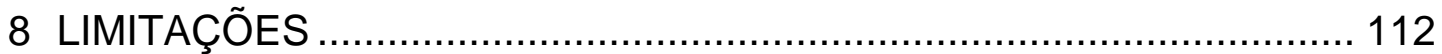

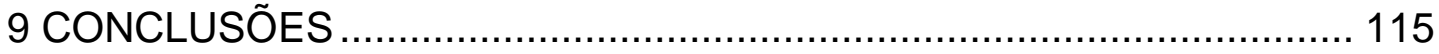

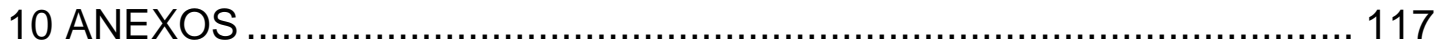

Anexo A - Índice de Complexidade da Farmacoterapia........................ 118

Anexo B - Ficha de Seguimento Telefônico....................................... 121

Anexo C - Termo de Consentimento Livre e Esclarecido .................... 123

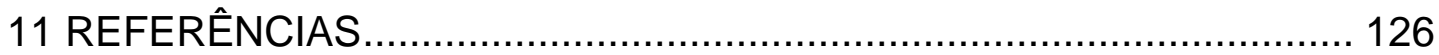




\section{Listas}

\section{ABREVIATURAS E SIGLAS}

$\begin{array}{ll}\text { BOMFAQ } & \begin{array}{l}\text { Brazilian Older Americans Resources and Services } \\ \text { Multidimensional Functional Assessment Questionnaire }\end{array} \\ \text { CAPPesq } & \text { Comitê de Ética para Análise de Projetos de Pesquisa } \\ \text { DP } & \text { Desvio Padrão }\end{array}$

FAPESP Fundação de Amparo à Pesquisa do Estado de São Paulo

GDS-15 Geriatric Depression Scale-15

HCFMUSP Hospital das Clínicas da Faculdade de Medicina da Universidade de São Paulo

HDG Hospital Dia Geriátrico

HR Hazard Ratio

IC Intervalo de Confiança

ICFT Índice de Complexidade da Farmacoterapia

MEEM Mini Exame do Estado Mental

MMAS-8 The Morisky Medication Adherence Scale

MOS Medical Outcomes Study

MRCI Medication Regimen Complexity Index

OMS Organização Mundial de Saúde

OR Odds Ratio

PPSUS Programa de Pesquisa para o SUS

PS Pronto Socorro

REALM Rapid Estimate of Adult Literacy in Medicine 
ROC Receiver Operating Characteristic

RR Risco Relativo

SAHLPA-18 Short Assessment of Health Literacy for PortugueseSpeaking Adults

SUS Sistema Único de Saúde

TOFHLA Test of Functional Health Literacy in Adults

VIF Variance Inflation Factor 


\section{SíMBOLOS}

$\begin{array}{ll}\% & \text { porcentagem } \\ < & \text { Menor } \\ \leq & \text { Maior } \\ \mathbf{x} & \text { Menor ou igual } \\ \mathbf{c m} & \text { Maior ou igual } \\ \mathbf{m E q} / \mathbf{L} & \text { centímetros } \\ \mathbf{m m H g} & \text { miliequivalente por litro } \\ \mathbf{p . e x} . & \text { por exemplo } \\ \boldsymbol{v} . \boldsymbol{s} . & \text { versus } \\ \text { X2 } & \text { qui-quadrado }\end{array}$




\section{TABELAS}

Tabela 1 - Motivos de encaminhamento dos participantes incluídos ao Hospital Dia Geriátrico ................................................... 58

Tabela 2 - Características sociodemográficas e clínicas dos

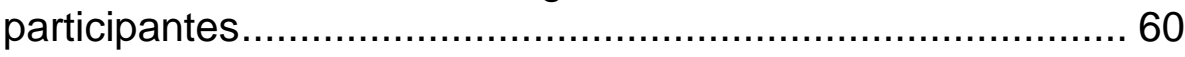

Tabela 3 - Fatores associados à adesão medicamentosa de acordo com a Escala de Morisky

Tabela 4 - Regressão Logistica Multivariada em Regressão Hierárquica dos fatores associados à baixa adesão pela Escala de Morisky

Tabela 5 - Fatores associados à Escala de Conhecimento do Regime Terapêutico dividido em tercis

Tabela 6 - Regressão Linear Múltipla em estratégia hierárquica dos fatores associados à Escala de Conhecimento Terapêutico

Tabela 7 - Fatores associados ao Teste da Caixa de Medicamentos...... 71

Tabela 8 - Regressão Logística Multivariada em estratégia hierárquica dos fatores associados ao preenchimento inadequado do Teste da Caixa de Medicamentos

Tabela 9 - Fatores associados ao Índice de Complexidade Farmacêutica dividido em tercis

Tabela 10 - Regressão Linear Múltipla em estratégia hierárquica dos fatores associados ao Índice de Complexidade Farmacêutica

Tabela 11 - Modelo de regressão de Cox em estratégia hierárquica para descrever a adição da escala de Morisky na predição de hospitalização

Tabela 12 - Modelo de regressão de Cox em estratégia hierárquica para descrever a adição do conhecimento do regime terapêutico na predição de hospitalização

Tabela 13 - Modelo de regressão de Cox em estratégia hierárquica para descrever a adição do Teste da Caixa de Medicamentos na predição de hospitalização

Tabela 14 - Modelo de Regressão de Cox em estratégia hierárquica para descrever a Adição do ICFT na predição de hospitalização

Tabela 15 - Modelo de regressão de Cox em estratégia hierárquica para descrever a adição da escala de Morisky na predição de visitas ao PS 
Tabela 16 - Modelo de regressão de Cox em estratégia hierárquica para descrever a adição do conhecimento do regime terapêutico na predição de visitas ao PS ................................ 89

Tabela 17 - Modelo de regressão de Cox em estratégia hierárquica para descrever a adição do Teste da Caixa de Medicamentos na predição de visitas ao PS

Tabela 18 - Modelo de regressão de Cox em estratégia hierárquica para descrever a adição do ICFT na predição de visitas ao PS 


\section{QUADROS}

Quadro 1 - Principais doenças agudas e crônicas descompensadas encaminhadas ao Hospital Dia Geriátrico ............................... 23

Quadro 2 - Critérios de inclusão e exclusão .......................................... 24

Quadro 3 - Características sociodemográficas ....................................... 25

Quadro 4 - Escala de Oito Itens do Medical Outcomes Study (MOS) -

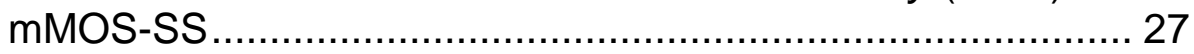

Quadro 5 - Índice de Multimorbidades de Charlson ................................. 28

Quadro 6 - Mini Exame do Estado Mental ............................................ 29

Quadro 7 - Escala de Depressão Geriátrica de 15 Itens (GDS-15)........... 30

Quadro 8 - Brazilian Multidimensional Functional Assessment Questionnaire (BOMFAQ) ................................................. 32

Quadro 9 - Escala de Adesão Terapêutica de Morisky de 8 Itens -

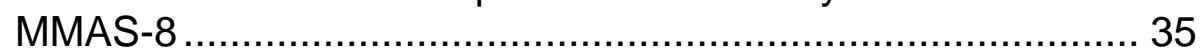

Quadro 10 - Escala do Conhecimento do Regime Terapêutico .................. 37

Quadro 11 - Modo de entrada das covariáveis nos modelos de regressão linear e logística .................................................. 50

Quadro 12 - Descrição das variáveis independentes na análise de sobrevida ................................................................... 51

Quadro 13 - Modo de entrada das covariáveis no modelo de regressão de riscos proporcionais de Cox 


\section{FIGURAS}

Figura 1 - Instrumentos utilizados para execução do Teste da Caixa de Medicamentos.

Figura 2 - Histograma da Escala do Conhecimento do Regime Terapêutico

Figura 2 - Histograma do Índice de Complexidade do Regime

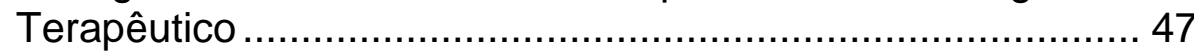

Figura 4 - Fluxograma do recrutamento da amostra ............................. 57

Figura 5 - Percentual médio de acertos de cada etapa da Escala de Conhecimento Terapêutico

Figura 6 - Percentual de acertos de cada etapa do Teste da Caixa de Medicamentos............................................................. 69

Figura 7 - Predição Linear Ajustada e IC95\% usando o índice de Complexidade do Regime Terapêutico como fator que modula o efeito do alfabetismo em saúde na Escala do Conhecimento do Regime Terapêutico.

Figura 8 - Curvas de Kaplan-Meier para Hospitalização em 6 meses de acordo com a Escala de Morisky

Figura 9 - Curvas de Kaplan-Meier para Hospitalização em 6 meses de acordo com a Escala do Conhecimento do Regime Terapêutico

Figura 10 - Curvas de Kaplan-Meier para Hospitalização em 6 meses de acordo com o Teste da Caixa de Medicamentos

Figura 11 - Curvas de Kaplan-Meier para Hospitalização em 6 meses de acordo com o índice de Complexidade do Regime Terapêutico

Figura 12 - Curvas de Kaplan-Meier para Visitas ao Pronto Socorro em 6 meses de acordo com a Escala de Morisky

Figura 13 - Curvas de Kaplan-Meier para Visitas ao Pronto Socorro em 6 meses de acordo com a Escala de Conhecimento do Regime Terapêutico.

Figura 14 - Curvas de Kaplan-Meier para Visitas ao Pronto Socorro em 6 meses de Acordo com o Teste da Caixa de Medicamentos.

Figura 15 - Curvas de Kaplan-Meier para Visitas ao Pronto Socorro em 6 meses de acordo como índice de Complexidade do Regime Terapêutico. 


\section{Resumo}

Melo JA. Adesão medicamentosa e complexidade do regime terapêutico em idosos com polifarmácia atendidos em hospital dia [tese]. São Paulo: Faculdade de Medicina, Universidade de São Paulo; 2019.

Introdução: Adesão ao tratamento medicamentoso e complexidade do regime terapêutico têm relação com o manejo de doenças crônicas em idosos com polifarmácia. No entanto, é escassa a avaliação da adesão e da complexidade terapêutica em idosos com condições agudas atendidos em ambiente com tempo e recursos limitados. Objetivos: Avaliar adesão medicamentosa e complexidade do regime terapêutico como preditores para hospitalização e visita ao Pronto Socorro (PS) em seis meses em idosos com polifarmácia atendidos em hospital dia. Avaliar os fatores clínicos e demográficos associados à adesão medicamentosa e complexidade do regime terapêutico. Métodos: Estudo de coorte prospectivo com 207 participantes (média de 77,8 $\pm 8,2$ anos de idade; $67 \%$ mulheres) admitidos em um hospital dia geriátrico. Adesão medicamentosa foi avaliada através de três instrumentos: Escala de Morisky, Escala do Conhecimento do Regime Terapêutico e Teste da Caixa Organizadora de Medicamentos. A complexidade do regime terapêutico foi avaliada através do índice de Complexidade da Farmacoterapia. Houve seguimento de seis meses por contato telefônico mensal para aferição dos desfechos hospitalização e visitas ao PS. Os fatores associados à adesão e à complexidade do regime foram avaliados através de modelos de regressão linear ou logística conforme a apresentação das variáveis independentes. Modelos de riscos proporcionais associaram os testes de adesão e de complexidade aos desfechos adversos. Resultados: Após ajuste de variáveis sociodemográficas e clínicas, alfabetismo em saúde inadequado foi fator associado a um baixo conhecimento do regime terapêutico ( $\beta$-11,3; IC95\% 16,6 - -6,1) e ao preenchimento incorreto da caixa organizadora de medicamentos (OR 5,5; IC95\% 2,6 - 11,6). A presença de sintomas depressivos foi associada a baixa adesão pela escala de Morisky (OR 2,4; IC95\% 1,1 - 5,4), a um baixo conhecimento do regime terapêutico ( $\beta-5,3$; IC95\% -10,2 - -0,4) e a maior complexidade do regime terapêutico $(\beta 6,1$; IC95\% 2,6 - 9,6). Alta complexidade do regime terapêutico foi fator protetor para hospitalização (HR 0,3; IC95\% 0,1 - 0,8). Os testes de adesão medicamentosa não foram preditores de hospitalização e visita ao PS. Conclusões: Alfabetismo em saúde e a presença de sintomas depressivos foram associados à adesão medicamentosa. A presença de sintomas depressivos foi associada a complexidade do regime terapêutico. Adesão medicamentosa e complexidade do regime terapêutico não foram preditores de hospitalização ou visita ao PS.

Descritores: Tratamento Farmacológico; Cooperação do paciente; Alfabetização em saúde; Hospitalização; Prognóstico; Hospital dia; Envelhecimento 


\section{Abstract}

Melo JA. Medication adherence and complexity of the therapeutic regimen among older adults with polypharmacy in a day hospital [thesis]. São Paulo: "Faculdade de Medicina, Universidade de São Paulo"; 2019.

Introduction: Medication adherence and complexity of the therapeutic regimen are associated with the management of chronic diseases in older adults with polypharmacy. However, the evaluation of adherence and therapeutic complexity in older adults with acute conditions attended in a busy healthcare setting with limited time and resources is scarce. Objectives: To evaluate the value of medication adherence and the complexity of the therapeutic regimen in predicting 6-month hospitalization and emergency room visits in older adults with polypharmacy. To evaluate sociodemographic and clinical factors associated with medication adherence and the complexity of the therapeutic regimen. Methods: A prospective cohort study with 207 participants (mean age $77.8 \pm 8.2$ years, $67 \%$ female) admitted to a geriatric day hospital. Medication adherence was measured with three instruments: 8-item Morisky Medication Adherence Scale, Medicine Knowledge Assessment Form and a mock prescription test. The complexity of the therapeutic regimen was evaluated with the Pharmacotherapy Complexity Index. We conducted 6-month follow-up by monthly phone contacts to assess the outcomes, which included hospitalization and emergency room visits. The factors associated with the medication adherence and the complexity of the therapeutic regime were evaluated with linear or logistic regression models according to the independent variables. Hazard models were used to associate adherence tests and complexity tool with adverse outcomes. Results: After adjusting sociodemographic and clinical variables, inadequate health literacy was associated with a low knowledge of the therapeutic regimen $(\beta-11.3,95 \% \mathrm{Cl}$ $-16.6--6.1$ ), and incorrect filling of the a mock prescription test (OR 5.5, IC95\% 2.6-11.6). The presence of depressive symptoms was associated with low adherence by the Morisky scale (OR 2.4, 95\% Cl 1.1 - 5.4), low knowledge of the therapeutic regimen $(\beta-5,3,95 \% \mathrm{Cl}-10,2--0.4)$ and a high complexity of the therapeutic regimen $(\beta 6.1,95 \% \mathrm{Cl} 2.6-9.6)$. During the 6 month follow-up period, the incidence of hospitalization was $27.4 \%$ and emergency room visits was $48.8 \%$. High complexity of the therapeutic

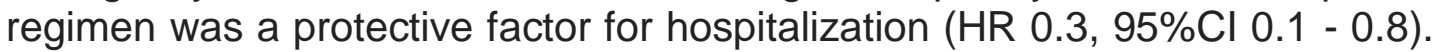
Conclusions: Medication adherence was associated with health literacy and depressive symptoms. The complexity of the therapeutic regimen was associated with depressive symptoms. Medication adherence and complexity of the therapeutic regimen were not predictors for hospitalization or emergency room visits.

Descriptors: Drug therapy; Patient compliance; Health literacy; Hospitalization; Prognosis; Day care, medical; Aging 


\section{INTRODUÇÃO E}

RELEVÂNCIA DO TEMA 


\section{INTRODUÇÃO E RELEVÂNCIA DO TEMA}

\subsection{ENVELHECIMENTO E POLIFARMÁCIA}

Um grande desafio para o sistema de saúde brasileiro, atualmente, é o fenômeno demográfico do acelerado envelhecimento populacional. Cerca de doze por cento da população brasileira nos dias atuais é composta por idosos e, aproximadamente, um terço dos gastos totais no Sistema Único de Saúde (SUS) pode ser atribuída a esta população (Turra et al., 2001; Camarano et al., 2009; IBGE, 2010; DATASUS, 2013). Em 2050, a estimativa é que o número de idosos cresça e represente aproximadamente 29\% da população (Instituto Brasileiro de Geografia e Estatística - IBGE, 2013).

As doenças crônicas, mais comuns na população idosa, requerem acompanhamento constante com o objetivo de reduzir o risco de perda de independência e autonomia e aumentar a expectativa e a qualidade de vida. A maior prevalência de doenças crônicas faz com que idosos sejam grandes consumidores de serviços de saúde e o grupo que, proporcionalmente, mais faz uso de medicações (Mathes et al., 2013).

A população idosa contribui com aproximadamente $25 \%$ do total das vendas de medicamentos em países desenvolvidos (Santos et al., 2013). Mais de $40 \%$ dos indivíduos maiores de 65 anos consomem cinco ou mais 
medicamentos por semana e $12 \%$ usam pelo menos dez drogas diferentes (Kaufman et al., 2002).

Conceitualmente, alguns estudos não especificam o número mínimo de medicações que definem o diagnóstico de polifarmácia. Esse ponto de corte varia entre o uso de mais de dois até dez medicamentos de modo contínuo. Contudo, a definição mais aceita e difundida na literatura internacional descreve polifarmácia como o uso de cinco ou mais medicações de forma contínua. Recentemente, essa definição foi corroborada pela associação do uso de cinco ou mais drogas de modo contínuo com desfechos desfavoráveis e efeitos adversos em idosos (Salvi et al., 2016; Wimmer et al., 2016). Outro conceito que merece destaque é a hiperpolifarmácia ou polifarmarmácia excessiva: uso de dez ou mais medicações de maneira contínua (Gnjidic et al., 2012).

Dados do estudo SABE apontam prevalência de polifarmácia de $36 \%$ entre os idosos da cidade de São Paulo. Sexo feminino (OR = 1,7; IC 95\%: 1,0-2,9), idade igual ou superior a 75 anos (OR = 1,9; IC 95\%: 1,3-2,7), maior renda $(\mathrm{OR}=1,8 ; \mathrm{IC} 95 \%: 1,2-2,8)$, estar trabalhando $(\mathrm{OR}=1,8 ; \mathrm{IC}$ $95 \%: 1,1 ; 2,9)$, auto avaliação de saúde regular (OR = 1,6; IC 95\%: 1,1-2,3) ou ruim $(O R=2,6 ;$ IC $95 \%$ : 1,4-4,9) apresentaram associação com polifarmácia. Usar apenas o sistema público de saúde (OR = 0,5; IC 95\%: 0,3-0,7) associou-se com menor risco de polifarmácia (Carvalho et al., 2012).

Uma coorte envolvendo 2057 participantes avaliou a polifarmácia como preditora de desfechos desfavoráveis em idosos atendidos em serviço de emergência. Nesse estudo, polifarmácia foi associada com maior 
mortalidade intra-hospitalar (OR=1,63; IC 95\% 1,0-2,65), retorno ao serviço de emergência em trinta dias (OR=1,28; IC 95\% 1,09-1,50) e readmissão hospitalar (OR=1,49; IC 95\% 1,42-1,80). Polifarmácia excessiva também foi fator preditor de mortalidade em seis meses (OR=1,74; IC 95\% 1,28-2,36) (Salvi et al., 2016).

Um estudo italiano de base populacional demonstrou que, na análise multivariada, polifarmácia crônica esteve associada à hospitalização em um ano $(\mathrm{OR}=1,16$; IC $95 \%$ 1,14-1,17), institucionalização (OR=1,21; IC 95\% 1,12-1,30) e morte (OR=1,11; IC 95\% 1,08-1,14) (Franchi et al., 2016).

Sganga et al. (2015) realizaram um estudo prospectivo de coorte com 480 participantes para avaliar se idosos com polifarmácia tinham maior risco de hospitalização e mortalidade em um ano. Neste trabalho, 26,9\% dos idosos no grupo sem polifarmácia e $39,1 \%$ no grupo polifarmácia foram reinternados $(p=0,004) ; 6,2 \%$ no grupo sem polifarmácia e $9,7 \%$ no grupo polifarmácia morreram durante 0 primeiro ano de acompanhamento $(p=0,16)$. Após o ajuste para possíveis fatores de confusão, os participantes do grupo polifarmácia tiveram um risco aumentado de rehospitalização em um ano, em comparação com os do grupo sem polifarmácia $(R R=1,81$; IC $95 \%$ 1,18-2,75). Não houve associação significativa entre mortalidade e polifarmácia.

Não adesão ao tratamento farmacológico, reações adversas, interações medicamentosas, alto custo com a medicação e hospitalizações estão frequentemente associados à polifarmácia (Costa et al., 2011). 


\subsection{ADESÃO AO TRATAMENTO MEDICAMENTOSO}

A Organização Mundial de Saúde (OMS) define adesão como o "grau em que o comportamento de uma pessoa coincide com as recomendações do profissional da saúde, em relação a tomada de medicamentos, seguimento de dieta ou mudanças no estilo de vida". Segundo relato da OMS, esse valor ocorre em torno de $50 \%$ quando são avaliadas doenças crônicas (OMS, 2003).

Melhorar a adesão pode ter um efeito maior sobre a saúde do indivíduo do que a própria otimização da terapia medicamentosa já prescrita. Por isso, a identificação da não adesão é um tema desafiador e extremamanete útil para a prática clínica. Se não identificada de maneira correta, a falta de adesão pode conduzir ao aumento da dose de uma medicação inicial ou adição de uma segunda droga, por exemplo, aumentando assim o risco de efeitos adversos, idas aos serviços de emergência, hospitalizações, menor qualidade de vida e aumento de custos para o sistema de saúde. Dados americanos demonstram que um a dois terços de todas as internações hospitalares estão associadas à não adesão medicamentosa (Osterberg et al., 2005).

Uma grande metanálise de 2016, composta por 57 estudos, demostrou que intervenções realizadas para melhorar adesão terapêutica em indivíduos com insuficiência cardíaca são fatores que reduzem readmissão hospitalar $(\mathrm{OR}=0,79$; IC $95 \% \quad 0,71-0,89)$ e mortalidade (RR=0,89; IC 95\%, 0,81-0,99) (Ruppar et al., 2016). Esse dado reforça a 
hipótese de que tentativas para melhorar a adesão são fundamentais para o seguimento e o manejo adequado de indivíduos com doenças crônicas.

No Brasil, estudos prévios também têm demonstrado que a não adesão ao tratamento medicamentoso é prevalente - em torno de $22 \%$ a $40 \%$ - e associada a resultados adversos e custos mais elevados para o sistema de saúde (Rocha et al., 2008; Carvalho et al., 2012). É a principal responsável pelas falhas no tratamento, pelo uso irracional de medicamentos e por agravos no processo patológico. Compromete a segurança e a qualidade do tratamento e está relacionada com aumento de mortalidade e morbidade (Oliveira-Filho et al., 2014).

A adesão ao tratamento medicamentoso é influenciada por diversos fatores, incluindo alguns fatores individuais (status socioeconômico, sexo, raça, idade) e outros relacionados ao sistema de saúde (disponibilidade de medicações gratuitas pelo governo e complexidade do regime terapêutico prescrito) (Núñez Montenegro et al., 2014).

Segundo a OMS (2003) há cinco dimensões que devem ser avaliadas quando se avalia adesão a medicamentos:

1. Fatores sociais: dificuldade para comparecer às consultas médicas em virtude de grandes distâncias ou por ausência de suporte social adequado; falta de disponibilidade para permanecer na fila da farmácia;

2. Fatores econômicos: dificuldade para pagamento de transporte ou medicações prescritas; 
3. Fatores relacionados ao sistema de saúde: prescrição de regimes terapêuticos complexos, barreiras de comunicação, comunicação ineficaz de informações sobre efeitos adversos, atendimento por vários médicos diferentes, tempo limitado para as consultas e falta de tecnologia da informação de saúde;

4. Fatores relacionados à terapia medicamentosa: explicação ineficaz sobre o uso correto das medicações bem como seus possíveis efeitos colaterais;

5. Fatores relacionados ao próprio indivíduo: desconhecimentos sobre a doença e suas consequências, alfabetização de saúde abaixo do ideal e falta de envolvimento no processo de tomada de decisões de tratamento.

Um dos grandes desafios relacionados ao tema adesão é a sua mensuração, uma vez que, existem diversos métodos disponíveis e cada um deles possui limitações. Os métodos para avaliação de adesão podem ser divididos em dois grupos: métodos diretos e indiretos. Métodos diretos incluem dosagem sérica da droga ou de metabólitos, dosagem de biomarcadores séricos ou observação direta da tomada. Apesar de serem considerados mais eficazes, os métodos diretos são influenciados por vários fatores e incluem custos mais elevados. Já os métodos indiretos incluem questionários baseados no autorrelato dos pacientes, contagem de pílulas, monitoração eletrônica de medicações e contagem de medicações dispensadas pela farmácia. O autorrelato dos pacientes é o método indireto 
mais utilizado e amplamente divulgado na literatura (Oliveira-Filho et al., 2014).

Outro ponto fundamental para avaliação da adesão é a medida do conhecimento do regime terapêutico prescrito. Recentemente, vários trabalhos publicados alertam para importância desse tema e sua associação com adesão adequada.

Entende-se como conhecimento do regime terapêutico: "O conjunto de informações adquiridas pelo paciente sobre seus medicamentos de uso contínuo, incluindo alvo terapêutico (visualização e eficácia), o processo de aplicação (dosagem, regime, via de administração e duração tratamento), a segurança (efeitos adversos, precauções, contraindicações e interações) e sua conservação" (García Delgado et al., 2009).

Outra definição sobre esse tópico admite que conhecimento sobre o regime terapêutico engloba consciência do nome do medicamento, finalidade, posologia, efeitos adversos ou efeitos colaterais e instruções especiais para a tomada (Ascione et al., 1986).

Existem diversos trabalhos na literatura que abordam esse tema. Cada trabalho descreve um formato diferente para mensurar o conhecimento dos pacientes sobre o regime terapêutico. A maioria questiona sobre nome, dose, motivo de uso e efeitos colaterais (Burge et al., 2005). Outros utilizam um modelo mais simplificado onde apenas dosagem, frequência e indicação são questionadas (Hope et al., 2004).

Em 2012, um estudo observacional teve como objetivo determinar se existe relação entre a falta de conhecimento do regime terapêutico prescrito 
e a adesão autorreferida. Foram avaliados 765 participantes com média de idade de 55 anos; 58\% relataram boa adesão e 64,5\% referiram conhecimento adequado do regime terapèutico prescito. Houve correlação estatisticamente significativa entre o conhecimento do regime terapêutico e o nível de adesão à medicação ( $r=0,964, p<0,001)$ (Okuyan et al., 2013).

Outro grande estudo transversal envolvendo mais de 1000 idosos palestinos avaliou a correlação entre o adequado conhecimento sobre o regime terapêutico prescrito e adesão. Nessa população, a porcetagem de conhecimento e adesão adequados foram 67,57\% e 89,29\%, respectivamente. Os fatores associados com níveis significativamente mais elevados de conhecimento do regime e adesão foram sexo masculino, maior escolaridade, maior renda e pratica de atividade física $(p<0,05)$. Houve correlação entre adesão e conhecimento do regime $(r=0,487 ; p<0,001)$. Foi encontrada também correlação entre o menor conhecimento do regime e o número de medicamentos tomados $(r=-0,130 ; p<0,001)$ (Najjar et al., 2015).

Estudo transversal publicado recentemente avaliou os fatores relacionados ao adequado conhecimento do regime terapêutico em idosos com polifarmácia atendidos na atenção primária. Setecentos e cinquenta e quatro participantes com idade média de 73,2 anos e uso de nove medicações diariamente (DP 3,0). Apenas 15\% dos pacientes foram capazes de recordar a indicação de cada um dos seus medicamentos prescritos. Variáveis associadas com menor conhecimento do regime terapêutico foram: uso de muitos medicamentos prescritos ( $\geq 10$ vs $\leq 5$ 
drogas: $\mathrm{OR}=0,05$ ), idade 80 anos ou mais (comparada 60-69 anos: $\mathrm{OR}=0,47$ ) e sexo masculino (vs. mulheres: $\mathrm{OR}=0,53$ ). Pacientes que vivem com um parceiro foram mais bem informados do que aqueles que vivem sozinhos $(\mathrm{OR}=2,11)$. Não foi evidenciada associação com o nível de escolaridade (Bosch-Lenders et al., 2016).

Giardini et al (2016), em uma revisão sistemática descreveram as vantagens e desvantagens dos métodos mais utilizados para avaliar a adesão em idosos com o objetivo de fornecer o melhor critério. Os autores sugerem que nenhum método é suficientemente confiável e preciso para avaliar adesão: uma combinação de métodos parece ser o mais adequado.

\subsection{ALFABETISMO EM SAÚDE E ADESÃO MEDICAMENTOSA}

Além de todos os fatores já descritos, a avaliação do alfabetismo em saúde também deve ser considerada primordial para adequada avaliação da adesão ao tratamento medicamentoso.

Alfabetismo em saúde é "a capacidade do indivíduo de obter, processar e compreender informações básicas sobre saúde e os serviços necessários para tornar sua saúde adequada" (Departamento de Saúde e Serviços Humanos, 2012 EUA). Pode ser entendido também como a capacidade de executar leitura e tarefas numéricas necessárias para manter os cuidados de saúde (Kwan et al., 2006; Apolinário et al., 2012). 
Os principais instrumentos utilizados para medir o alfabetismo funcional em saúde estão descritos de modo sucinto a seguir.

O REALM (Rapid Estimate of Adult Literacy in Medicine) é um instrumento, inicialmente, descrito em 1991 por Davis et al. Originalmente, esse teste é composto por 125 palavras que o entrevistado deve ler com pronúncia correta em ordem crescente de dificuldade. Apesar de ser um teste amplamente utilizado na literatura, algumas criticas podem ser apontadas: avalia apenas a habilidade de leitura, demanda grande tempo para aplicação e não existe validação para a língua portuguesa (Davis et al., 1991).

Outro instrumento, o TOFHLA (The Test of Functional Health Literacy in Adults) desenvolvido por Parker et al. (1995) avalia um maior número de domínios relacionados ao alfabetismo em saúde como a capacidade de leitura, compreensão e habilidades numéricas. O teste é dividido em duas etapas. Na primeira, o entrevistado é orientado a ler passagens de texto com palavras omissas e escolher, entre quatro opções aquela que se encaixa de forma mais adequada para completar a frase. Na segunda etapa, o entrevistado precisa ler e entender informações relacionadas a prescrições médicas ou orientações para marcações de consulta. A grande desvantagem desse instrumento é o tempo para aplicação: média de 20 minutos (Parker et al., 1995). Uma versão reduzida (S-TOFHLA) foi desenvolvida em 1999 (Baker et al., 1999).

Por fim, o SAHLPA (Short Assessment of Health Literacy for Portuguese-Speaking Adults). Esse instrumento é uma adaptação do Short 
Assessment of Health Literacy for Spanish-Speaking Adults (SAHLSA), que já vem sendo utilizado em populações de língua espanhola (Lee et al., 2006). Na versão original, é composto de 50 itens e demora cerca de 20 minutos para sua aplicação. Em 2012, foi realizado um estudo para a validação de uma versão reduzida, o SAHLPA-18, no Brasil. Sua grande vantagem é a fácil aplicabilidade e a curta duração. O ponto de corte para definir alfabetismo em saúde é 15 ou mais pontos, com $83,3 \%$ de sensibilidade e $66,7 \%$ de especificidade (Apolinário et al., 2012).

Apesar do crescente número de estudos sobre o tema, é escasso o número de estudos que utilizam esses instrumentos para avaliar o alfabetismo em saúde em idosos com condições agudas ou crônicas descompensadas.

Baixos níveis de alfabetismo em saúde são prevalentes em todo o mundo e alfabetismo em saúde inadequado está associado com não adesão medicamentosa, aumento de internações e custos de saúde (Eichler et al., 2009; Jovic-Vranes et al., 2011).

Um recente estudo de coorte retrospectivo avaliou o alfabetismo em saúde como fator preditivo para adesão em pacientes idosos com e sem polifarmácia. O grau de alfabetismo em saúde e nível de adesão a medicação foram analisados através de registros eletrônicos de saúde. Houve associação significativa entre adesão medicamentosa e polifarmácia. Não houve associação entre o grau de alfabetismo em saúde e o nível de adesão ao regime terapêutico prescrito. Além disso, não houve relação entre o grau de polifarmácia e alfabetismo em saúde. Os indivíduos que faziam 
uso de mais medicamentos também tiveram níveis mais baixos de adesão medicamentosa e vice-versa (Lyles et al,, 2013).

Uma coorte brasileira avaliou a relação entre alfabetismo em saúde e adesão ao tratamento com varfarina. Foram avaliados 422 idosos com média de 62,1 anos. A prevalência de alfabetismo em saúde inadequado foi de $72,3 \%$. Na análise logística multivariada, déficit cognitivo (OR=3,57; IC $95 \%$ 2,05-6,23; $p<0,001)$ e necessidade de auxílio para a tomada da medicação (OR=2,64; IC 95\% 1,02-6,84; $\mathrm{p}=0,046)$ foram associados à alfabetização em saúde inadequada. Contudo, não foi observada relação estatisticamente significativa entre alfabetismo em saúde e adesão ao uso da varfarina tanto analisando o alfabetismo como variável categórica (OR=1,05; IC 95\% 0,65-1,70) quanto como variável contínua (Coeficiente de Spearman 0,02; $p=0,70$ ) (Martins et al., 2017).

Outro estudo brasileiro analisou idosos diabéticos e a relação entre alfabetismo de saúde e controle glicêmico adequado. A prevalência de alfabetismo em saúde inadequado foi de $56,6 \%$. Após o controle de potenciais fatores de confusão, pacientes com alfabetismo em saúde inadequado apresentaram maior probabilidade de apresentar controle glicêmico inadequado quando comparados aos pacientes com alfabetismo adequado $(O R=4,76$; IC 95\% 1,36-16,63). No modelo de regressão linear totalmente ajustado, menor alfabetismo em saúde $(\beta=-0,42 ; p<0,001)$, maior duração do diabetes $(\beta=0,24 ; p=0,012)$ e falta de auxílio para tomar medicamentos $(\beta=0,23 ; p=0,014)$ foram associados a níveis glicêmicos mais elevados (Souza et al., 2014). 
Alfabetismo em saúde inadequado é prevalente em todo o mundo. Contudo, a relação entre alfabetismo e adesão medicamentosa em idosos, ainda permanece controversa na literatura.

\subsection{COMPLEXIDADE DO REGIME TERAPÊUTICO}

Existem diversas definições sobre complexidade do regime terapêutico na literatura: algumas muito simples, que avaliam apenas o número de medicações tomadas; outras mais complexas que avaliam a posologia e a forma farmacêutica, por exemplo (Melchiors et al., 2007). Na realidade, a complexidade do regime terapêutico engloba múltiplas características do regime prescrito, incluindo, pelo menos, número de diferentes medicações no esquema, número de doses por dia, número de unidades de dosagem por dose, número total de doses por dia e relações da dose com a alimentação (Svarstad et al., 1999).

Reduzir a complexidade do regime terapêutico é um dos grandes desafios dos pacientes com doenças crônicas. Já é bem estabelecido na literatura que o aumento da complexidade está relacionado com não adesão e erros de tomada de medicação. É estimado que $40 \%$ a $75 \%$ dos idosos com regimes terapêuticos rotineiros não os cumprem adequadamente. Isso se deve a diferentes fatores, tais como déficit cognitivo e diminuição da compreensão das instruções, falta de comunicação adequada, aumento das 
limitações físicas e a própria complexidade do regime terapêutico (Hayes et al., 1999).

Há na literatura alguns instrumentos que são utilizados para medir a complexidade do regime terapêutico, contudo, as diferentes definições e interpretações não garantem a uniformidade na medida desse parâmetro. $\mathrm{Na}$ tentativa de padronizar essa medida, George e colaboradores desenvolveram um índice chamado Medication Regimen Complexity Index $\mathrm{MRCl}$ (George et al., 2004).

O $\mathrm{MRCl}$ considera como indicadores: o número, a forma farmacêutica, a frequência das tomadas dos medicamentos, as ações mecânicas necessárias para administrar o medicamento corretamente e as indicações necessárias que garantam a tomada eficaz e segura. É amplamente difundido na literatura mundial e validado para o português como Índice de Complexidade da Farmacoterapia (ICFT), podendo ser utilizado para comparar tanto grupos de pacientes como pacientes individualmente (Melchiors et al., 2007).

Recentemente, um estudo de coorte de base populacional envolvendo mais de 3.000 indivíduos com seguimento de três anos avaliou a associação entre ICFT e polifarmácia com mortalidade. No modelo ajustado, ICFT mais elevado foi associado com mortalidade (HR ajustado $=1,12$; IC $95 \%$ 1,01-1,25). Polifarmácia não foi associada com mortalidade (HR ajustado = 1,03; IC 95\% 0,99-1,06) (Wimmer et al., 2016).

Um estudo transversal com mais de 3.300 participantes avaliou os fatores relacionados com a complexidade do regime terapêutico em idosos. 
$\mathrm{Na}$ análise ajustada, os participantes no mais alto quintil do ICFT (ICFT> 20) eram mais idosos ( $O R=1,04$; IC 95\% 1,02-1,05), menos propensos a viver em casa $(O R=0,35 ;$ IC $95 \% 0,15-0,86)$, tinham mais comorbidades $(O R=$ 2,17; IC 95\% 1,89-2,49), pior estado cognitivo (OR = 1,06; IC 95\% 1,01-1,11) e foram mais propensos para receber ajuda com medicamentos $(O R=4,43$; IC $95 \% 2,39-8,56$ ) do que aqueles com baixa complexidade do esquema (ICFT> 0-5,5) (Wimmer et al., 2015).

Um estudo de coorte incluiu 163 idosos hospitalizados com mais de 70 anos e investigou a associação entre complexidade do regime no momento da alta hospitalar e ocorrência de rehospitalização em doze meses. Nesse estudo, quando ajustado para idade, sexo, atividades da vida diária, depressão, comorbidades e estado cognitivo, ICFT (HR = 1,01; IC $95 \%$ 0,81-1,26) e polifarmácia ( $H R=1,12$; IC 95\% 0,69-1,80) não foram associados com rehospitalização (Wimmer et al., 2014).

Um estudo americano retrospectivo avaliou se mudanças relacionadas com a complexidade do regime terapêutico eram capazes de reduzir o risco de readmissão hospitalar ou visitas aos serviços de emergência em noventa dias. Foram incluídos 174 idosos com insuificiência cardíaca. Após análise de regressão logística multivariada, cada aumento de unidade na pontuação ICFT foi associado com $4 \%$ de redução na probabilidade de readmissão ou visita ao serviço de emergência em 90 dias, contudo, este dado não foi estatisticamente significativo (OR=0,955; IC $95 \%$ 0,911-1,001). O estudo conclui que mudanças na complexidade do regime que ocorrem durante a hospitalização também podem estar associadas a 
otimização da terapêutica médica e não necessariamente anunciam desfechos desfavoráveis nessa população (Yam et al., 2016).

Outra coorte, que envolveu 163 idosos com mais de 70 anos internados em um hospital terciário australiano, avaliou se a complexidade do regime terapêutico possuía relação com o destino da alta hospitalar. Nesse estudo, idosos que apresentavam maior complexidade do regime terapêutico (ICFT>35) tinham menor índice de alta para casa $(R R=0,39$; IC $95 \%$ 0,20-0,73) (Wimmer et al., 2014).

Sendo assim, complexidade do regime terapêutico é um tema de relevância crescente à medida que a população envelhece e a polifarmácia se torna mais frequente. Dado que a complexidade do regime terapêutico está associada a menor adesão e que tanto a complexidade do regime terapêutico, quanto baixos níveis de alfabetismo em saúde podem estar associados a desfechos desfavoráveis em idosos com condições agudas, propomos os objetivos descritos a seguir para o presente estudo. 


\section{OBJETIVOS}




\section{OBJETIVOS}

\subsection{OBJETIVO PRIMÁRIO}

Avaliar adesão medicamentosa e complexidade do regime terapêutico como fatores preditores de hospitalização em seis meses para idosos com polifarmácia atendidos no Hospital Dia Geriátrico.

\subsection{OBJETIVOS SECUNDÁRIOS}

Avaliar adesão medicamentosa e complexidade do regime terapêutico como fatores preditores de visitas ao Pronto Socorro em seis meses para idosos com polifarmácia atendidos no Hospital Dia Geriátrico.

Avaliar os fatores associados à adesão medicamentosa e complexidade do regime terapêutico para idosos com polifarmácia atendidos no Hospital Dia Geriátrico, entre eles o alfabetismo em saúde. 
3 METODOLOGIA 


\section{METODOLOGIA}

\subsection{CENÁRIO}

O Hospital Dia Geriátrico (HDG) constitui-se em um serviço de assistência à saúde intermediária para o idoso cuja necessidade terapêutica e de orientação de seus cuidadores não justifiquem sua permanência contínua em ambiente hospitalar (Ministério da Saúde, 2002).

No Brasil, incentivado pela Política Nacional de Saúde da Pessoa Idosa, atualizada em 2006, o Hospital das Clínicas da Faculdade de Medicina da Universidade de São Paulo (HCFMUSP), através do Serviço de Geriatria, expandiu o já existente Hospital Dia para o atendimento de idosos em 2008. Esse novo modelo de assistência foi desenvolvido para oferecer seguimento clínico intensificado de curto prazo com foco em condições clínicas agudas, doenças crônicas descompensadas e realização de procedimentos de baixa complexidade (Aliberti et al., 2016).

Aliberti et al. (2016), no estudo retrospectivo que descreveu este modelo inovador de HDG, encontrou uma amostra de idosos com alta prevalência de polifarmácia (média de 7,6 medicamentos de forma contínua).

Todos os idosos avaliados nesse ambiente são atendidos por uma equipe interdisciplinar que é formada por médicos residentes em geriatria supervisionados por médicos geriatras, enfermeiras e auxiliares de 
enfermagem, nutricionista, farmacêutica, fisioterapeuta e residentes em serviço social e fonoaudiologia; todos os profissionais atuam com supervisão. Após avaliação, com foco no motivo de encaminhamento, um plano terapêutico é elaborado e desenvolvido em até oito visitas, diárias ou semanais por dois meses.

Um dos principais motivos de encaminhamento para o setor são as doenças crônicas descompensadas, sendo a mais frequente, a insuficiência cardíaca. Essas descompensações de doenças crônicas que, em grande parte, resultam da não adesão ao tratamento medicamentoso prescrito. Por isso, na rotina assistencial, além do atendimento médico, a farmácia clínica tem atuação importante para educação dos pacientes e, consequentemente, melhora da adesão.

\subsection{DELINEAMENTO}

Trata-se de um subprojeto do projeto integrado (projeto guardachuva) intitulado "Hospital Dia Geriátrico para idosos com risco de hospitalização: um estudo de coorte prospectivo".

Os pacientes foram avaliados no HDG, do Serviço de Geriatria, do HCFMUSP, um setor que ocupa seis leitos dentro de um Hospital Dia Clínico-Cirúrgico de 25 leitos situado no prédio dos ambulatórios dessa instituição. Este setor dispõe de uma equipe multidisciplinar que realiza avaliação o seguimento dos idosos. 


\subsection{PARTICIPANTES}

Idosos (60 anos ou mais), com polifarmácia (uso contínuo de cinco ou mais medicações) e encaminhados ao HDG por doença aguda ou por doença crônica descompensada foram incluídos no estudo. O Quadro 1 descreve as principais doenças agudas e crônicas descompensadas encaminhadas ao HDG.

Quadro 1 - Principais doenças agudas e crônicas descompensadas encaminhadas ao Hospital Dia Geriátrico (Aliberti et al., 2016)

\begin{tabular}{|c|c|}
\hline Doenças & Descrição \\
\hline Infecções & $\begin{array}{l}\text { Pneumonia, Infecção do Trato Urinário, Erisipela, Celulite, } \\
\text { Gastroenterite aguda }\end{array}$ \\
\hline Diabetes descompensado & $\begin{array}{l}\text { Hemoglobina Glicada maior que } 8,5 \% \text { em uso de medicações } \\
\text { orais e/ou insulinoterapia }\end{array}$ \\
\hline $\begin{array}{l}\text { Hipertensão Arterial } \\
\text { Descompensada }\end{array}$ & $\begin{array}{l}\text { Pressão arterial maior que } 160 \times 100 \mathrm{mmHg} \text { em uso de três ou } \\
\text { mais anti-hipertensivos }\end{array}$ \\
\hline $\begin{array}{l}\text { Insuficiência Cardíaca } \\
\text { Descompensada }\end{array}$ & Classe funcional III ou IV segundo a New York Association \\
\hline $\begin{array}{l}\text { Sintomas comportamentais } \\
\text { da demência }\end{array}$ & $\begin{array}{l}\text { Sintomas moderados a intensos iniciados nas últimas duas } \\
\text { semanas }\end{array}$ \\
\hline Distúrbios hidroeletrolíticos & $\begin{array}{l}\text { Hiponatremia, Hipernatremia, Hipocalemia, Hipercalemia, } \\
\text { Hipercalcemia }\end{array}$ \\
\hline Síndrome Consumptiva & $\begin{array}{l}\text { Perda ponderal não intencional }>5 \% \text { em } 1 \text { mês ou }>10 \% \text { em } 6 \\
\text { meses }\end{array}$ \\
\hline Dor refratária & Investigação diagnóstica e/ou tratamento \\
\hline
\end{tabular}

Os critérios de exclusão incluíam situações de gravidade, no momento da admissão, que exigisse imediata internação hospitalar ou atendimento em unidade de emergência. Além disso, também foram excluídos os indivíduos totalmente dependentes para a tomada de medicações e aqueles com déficit auditivo/visual grave que impedisse a 
aplicação dos questionários. Foi definido como indivíduo totalmente dependente para tomada de medicação aquele que recebia auxílio para obter, organizar e lembrar de tomar as medicações de uso contínuo. O Quadro 2 descreve os critérios de inclusão e exclusão.

Quadro 2 - Critérios de inclusão e exclusão

\section{CRITÉRIOS DE INCLUSÃO}

1. Idosos com polifarmácia encaminhados ao HDG por doença aguda ou cônica descompensada

\section{CRITÉRIOS DE EXCLUSÃO}

1. Presença de condições que necessitassem imediatamente de internação hospitalar ou atendimento em unidade de emergência

- Sinais clínicos de gravidade (instabilidade hemodinâmica, insuficiência respiratória aguda e rebaixamento do nível de consciência);

- Exames laboratoriais seriamente alterados

- Suspeita de doença aguda grave (acidente vascular cerebral, infarto agudo do miocárdio, embolia pulmonar, sepse, traumatismo crânio encefálico)

2. Impossibilidade de contato telefônico para seguimento;

3. Hospitalização eletiva para os próximos seis meses;

4. Indivíduos em cuidados paliativos exclusivos;

5. Indivíduos totalmente dependentes para a tomada de medicações;

6. Indivíduos em delirium;

7. Déficit auditivo e/ou visual grave.

\subsection{AVALIAÇÃO INICIAL}

Para todos os casos incluídos, foi aplicada uma Avaliação Geriátrica Ampla (AGA) conduzida por uma equipe treinada com duração aproximada de 50 minutos e realizada no primeiro dia de atendimento no HDG. 
Essa avaliação contém informações sobre dados sociodemográficos e econômicos, suporte social, uso recente do sistema saúde, multimorbidades, cognição, depressão, funcionalidade e medicações em uso.

Além dessa avaliação global, os pacientes elegíveis para o nosso estudo foram avaliados em relação à adesão medicamentosa (escala de adesão de Morisky de 8 itens, conhecimento do regime terapêutico e capacidade de manejo das medicações através do Teste da Caixa de Medicamentos), alfabetismo em saúde e complexidade do regime terapêutico.

\subsubsection{Características sociodemográficas}

Idade, sexo, cor, estado civil, renda familiar per capita e necessidade de cuidador foram as variáveis sociodemográficas coletadas. As definições estão descritas no Quadro 3.

Quadro 3 - Características sociodemográficas

\begin{tabular}{|ll|}
\hline Variável & Descrição \\
\hline Idade & Número de anos completos \\
Sexo & Feminino ou Masculino \\
Escolaridade & Número de anos (séries) que estudou \\
Estado civil & Com parceiro e sem parceiro \\
Cor & Definida pelo participante: branca, parda, negra ou \\
& $\begin{array}{l}\text { amarela. Na análise foi utilizada como dicotômica: branca } \\
\text { Renda familiar per capita }\end{array}$ \\
Modo como reside & Número de salários mínimo dividido pelo número de \\
Necessidade de cuidador & Sozinho ou acompanhado \\
\hline
\end{tabular}




\subsubsection{Suporte social}

A avaliação do suporte social foi coletada por meio da escala de apoio social utilizada no Medical Outcomes Study (MOS) descrita no Quadro 4 (Sherbourne et al., 1991). Originalmente, esta escala é composta por 19 itens, compreendendo cinco dimensões funcionais: material, afetivo, emocional, interação social positiva e informação. Em 2012, foi validada uma versão curta com oito questões, denominada mMOS-SS, que também avalia as cinco dimensões funcionais da escala original (Moser et al., 2012). Para todos os itens, cinco opções de resposta, variando de "nunca" a "sempre", eram apresentadas. A pontuação de cada item variou de 1 a 5 , sendo utilizado o somatório das respostas, cujo resultado poderia variar de 0 a 40; valores elevados representando maior apoio social. Conforme a distribuição da amostra, o escore foi dividido de forma dicotômica: 40 pontos ou $<40$ pontos. 
Quadro 4 - Escala de oito itens do Medical Outcomes Study (MOS) mMOS-SS

\begin{tabular}{|c|c|c|c|c|c|}
\hline $\begin{array}{l}\text { Se você precisar, com que frequência conta } \\
\text { com alguém... }\end{array}$ & Nunca & Raramente & $\begin{array}{c}\text { Às } \\
\text { vezes }\end{array}$ & $\begin{array}{l}\text { Quase } \\
\text { sempre }\end{array}$ & Sempre \\
\hline \multicolumn{6}{|l|}{ MATERIAL } \\
\hline Que o ajude, se ficar de cama? & 1 & 2 & 3 & 4 & 5 \\
\hline Para levá-lo ao médico? & 1 & 2 & 3 & 4 & 5 \\
\hline $\begin{array}{l}\text { Para ajudá-lo nas tarefas diárias, se ficar } \\
\text { doente? }\end{array}$ & 1 & 2 & 3 & 4 & 5 \\
\hline $\begin{array}{l}\text { Para preparar suas refeições, se você não } \\
\text { puder prepará-las? }\end{array}$ & 1 & 2 & 3 & 4 & 5 \\
\hline \multicolumn{6}{|l|}{ AFETIVO } \\
\hline $\begin{array}{l}\text { Que você ame e que faça você se sentir } \\
\text { querido? }\end{array}$ & 1 & 2 & 3 & 4 & 5 \\
\hline \multicolumn{6}{|l|}{ EMOCIONAL } \\
\hline Que compreenda seus problemas? & 1 & 2 & 3 & 4 & 5 \\
\hline \multicolumn{6}{|l|}{ INFORMAÇÃO } \\
\hline $\begin{array}{l}\text { Para dar sugestões de como lidar com um } \\
\text { problema pessoal? }\end{array}$ & 1 & 2 & 3 & 4 & 5 \\
\hline \multicolumn{6}{|l|}{ INTERAÇÃO SOCIAL POSITIVA } \\
\hline \multirow[t]{2}{*}{ Para se divertir junto? } & 1 & 2 & 3 & 4 & 5 \\
\hline & \multicolumn{2}{|c|}{ PONTUAÇÃO = } & & & \\
\hline
\end{tabular}

\subsubsection{Uso recente do Sistema de Saúde}

Esse quesito foi avaliado através de duas perguntas objetivas feitas para o paciente ou acompanhante, sobre o uso recente do sistema de saúde. Idas ao serviço de emergência nos últimos seis meses eram questionadas de forma dicotômica: sim ou não. Outro questionamento que foi realizado era sobre a ocorrência de internações (permanência hospitalar maior que vinte e quatro horas) nos últimos seis meses. A resposta obtida também era dicotômica: sim ou não. 


\subsubsection{Multimorbidades}

O Índice de Multimorbidades de Charlson foi utilizado para medida das multimorbidades (Quadro 5). Este índice foi validado por Charlson e colaboradores, em 1987, com o objetivo de estabelecer a taxa de mortalidade em um ano de indivíduos com câncer. Utilizado na versão atualizada por Sundararajan et al. (2004), é composto por 17 doenças, na qual cada uma recebe uma pontuação diferente conforme a definição do risco relativo de mortalidade. A pontuação total é soma dos pontos de cada doença. Quanto maior a pontuação, maior o risco de desfecho desfavorável. Nessa pesquisa, foram estabelecidas quatro categorias conforme a distribuição da amostra: 0,1 ponto, 2 pontos e $\geq 3$ pontos.

Quadro 5 - Índice de Multimorbidades de Charlson

\begin{tabular}{|lc|}
\hline Doença & Pontuação \\
\hline Diabetes Melitos & 1 \\
$\quad$ Com lesão de órgão alvo? & 2 \\
Infarto do miocárdio & 1 \\
Insuficiência Cardíaca & 1 \\
Doença Cerebrovascular & 1 \\
$\quad$ Hemiplegia? & 2 \\
Insuficiência Arterial Periférica & 1 \\
Neoplasia & 2 \\
$\quad$ Metastática? & 3 \\
Demência & 1 \\
Doença Pulmonar Obstrutiva Crônica & 1 \\
Doenças do Tecido Conjuntivo & 1 \\
Úlcera Péptica & 1 \\
Doença Hepática & 1 \\
$\quad$ Moderada/Grave? & 3 \\
Disfunção Renal Moderada/Grave & 2 \\
Síndrome da Imunodeficiência Adquirida & 6 \\
\hline
\end{tabular}




\subsubsection{Avaliação cognitiva}

O Mini Exame do Estado Mental (MEEM) foi o instrumento utilizado para a avaliação cognitiva. Ele fornece uma medida global de cognição com uma pontuação que varia de 0 a 30 pontos, no qual quanto menor o número de pontos, pior o desempenho cognitivo (Quadro 6). Este instrumento é o mais utilizado para avaliação inicial e acompanhamento de idosos com suspeita e diagnóstico confirmado de demência.

Utilizamos a versão descrita e adaptada ao Brasil por Bruck et al. (2003). No nosso trabalho, optamos por utilizar o MEEM dividido em tercis para possibilitar a realização da regressão linear, uma vez que a distribuição desta variável foi não paramétrica.

Quadro 6 - Mini Exame do Estado Mental

\begin{tabular}{|llc|}
\hline Função Avaliada & Tarefa & Pontos \\
\hline Orientação temporal & Dia do mês, mês, dia da semana, horário aproximado & 5 \\
Orientação espacial & Local específico, local geral, bairro, cidade, estado & 5 \\
Memória imediata & Repetir três palavras: carro, vaso, tijolo & 3 \\
Cálculos & Subtração seriada de sete a partir de 100 & 5 \\
Evocação & $(93 / 86 / 79 / 72 / 65)$ & 3 \\
Nomeação & Evocação das três palavras & 2 \\
Repetição & Relógio e caneta & 1 \\
Comando Verbal & "Nem aqui, nem ali, nem lá" & "Pegue o papel com a mão direita, dobre-o no meio e \\
Comando escrito & "Fechha-o no chão" os olhos" & 3 \\
Escrita & Elabore uma frase & 1 \\
Cópia do desenho & Copiar dois pentágonos interseccionados & 1 \\
\hline
\end{tabular}




\subsubsection{Avaliação de sintomas depressivos}

Os sintomas depressivos foram avaliados através da Escala de Depressão Geriátrica (GDS). Descrita por Yesavage et al. (1983), a escala original tem 30 itens e foi desenvolvida especialmente para o rastreio dos transtornos de humor em idosos. A versão de 15 itens, validada no Brasil por Almeida e Almeida (2003), teve boa acurácia no diagnóstico de transtorno depressivo maior. Composta de respostas sim ou não, quanto maior a pontuação, mais sintomas depressivos o participante possui no momento da avaliação. Uma pontuação acima de cinco pontos é considerada positiva para triagem de depressão. Sendo assim, foi utilizada como variável dicotômica. A versão reduzida de 15 itens (GDS-15) utilizada neste estudo está descrita no Quadro 7.

Quadro 7 - Escala de Depressão Geriátrica de 15 itens (GDS-15)

\begin{tabular}{|lll|}
\hline Perguntas de sim ou não & & \\
\hline 1. Você está satisfeito(a) com a sua vida? & $\operatorname{Sim}(0)$ & Não (1) \\
2. Você abandonou muitas das suas atividades e dos seus interesses? & $\operatorname{Sim}(1)$ & Não (0) \\
3. Você sente que sua vida está vazia? & $\operatorname{Sim}(1)$ & Não (0) \\
4. Você se aborrece com frequência? & $\operatorname{Sim}(1)$ & Não (0) \\
5. Você se sente de bom humor a maior parte do tempo? & $\operatorname{Sim}(0)$ & Não (1) \\
6. Você tem medo de que alguma coisa ruim lhe aconteça? & $\operatorname{Sim}(1)$ & Não (0) \\
7. Você se sente feliz a maior parte do tempo? & $\operatorname{Sim}(0)$ & Não (1) \\
8. Você se sente desamparado(a) com frequência? & $\operatorname{Sim}(1)$ & Não (0) \\
9. Você prefere ficar em casa em vez de sair e fazer coisas novas? & $\operatorname{Sim}(1)$ & Não (0) \\
10. Você se sente com mais problemas de memória do que a maioria? & $\operatorname{Sim}(1)$ & Não (0) \\
11. Você acha maravilhoso(a) estar vivo? & $\operatorname{Sim}(0)$ & Não (1) \\
12. Você se sente inútil nas atuais circunstâncias? & $\operatorname{Sim}(1)$ & Não (0) \\
13. Você se sente cheio(a) de energia? & $\operatorname{Sim}(0)$ & Não (1) \\
14. Você se sente sem esperança? & $\operatorname{Sim}(1)$ & Não (0) \\
15. Você sente que a maioria das pessoas está melhor que você? & $\operatorname{Sim}(1)$ & Não (0) \\
\hline
\end{tabular}




\subsubsection{Avaliação de funcionalidade}

O BOMFAQ (Brazilian OARS Multidimensional Functional Assessment Questionnaire) foi utilizado como instrumento para avaliação da funcionalidade. Originalmente descrito por Ramos em 1987, ele é composto por perguntas que envolvem dados sobre a situação socioeconômica, estrutura familiar, condições de saúde física e mental e grau de autonomia no dia a dia dos idosos (Ramos et al., 1993). Nesse estudo foi utilizada a versão reduzida de quinze itens que avalia funcionalidade através de atividades básicas e instrumentais da vida diária. Para cada item, é atribuída uma pontuação de 0 a 2; sendo 0 , não é capaz de realizar; 1 , realiza parcialmente; 2 , realiza completamente. Num total de 30 pontos, quanto menor a pontuação, maior é a perda funcional.

Nesse trabalho, o BOMFAQ foi dividido em tercis por dois motivos: não há ponto de corte definido na literatura e também para possibilitar a realização da regressão linear uma vez que a distribuição desta variável foi não paramétrica.

A escala BOMFAQ está descrita no Quadro 8. 


\section{Quadro 8 - Brazilian Multidimensional Functional Assessment Questionnaire (BOMFAQ)}

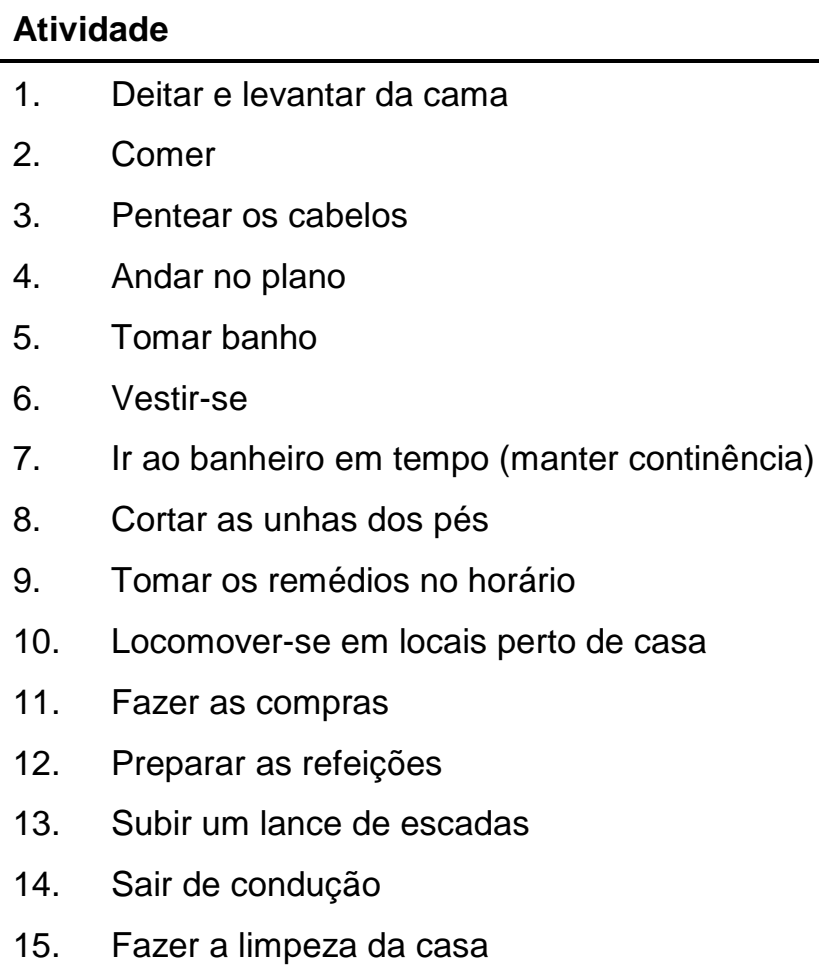

\subsubsection{Uso de medicamentos}

As informações sobre os medicamentos foram obtidas por meio da lista completa definida pela somatória de todos os medicamentos que possuíam prescrição médica e que deveriam ser utilizados de modo contínuo. Uso contínuo foi estabelecido como o uso por mais de três meses. Os participantes eram orientados a trazer todas as prescrições médicas recentes. Para garantir maior confiabilidade aos dados obtidos, essas informações eram confirmadas por meio das prescrições eletrônicas registradas no sistema informatizado do HCFMUSP. Foram consideradas todas as formas farmacêuticas (comprimidos, cápsulas, soluções, pomadas, etc). 
Além do uso intervalar do número de medicações de uso contínuo, foi definida polifarmácia como uso de cinco ou mais medicações de modo contínuo e hiperpolifarmácia como uso de dez ou mais medicações de modo contínuo.

\subsubsection{Avaliação de déficits sensoriais (visão e audição)}

A presença de déficit visual foi avaliada de maneira auto-referida. $\mathrm{Na}$ tentativa de tornar um pouco mais objetivo esse dado, uma pergunta simples era realizada para cada participante: "O senhor (a) consegue enxergar e reconhecer um amigo do outro lado da rua?". Resposta negativa era considerada déficit visual. Já a avaliação da audição, também auto-referida, foi mensurada com a seguinte pergunta: "O senhor (a) consegue ouvir e entender uma pessoa falando em um tom de voz normal?". Resposta negativa era considerada déficit auditivo. Essas variáveis foram analisadas como dicotômicas.

\subsubsection{Avaliação do alfabetismo em saúde}

Para avaliação do alfabetismo em saúde foi utilizado um teste que apresenta boa reprodutibilidade na população brasileira: o Short Assessment of Health Literacy for Portuguese-Speaking Adults (SAHLPA-18) (Apolinário et al., 2012).

Para realização desse teste, dezoito palavras relacionadas à saúde impressas em cartões foram mostradas aos pacientes. Após ler corretamente cada palavra, o indivíduo escolhia, entre outras duas, aquela 
que considerava mais semelhante à primeira. Por exemplo, se a palavra impressa era "menopausa", o primeiro passo era ler corretamente em voz alta esta palavra; na sequência, ele deveria escolher com qual das duas outras palavras impressas no mesmo cartão a palavra "menopausa" se relacionava, no caso em questão, "meninas" ou "senhoras". Caso não soubesse, era estimulado a responder "não sei" para evitar falsos acertos. Caso a palavra não fosse lida, inicialmente, corretamente era considerado um erro. Ao final das dezoito palavras, o examinador contava a quantidade de acertos e erros. Foi considerado alfabetismo adequado em saúde ocorrência de quinze acertos.

\subsection{AVALIAÇÃO DA ADESÃO MEDICAMENTOSA}

\subsubsection{The Morisky Medication Adherence Scale: MMAS-8}

Os pacientes responderam um questionário validado para o português: a escala de adesão de Morisky de oito itens (The Morisky Medication Adherence Scale: MMAS-8) (Morisky et al., 2008; Oliveira-Filho et al., 2014).

A MMAS-8 é o método mais utilizado para mensuração da adesão medicamentosa e foi validado para o português em 2011. Contém oito perguntas com respostas fechadas de caráter dicotômico formuladas para evitar o viés de respostas positivas dos pacientes a perguntas feitas por profissionais de saúde, por meio da inversão das respostas relacionadas ao 
comportamento aderente do entrevistado (Morisky et al., 2008; Voils et al., 2011).

O grau de adesão terapêutica é determinado de acordo com a pontuação resultante da soma de todas as respostas corretas: alta adesão (oito pontos), média adesão (6 e 7 pontos) e baixa adesão (< 6 pontos) (Morisky et al., 2008). Alguns autores utilizam ponto de corte diferente ao analisar a escala como uma variável dicotômica: 8 pontos (adesão) e $<8$ pontos (não adesão) (Oliveira-Filho et al., 2014a). Nesse trabalho, utilizamos essa escala tanto como variável dicotômica quanto como categórica (3 categorias). Maiores detalhes serão fornecidos na descrição da análise estatística.

O quadro 9 descreve a escala em português (Oliveira-Filho et al., 2014).

Quadro 9 - Escala de Adesão Terapêutica de Morisky de 8 Itens - MMAS-8

\begin{tabular}{|c|c|c|}
\hline & Sim & Não \\
\hline 1. Você às vezes esquece de tomar os seus remédios? & 0 & 1 \\
\hline $\begin{array}{l}\text { 2. Nas duas últimas semanas, houve algum dia em que você não tomou seus } \\
\text { remédios? }\end{array}$ & 0 & 1 \\
\hline $\begin{array}{l}\text { 3. Você já parou de tomar seus remédios ou diminuiu a dose sem avisar seu médico } \\
\text { porque se sentia pior quando os tomava? }\end{array}$ & 0 & 1 \\
\hline $\begin{array}{l}\text { 4. Quando você viaja ou sai de casa, às vezes esquece de levar seus } \\
\text { medicamentos? }\end{array}$ & 0 & 1 \\
\hline 5. Você tomou seus medicamentos ontem? & 1 & 0 \\
\hline $\begin{array}{l}\text { 6. Quando sente que a sua saúde está controlada, você às vezes para de tomar } \\
\text { seus medicamentos? }\end{array}$ & 0 & 1 \\
\hline $\begin{array}{l}\text { 7. Você já se sentiu incomodado por seguir corretamente o seu tratamento para } \\
\text { saúde? }\end{array}$ & 0 & 1 \\
\hline $\begin{array}{l}\text { 8. Com que frequência você tem dificuldade para se lembrar de tomar todos os seus } \\
\text { remédios? } \\
\begin{array}{lllll}\text { [1] Nunca } & \text { [2] Quase nunca } & \text { [3] Às vezes } & \text { [4] Frequentemente } & \text { [5] Sempre }\end{array}\end{array}$ & 0 & 1 \\
\hline $\begin{array}{l}\text { Para a questão no } 8: \text { 1-2 = } 1 \text { ponto/ }>2=0 \text { ponto } \\
\text { Escore: } 8 \text { pontos=alta adesão/ } 6-7 \text { pontos=média adesão/ }<6 \text { pontos=baixa } \\
\text { adesão }\end{array}$ & & \\
\hline
\end{tabular}




\subsubsection{Conhecimento do regime terapêutico}

Como não há um padrão ouro na literatura, para avaliação desse quesito, nesse trabalho, foi aplicada uma escala adaptada do modelo proposto pela Sociedade Americana sobre o Envelhecimento: Medicine Knowlege Assement Form. Essa escala, originalmente descrita num manual sobre adesão medicamentosa em idosos, faz parte de uma extensa avaliação sobre não adesão. Neste modelo, eram solicitadas as seguintes informações sobre as medicações: nome, indicação, posologia, horário, efeitos colaterais, local de armazenamento e necessidade de novo reabastecimento (OMS, 2003).

A versão adaptada, que foi utilizada para o nosso trabalho, consistiu de cinco questionamentos sobre cada medicação de uso contínuo: nome (principio ativo ou nome fantasia), dose (miligrama, unidades, concentração), horário (manhã// tarde ou noite, 12/12h), quantidade (número de gotas ou comprimidos) e qual a função de cada medicação. No item que questionava qual a função da medicação, foram aceitas como corretas tanto respostas em linguagem formal/técnica como, por exemplo, diabetes melitus tipo 2, quanto respostas em linguagem coloquial mas que fizessem sentido como, por exemplo, glicemia alta ou apenas diabetes. O julgamento desse quesito foi realizado por um pesquisador médico logo após a entrevista.

A lista completa de medicamentos obtida anteriormente como descrito no tópico "Uso de Medicamentos" foi utilizada como referência para a avaliação do conhecimento do regime terapêutico. Ao final do teste, caso o participante esquecesse de mencionar um ou mais medicamentos que 
estavam na sua lista de uso contínuo, o pesquisador poderia falar o nome e questionar sobre quantidade, horário, dose e qual a função do medicamento. Apenas era considerado acerto se os dados eram informados de forma precisa e com pronúncia correta pelo paciente.

Sobre a pontuação da escala: cada um dos cinco itens tinha peso 1. O escore total foi dado pela proporção de itens corretos, variando de 0 a 100 pontos. Dessa forma, uma nota em porcentagem para esse quesito foi estimada, pois não há ponto de corte definido na literatura. Na nossa pesquisa, essa escala foi divida em tercis. O Quadro 10 ilustra a escala do conhecimento do regime terapêutico.

Quadro 10 - Escala do conhecimento do regime terapêutico

\begin{tabular}{|c|c|c|c|c|c|c|c|c|c|c|}
\hline & AÇÕES & & & & & & RIO & & $\begin{array}{l}\text { QUE } \\
\text { VE? }\end{array}$ & PONTOS \\
\hline 1. & & & & & & & & & & \\
\hline 0 & 1 & 0 & 1 & 0 & 1 & 0 & 1 & 0 & 1 & \\
\hline 2. & & & & & & & & & & \\
\hline 0 & 1 & 0 & 1 & 0 & 1 & 0 & 1 & 0 & 1 & \\
\hline 3. & & & & & & & & & & \\
\hline 0 & 1 & 0 & 1 & 0 & 1 & 0 & 1 & 0 & 1 & \\
\hline 4. & & & & & & & & & & \\
\hline 0 & 1 & 0 & 1 & 0 & 1 & 0 & 1 & 0 & 1 & \\
\hline 5. & & & & & & & & & & \\
\hline 0 & 1 & 0 & 1 & 0 & 1 & 0 & 1 & 0 & 1 & \\
\hline & s (SOMA) & & & $\begin{array}{l}\text { ontos } \\
\text { ossíve } \\
\text { oo mec } \\
\text { tais u u }\end{array}$ & $\begin{array}{l}\text { s } \\
\text { ães } \\
\text { as } x\end{array}$ & & & ent & n Final & \\
\hline
\end{tabular}




\subsubsection{Teste da Caixa Organizadora de Medicamentos}

Em busca de uma avaliação mais objetiva com relação ao manejo das medicações, optamos por realizar um teste para avaliar qual o real entendimento do paciente sobre uma prescrição e o manejo das medicações prescritas 0 qual chamamos de teste da caixa organizadora de medicamentos ou, de um modo mais simplificado, teste da caixa de medicamentos.

Esse teste foi inspirado no Pill Box Test que é um método descrito originalmente para avaliação de função executiva no manejo de medicações. Ele considera que a função executiva é uma habilidade multidimensional composta por ação, planejamento, volição e auto-monitoração e testa cada

um desses domínios. Foram demonstradas sensibilidade de $75 \%$ e especificidade de $87,5 \%$. Para a execução do Pill Box Test, são necessários cinco potes contendo comprimidos coloridos e com instruções de posologias diferentes no rótulo além de uma caixa contendo divisórias para os dias da semana e as principais refeições. É solicitado ao participante que organize os comprimidos coloridos distribuídos em cinco cores diferentes para uso em uma semana baseado na prescrição médica contida no rótulo de cada pote. O tempo máximo para executar a tarefa é de cinco minutos. Na versão original, eram contabilizados erros de omissão, erros de extravio e erros de direção, por exemplo. Ao final da execução do teste uma pontuação complexa era criada de acordo com o comprometimento específico de cada componente da função executiva (Zartman et al., 2013). 
No nosso trabalho, utilizamos uma versão adaptada, pois nosso objetivo era verificar a capacidade do indivíduo de interpretar uma prescrição médica e manejar as medicações e não fazer avaliações detalhadas da função executiva.

Para execução do teste da caixa de medicamentos, uma caixa de madeira de $40 \mathrm{~cm} \times 20 \mathrm{~cm}$ contendo as seguintes divisões: na vertical, os horários para tomada de medicações "café da manhã", "almoço", "jantar" e "ao deitar"; na horizontal, todos os dias da semana. Todas as legendas estavam impressas em letras grandes para facilitar a visualização. Além disso, receberam também cinco potes padronizados contendo cápsulas coloridas. As cápsulas eram placebo e fabricadas exclusivamente para a realização desta pesquisa. No rótulo de cada pote havia a prescrição médica a qual o participante deveria seguir:

- Pílula azul - Tomar 1 comprimido 1 vez ao dia pela manhã.

- Pílula laranja - Tomar 1 vez ao dia ao deitar.

- Pílula verde - Tomar 1 comprimido 2 vezes ao dia, no café e no jantar.

- Pílula vermelha - Tomar 1 comprimido em dias alternados.

- Pílula amarela - Tomar 1 comprimido 3 vezes ao dia.

Os participantes receberam todas as orientações previamente ao início da tarefa. Eram informados de que iriam receber uma caixa contendo divisões por dias da semana e horários de refeições bem como cinco potes que continham pílulas coloridas com instruções para tomada no rótulo. Em seguida, eram orientados a organizar todas as medicações contidas nos 
potes na caixa para uma semana de acordo com as instruções contidas nos rótulos. O tempo para se completar a tarefa era livre e o total para execução foi cronometrada em minutos.

Depois de completado o teste, o examinador anotava o total de erros e acertos. Apenas era considerado acerto a separação da medicação exatamente como estava orientado no rótulo. Definimos a ocorrência de um erro como incapacidade no manejo correto das medicações prescritas. A pontuação final variava de zero a cinco pontos. No nosso trabalho o Teste da Caixa de Medicamentos foi utilizado como variável dicotômica: 5 acertos ou $<5$ acertos. A Figura 1 ilustra os instrumentos utilizados para execução do teste da caixa organizadora de medicamentos. 

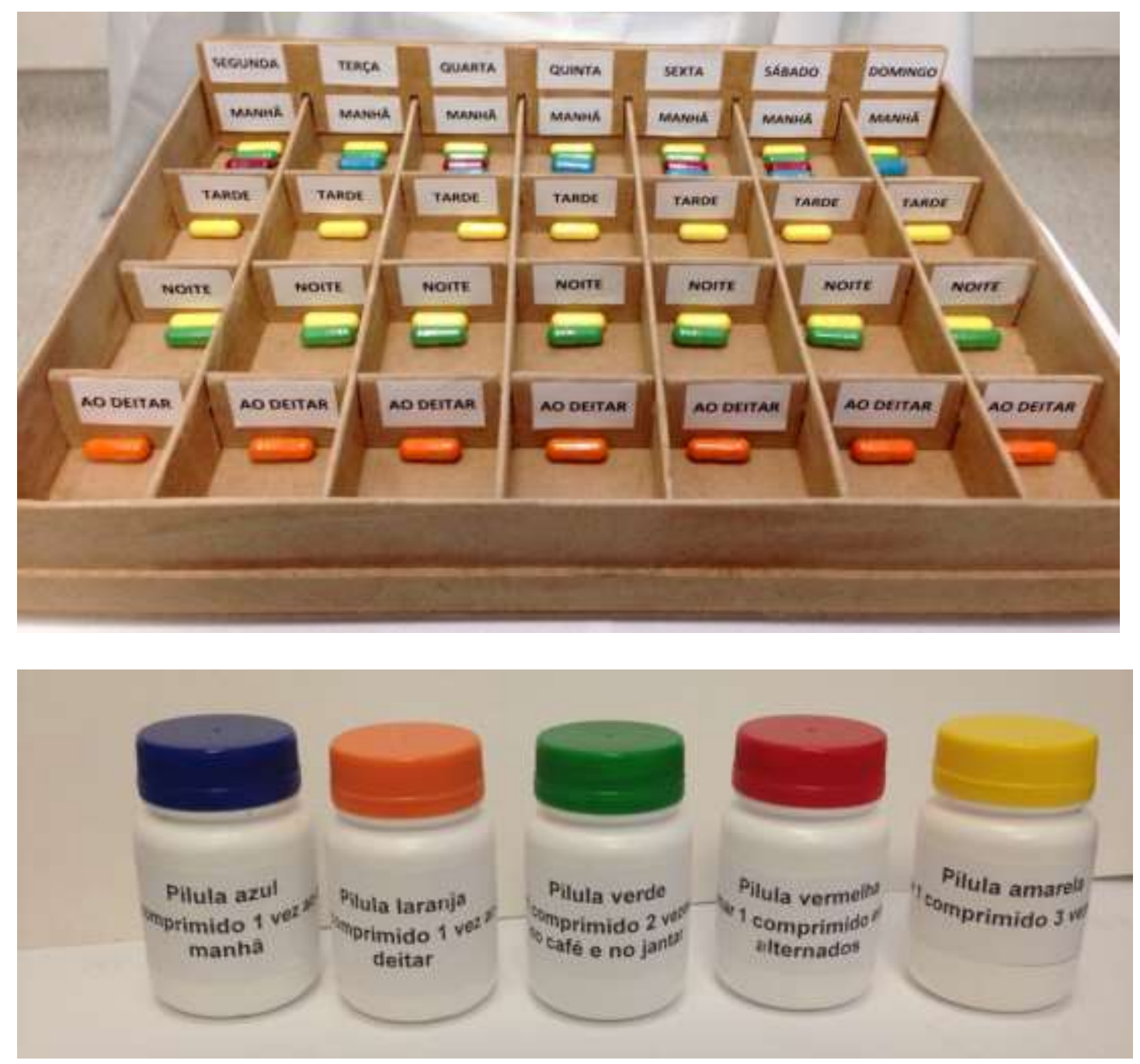

Figura 3 - Instrumentos utilizados para execução do Teste da Caixa de Medicamentos

\subsection{AVALIAÇÃO DA COMPLEXIDADE DO REGIME TERAPÊUTICO}

A avaliação da complexidade do regime terapêutico foi realizada através do cálculo do índice de complexidade da farmacoterapia (ICFT). Atualmente, é o único instrumento validado na língua portuguesa para medir a complexidade terapêutica (Arcucio et al., 2009). 
Trata-se de um índice utilizado para medir a complexidade das medicações utilizadas pelo indivíduo. $O$ instrumento é dividido em três seções: A, B e C. A seção A corresponde as informações sobre formas de dosagens; a seção B, às informações sobre frequências de doses; e a seção C corresponde às informações adicionais, como horários específicos e uso com alimentos, entre outras. Cada seção é pontuada a partir da análise da farmacoterapia do paciente e o índice de complexidade é obtido pela soma dos pontos (escores) das três seções (Melchiors et al., 2007). O ANEXO A exemplifica o instrumento.

A pontuação total do ICFT é a soma das pontuações atribuídas a cada secção. $O$ índice tem um limite superior aberto, pois a cotação depende do número de medicamentos, da ação mecânica e das informações adicionais para cada medicamento (Melchiors et al., 2007).

O cálculo do ICFT nesse estudo foi realizado por duas farmacêuticas treinadas e cegadas para os desfechos. As informações sobre os medicamentos foram levantadas por meio da lista completa de remédios descrita no item "Uso de Medicamentos". Nessa pesquisa, o ICFT foi dividido em tercis.

\subsection{TÉCNICA DE AMOSTRAGEM E RECRUTAMENTO}

A amostragem ocorreu de maneira consecutiva, no período de janeiro de 2015 a dezembro de 2015 (12 meses). Todos os indivíduos 
encaminhados ao HDG foram recrutados e avaliados quanto à elegibilidade para o estudo. Os sujeitos excluídos tinham registrados o motivo da exclusão, sexo, idade, escolaridade, multimorbidades (índice de Charlson), internação hospitalar ou visita ao PS.

Após a avaliação inicial, independente da pesquisa, todos os sujeitos receberam tratamento habitual pela equipe multidisciplinar do HDG de acordo as necessidades clínicas particulares de cada caso.

\subsection{SEGUIMENTO E DESFECHO}

Os participantes admitidos no estudo receberam ligações telefônicas mensais por um período de seis meses. Nas ligações, realizadas por membro da equipe de pesquisa cegado às informações colhidas na avaliação inicial, foram aplicados questionários padronizados para análise dos desfechos. Na impossibilidade de contato com o participante, um cuidador próximo foi 0 entrevistado. Perguntas sobre hospitalização (inclusive a duração) e idas ao serviço de emergência faziam parte do questionário (ANEXO B).

O desfecho primário foi hospitalização (variável dicotômica definida como permanência em ambiente hospitalar por um período contínuo de 24 horas ou mais). 
Visita ao serviço de pronto socorro (variável dicotômica definida pela ida a qualquer serviço de urgência/emergência por qualquer causa) foi o desfecho secundário.

Foi escolhido o seguimento de seis meses porque esse intervalo de tempo é considerado suficiente para avaliação do desfecho proposto em uma população de indivíduos muito idosos (média de 80 anos) portadores de doença crônica descompensada.

\subsection{CÁLCULO DA AMOSTRA}

Como não havia estudos semelhantes na literatura, no início da pesquisa, sobre adesão e hospitalização não foi possível adotar uma referência para o cálculo amostral. Foi utilizado o programa open epi para realização do cálculo (Dean et al., 2006). Admitindo-se a ocorrência do desfecho hospitalização em seis meses de $40 \%$ no grupo de pior adesão e complexidade farmacêutica e de $20 \%$ no grupo de melhor adesão e complexidade farmacêutica, erro alfa de 0,05 , erro beta de 0,2 e uma diferença entre os grupos de 0,5 seriam necessários 186 participantes. Considerando uma perda de seguimento de 10\%, uma amostra total de 204 seria necessária para o presente estudo. 


\subsection{ANÁLISE ESTATÍSTICA}

O índice de complexidade do regime terapêutico, a escala de conhecimento terapêutico, a escala de Morisky e o teste da caixa de medicamentos foram analisados em três etapas:

a) Análise descritiva: descrição do desempenho total e em cada etapa dos testes;

b) Análise transversal: associação dos testes com as variáveis sociodemográficas e clínicas, com ênfase no analfabetismo funcional;

c) Análise de sobrevida: análise dos testes como variáveis independentes na predição dos desfechos hospitalização e visitas ao pronto socorro.

As análises foram realizadas através do software Stata 14.0. Todos os testes estatísticos foram bicaudais e o erro alfa menor do que 0,05 foi utilizado para indicar significância estatística.

\subsubsection{Análise Descritiva}

Inicialmente, foram descritas as características da amostra através de médias, desvio padrão, números e proporções. O teste de Spearman foi utilizado para a análise da correlação entre escolaridade e alfabetismo em saúde e escala de cognição e alfabetismo em saúde. 


\subsubsection{Escala do Conhecimento do Regime Terapêutico}

Cada uma das cinco etapas da escala de conhecimento do regime terapêutico foi descrita como número e proporção de acertos. A pontuação total desta escala foi reportada com média e desvio padrão (DP). Esta variável intervalar foi considerada com distribuição normal (Figura 2) e utilizada como variável contínua.

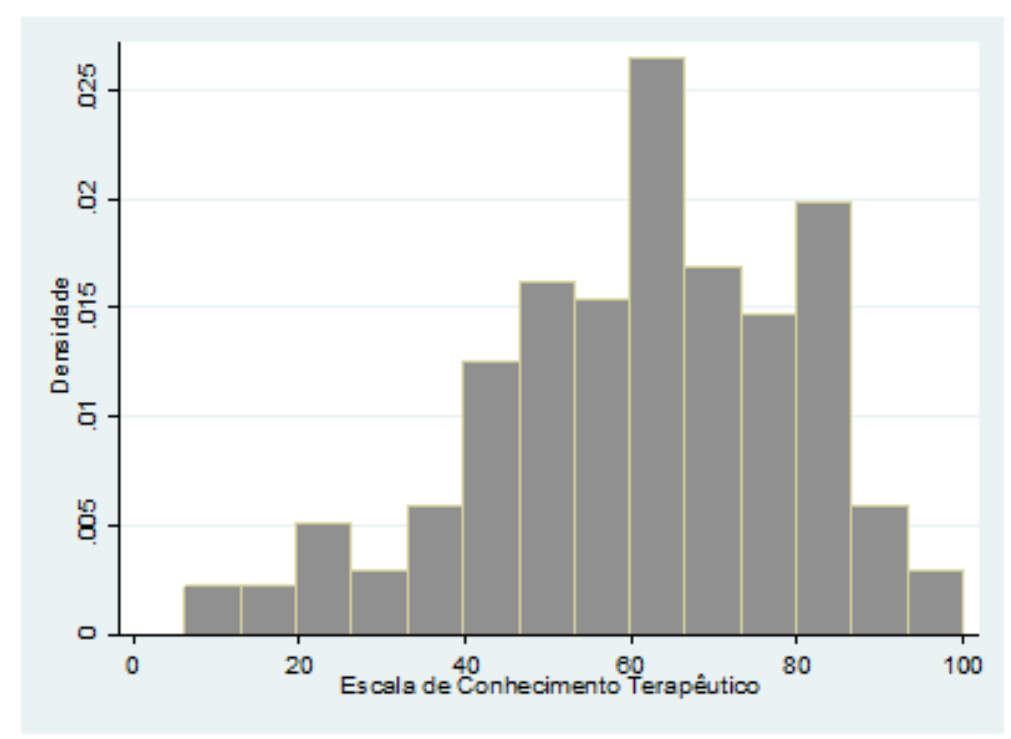

Figura 2 - Histograma da escala do conhecimento do regime terapêutico

\subsubsection{Teste da Caixa de Medicamentos}

Número e proporção foram utilizados para a descrição de cada um dos cinco acertos do teste (azul, amarelo, verde, vermelho e laranja). Para fins práticos, conforme descrito anteriormente, esta variável foi descrita como dicotômica, cinco acertos (0) ou menor que cinco acertos (1). 


\subsubsection{Escala de Morisky}

Foi utilizada como variável qualitativa ordinal, dividida em baixa (0 a 5 pontos), média (6 a 7 pontos) e alta (8 pontos) adesão descrita como número e proporção. Foi descrito ainda, a média e o desvio padrão.

\subsubsection{4 Índice de Complexidade do Regime Terapêutico}

As três etapas do índice ( $A, B$ e $C$ ) foram descritas em número e proporção. A pontuação total foi descrita como média e desvio padrão. Pela análise do histograma foi considerada com distribuição normal (Figura 3) e utilizada como variável contínua.

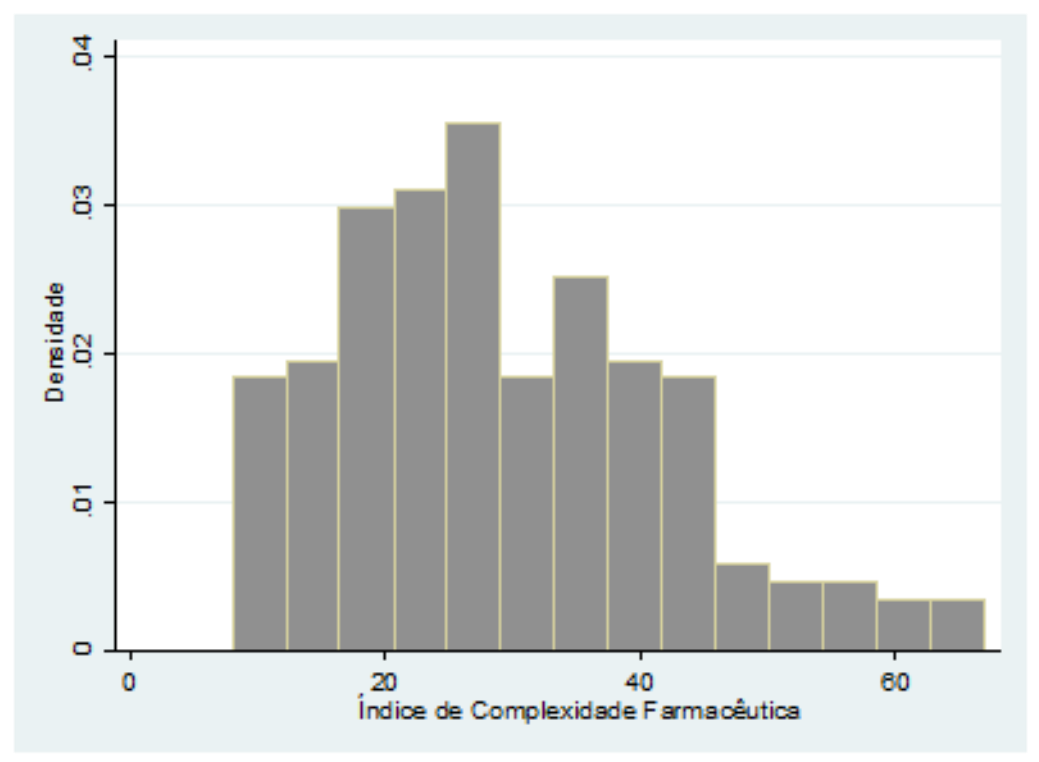

Figura 3 - Histograma do Índice de Complexidade do Regime Terapêutico

\subsubsection{Análise Transversal}

O índice de complexidade da farmacoterapia, a escala de conhecimento do regime terapêutico, a escala de Morisky e o teste da caixa 
de medicamentos foram associados com as variáveis sociodemográficas e clínicas. $\mathrm{Na}$ análise univariada, foi utilizado o teste qui-quadrado para as variáveis categóricas, o teste de T de Student ou o teste de ANOVA para as variáveis contínuas com distribuição normal e o teste de Mann-Whitney ou o teste de Kruskall-Wallis para as variáveis contínuas com distribuição assimétrica.

Para a análise de associação do índice de complexidade da famacoterapia e da escala de conhecimento do regime terapêutico com as covariáveis foi utilizada a regressão linear múltipla.

Para a análise de associação da escala de Morisky e do teste da caixa de medicamentos com as covariáveis foi utilizada a regressão logística binária. Sendo a primeira escala dividida em baixa (0-7 pontos) e alta adesão (8 pontos) e o segundo teste em correto ( 5 acertos) e incorreto ( 0 a 4 acertos). Apesar da regressão logística ordinal ser uma opção de análise da escala de Morisky dividida em três categorias, optamos por não utilizá-la devido à complexidade de interpretação dos resultados. Estudos prévios também optaram por utilizar a regressão logística binária (Oliveira-Filho et al. 2012).

As variáveis incluídas no modelo foram padronizadas e estão descritas no Quadro 11. A entrada no modelo foi realizada através de estratégia hierárquica com o objetivo de mensurar passo a passo a importância de cada conjunto de variáveis na associação de cada teste. No modelo 1 , entraram variáveis sociodemográficas; no modelo 2 , variáveis 
clínicas; e no modelo 3, a escala de alfabetismo funcional. Foi descrito o R2 do modelo de regressão de cada uma das etapas.

O teste $F$ (regressão linear) ou o teste de Wald (regressão logística) foi utilizado para descrever a significância da entrada de cada bloco de variáveis no modelo. Ao final de cada modelo foi gerado um $p$. Valores de $p$ menores que 0,05 representaram que a adição do conjunto de variáveis foi estatisticamente significativa. Para as suspeitas de multicolinearidade foi realizado o VIF (Variance Inflation Factor) do modelo.

Foram realizadas ainda, interações entre os fatores significativamente estatísticos e os testes de adesão medicamentosa. O objetivo desta análise foi verificar potenciais modulações entre a associação das variáveis de estudo e demais covariáveis. As variáveis utilizadas nas interações foram: idade, escala de suporte social, complexidade do regime terapêutico, escala de depressão e MEEM. 
Quadro 11 - Modo de entrada das covariáveis nos modelos de regressão linear e logística

\begin{tabular}{|lll|}
\hline Variável & Modo de entrada & Código \\
\hline Idade & Intervalar & Em anos \\
Sexo & Categórica & Feminino $=0$ \\
& & Masculino $=1$ \\
Escala de Suporte Social: Medical & Categórica & 40 pontos $=0$ \\
Outcome Study & & Inferior a 40 pontos $=1$ \\
Índice de Multimorbidades de & Categórica & 0 pontos $=0$ \\
Charlson & & 1 ponto $=1$ \\
& & 2 pontos $=2$ \\
& & 3 pontos $=3$ \\
Atividade de Vida Diária: Escala & Categórica & $\leq 21$ pontos $=0$ \\
BOMFAQ & & $22-26$ pontos $=1$ \\
& & $27-30$ pontos $=2$ \\
Mini Exame do Estado Mental & Categórica & $\leq 21$ pontos $=0$ \\
& & $22-26$ pontos $=1$ \\
& & $27-30$ pontos $=2$ \\
Escala de Depressão Geriátrica & Categórica & $0-4$ pontos $=0$ \\
(GDS-15) & & $\geq 5$ pontos $=1$ \\
SAHLPA & Categórica & $15-18$ pontos $=0$ \\
& & $\leq 14$ pontos $=1$ \\
\hline
\end{tabular}

\subsubsection{Análise de Sobrevida}

Nesta etapa de análise da coorte, foi realizada a probabilidade de ocorrência dos desfechos ao longo dos seis meses de acompanhamento. Durante o seguimento, não se quis analisar, simplesmente, a ocorrência dos desfechos, mas também, a probabilidade de ocorrência ao longo do tempo. Sobrevida foi considerada como o tempo desde a entrada do participante no estudo até a ocorrência do desfecho ou até a censura, término do período de acompanhamento. A medida de risco utilizada para a relação das variáveis com o desfecho foi o Harzard Ratio (HR). 
A incidência foi usada para descrever a ocorrência dos desfechos de acordo com o ICFT e os testes de adesão. Curvas de Kaplan-Meier foram utilizadas como representação gráfica da ocorrência dos desfechos ou censura ao longo do tempo. O teste de log-rank foi aplicado para a comparação das curvas de sobrevida entre os grupos de interesse.

A verificação da adequação de proporcionalidade dos riscos ao longo do tempo foi realizada por meio da análise de resíduos de Schoenfeld. Valores de p maiores ou iguais a 0,05 confirmaram que a suposição de proporcionalidade foi respeitada.

As quatro variáveis estudadas como independentes foram: a escala de conhecimento do regime terapêutico; o teste da caixa de medicamentos; a escala de Morisky e o índice de complexidade da farmacoterapia. Para melhor interpretação dos resultados e representação gráfica nas curvas de Kaplan-Meier todas elas foram categorizadas conforme o Quadro 12.

Quadro 12 - Descrição das variáveis independentes na análise de sobrevida

\begin{tabular}{|ll|}
\hline Variável & Categorias \\
\hline $\begin{array}{l}\text { Escala de conhecimento do Regime } \\
\text { Terapêutico }\end{array}$ & $\begin{array}{l}\text { Baixo, médio e alto conhecimento - dividido em } \\
\text { tercis }\end{array}$ \\
Teste da Caixa de Medicamentos & $\begin{array}{l}\text { Correto }-5 \text { acertos } \\
\text { Incorreto - } 4 \text { certos ou menos }\end{array}$ \\
& Alta adesão - 8 pontos \\
Escala de Morisky & Média adesão - 6 e 7 pontos \\
& Baixa adesão - 5 pontos ou menos \\
Índice de Complexidade da & Baixa, média e alta complexidade - dividido em \\
Farmacoterapia & tercis \\
\hline
\end{tabular}


O modelo de riscos proporcionais de Cox foi utilizado para o estudo de associação entre as variáveis independentes e os desfechos. A estratégia de entrada das variáveis foi de maneira hierárquica e forçada. O modelo 1 foi composto por variáveis sociodemográficas: idade, sexo e MOS. O modelo 2 foi composto pela adição de variáveis clínicas: índice de multimorbidades de Charlson e funcionalidade. $O$ modelo 3 adicionou cada teste de adesão ou o ICFT. O Quadro 13 descreve como cada covariável entrou no modelo.

O teste de Wald foi utilizado como o teste de hipótese para estimar a significância estatística da entrada de cada grupo de variáveis no modelo.

Quadro 13 - Modo de entrada das covariáveis no modelo de regressão de riscos proporcionais de Cox

\begin{tabular}{|lll|}
\hline Variável & Modo de entrada & Código \\
\hline Idade & Intervalar & Em anos \\
Sexo & Categórica & Feminino $=0$ \\
& & Masculino $=1$ \\
Escala de Suporte Social: Medical & Categórica & 40 pontos $=0$ \\
Outcome Study & & Inferior a 40 pontos $=1$ \\
Índice de Multimorbidades de & Categórica & 0 pontos $=0$ \\
Charlson & & 1 ponto $=1$ \\
& & 2 pontos $=2$ \\
& & 3 pontos $=3$ \\
Atividade de Vida Diária: Escala & Categórica & $\leq 21$ pontos $=0$ \\
BOMFAQ & & $22-26$ pontos $=1$ \\
& & $27-30$ pontos $=2$ \\
\hline
\end{tabular}

Por fim, foram realizadas interações com objetivo de verificar potenciais modificações nas associações entre os desfechos e as variáveis de estudo, determinadas por covariáveis. As variáveis utilizadas nas 
interações foram: idade, sexo, sintomas depressivos, escala de suporte social, SAHLPA, MEEM, hiperpolifarmácia e dependência para tomada de medicações. 
4 QUESTÕES ÉTICAS, PROJETO

"GUARDA-CHUVA" E FINANCIAMENTO 


\section{QUESTÕES ÉtICAS, PROJETO "GUARDA-CHUVA" E FINANCIAMENTO}

Todos os pacientes receberam uma descrição verbal sobre a proposta do projeto "guarda-chuva" desenvolvido no HDG intitulado "Hospital Dia para idosos com risco de hospitalização". Aqueles que concordaram participar, assinaram o consentimento informado livre e esclarecido (ANEXO C) antes da inclusão no estudo. No caso de prejuízo cognitivo, o consentimento foi obtido do cuidador responsável legal pelo paciente.

Esta pesquisa foi submetida individualmente Comitê de Ética e Pesquisa do Hospital das Clínicas de São Paulo (CAPPesq). Foi aprovada em março de 2015 pelo parecer número 998.609.

Esse estudo é um subprojeto do projeto integrado (projeto "guardachuva") intitulado Hospital Dia Geriátrico para idosos com risco de hospitalização, que foi aprovado para financiamento por meio da chamada de propostas para o Programa de Pesquisa para o SUS: gestão compartilhada em Saúde - PPSUS - Edital 2013. 


\section{RESULTADOS}




\section{RESULTADOS}

Trezentos e dezesseis idosos foram atendidos no HDG por doença aguda, ou por crônica descompensada, no período de recrutamento de janeiro de 2015 a dezembro de 2015. O motivo de exclusão mais prevalente foi ausência de polifarmácia em 34 indivíduos. Em seguida, situações de emergência na admissão em 12 idosos. Todos os motivos de exclusão estão apresentados no fluxograma na Figura 4. Nenhum participante foi excluído por impossibilidade de contato telefônico. A amostra final foi de 207 participantes.

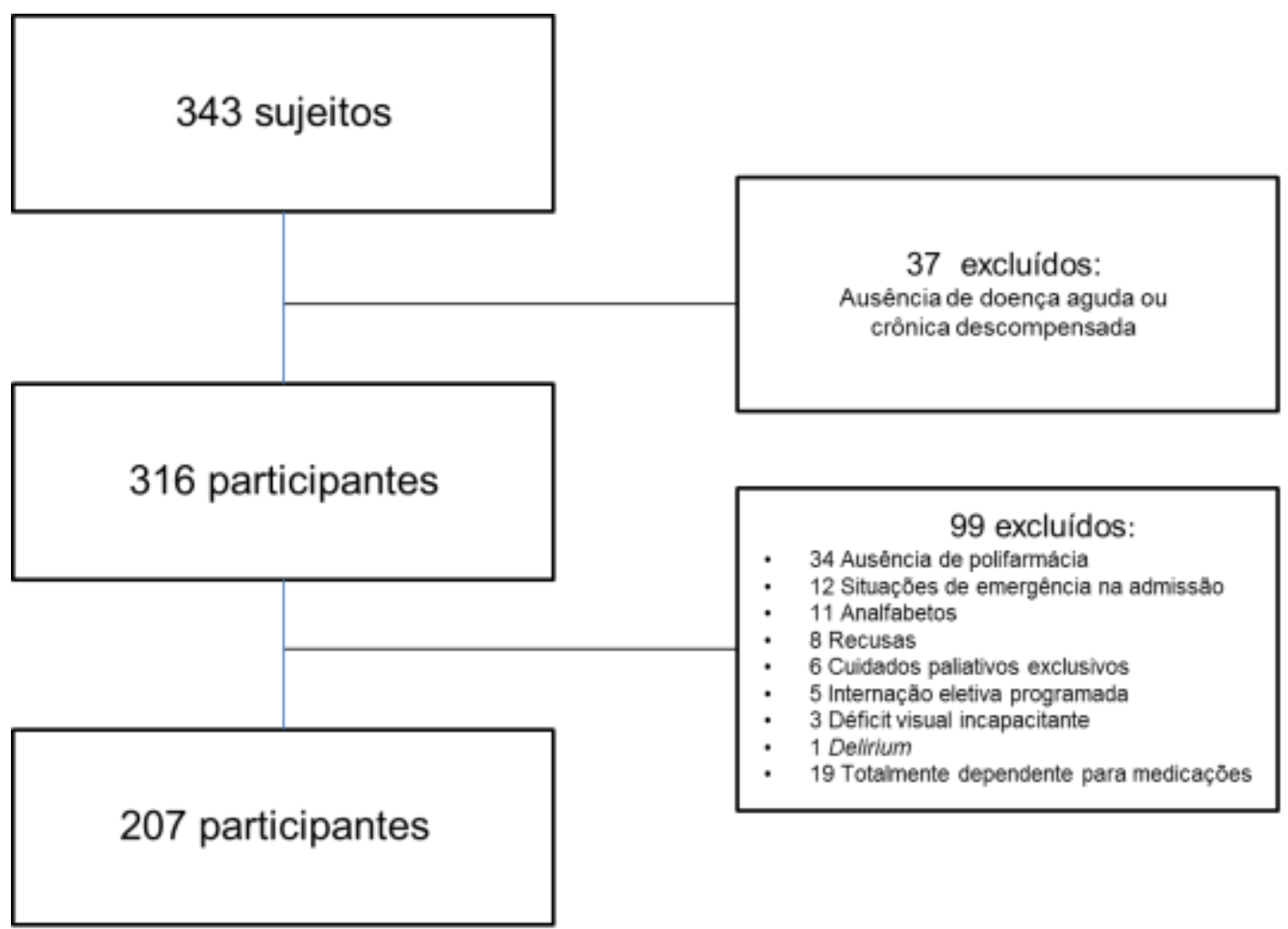

Figura 4 - $\quad$ Fluxograma do recrutamento da amostra 
Os motivos de encaminhamentos para o HDG dos participantes incluídos na pesquisa foram heterogêneos. As duas principais causas de encaminhamento foram anemia e diabetes descompensada. A Tabela 1 descreve esses motivos pelo grupo de doenças e por diagnósticos.

Tabela 1 - Motivos de encaminhamento dos participantes incluídos ao Hospital Dia Geriátrico $(n=207)$

\begin{tabular}{|c|c|c|c|}
\hline $\begin{array}{l}\text { GRUPO DE } \\
\text { DOENÇAS }\end{array}$ & $\mathbf{N}(\%)$ & DOENÇAS & $N(\%)$ \\
\hline \multirow{4}{*}{ Infecção } & \multirow{4}{*}{$23(11,1)$} & Trato urinário & $16(7,7)$ \\
\hline & & Diarréia aguda & $2(1)$ \\
\hline & & Pele & $1(0,5)$ \\
\hline & & Outra & $4(2)$ \\
\hline \multirow{6}{*}{$\begin{array}{l}\text { Doença Crônica } \\
\text { Descompensada }\end{array}$} & \multirow{6}{*}{$84(40,6)$} & Diabetes Mellitus & $42(20,3)$ \\
\hline & & Hipertensão Arterial & $7(3,4)$ \\
\hline & & Doença Pulmonar Obstrutiva Crônica & $5(2,4)$ \\
\hline & & Doença Renal Crônica & $2(1)$ \\
\hline & & Insuficiência Cardíaca Descompensada & $25(12,1)$ \\
\hline & & Outras & $3(1,5)$ \\
\hline \multirow{2}{*}{$\begin{array}{l}\text { Doença } \\
\text { Neuropsiquiátrica }\end{array}$} & \multirow{2}{*}{$10(4,8)$} & Alteração comportamental & $3(1,5)$ \\
\hline & & Investigação de declínio cognitivo & $7(3,4)$ \\
\hline \multirow{10}{*}{ Outras } & \multirow{10}{*}{$90(43,5)$} & Investigação diagnóstica & $1(0,5)$ \\
\hline & & Reação adversa à medicação & $2(1)$ \\
\hline & & Síndrome consumptiva & $6(2,9)$ \\
\hline & & Anemia & $47(22,7)$ \\
\hline & & Distúrbio hidroeletrolítico & $5(2,4)$ \\
\hline & & Dispnéia & $3(1,5)$ \\
\hline & & Quedas & $5(2,4)$ \\
\hline & & Trombose venosa profunda & $4(2)$ \\
\hline & & Dor & $14(6,8)$ \\
\hline & & Síndrome dispéptica & $3(1,5)$ \\
\hline
\end{tabular}


Quanto às características sociodemográficas, os participantes tiveram média de idade de 77,8 (DP 8,2) anos, $67,1 \%$ eram do sexo feminino, $60,3 \%$ consideravam-se da cor branca, $59,9 \%$ eram casados, a mediana (intervalo interquartil) de escolaridade em anos foi de 4 (3-8) anos e a mediana de renda familiar per capita de $1(0,85-1,75)$ salários mínimos. Quanto a pontuação no índice de multimorbidades de Charlson, 37,2\% tinham índice maior que 3; 30,4\% tinham índice de 1; 22,7\% índice igual a 2 e 9,7\% índice zero. Quanto à funcionalidade, a média foi de 22,5 (DP 6,0) pontos na escala BOMFAQ, a média da pontuação no teste do MEEM foi de $23(5,5)$ pontos e a proporção de idosos com mais de cinco pontos no GDS-15 foi de $40 \%$. A prevalência de idosos com diagnóstico de demência prévia foi de 16,4\% (34 participantes). A média de medicações utilizadas pelos participantes foi de 9,6. $64 \%$ dos indivíduos tinham alfabetismo em saúde adequado medido pelo SAHLPA. As características sociodemográficas e clínicas da população estudada estão descritas abaixo na Tabela 2.

Verificamos baixa correlação entre escolaridade e SAHLPA $(r=0,25)$ e baixa correlação entre MEEM e SAHLPA $(r=0,07)$. 
Tabela 2 - Características sociodemográficas e clínicas dos participantes $(n=207)$

\begin{tabular}{|c|c|c|}
\hline \multicolumn{2}{|c|}{ VARIÁVEIS SOCIODEMOGRÁFICAS } & N (207) \\
\hline \multicolumn{2}{|l|}{ Idade (anos), média (DP) } & $77,9(8.2)$ \\
\hline \multicolumn{2}{|l|}{ Sexo feminino, $\mathrm{n}(\%)$} & $139(67.1)$ \\
\hline \multicolumn{2}{|l|}{ Raça branca, n (\%) } & $125(60,3)$ \\
\hline \multicolumn{2}{|l|}{ Com parceiro, n (\%) } & $124(59,9)$ \\
\hline \multicolumn{2}{|l|}{ Morar sozinho, n (\%) } & $53(25,6)$ \\
\hline \multirow{3}{*}{ Escolaridade (anos) } & $0-3, \mathrm{n}(\%)$ & $68(32,8)$ \\
\hline & $4-7, \mathrm{n}(\%)$ & $79(38,2)$ \\
\hline & $\geq 8, \mathrm{n}(\%)$ & $70(29)$ \\
\hline \multirow{3}{*}{$\begin{array}{l}\text { Renda familiar per } \\
\text { capita(salário mínimo) }\end{array}$} & $0-0,99, \mathrm{n}(\%)$ & $53(25,6)$ \\
\hline & $1-1,99, \mathrm{n}(\%)$ & $103(49,8)$ \\
\hline & $\geq 2, \mathrm{n}(\%)$ & $51(24,6)$ \\
\hline \multicolumn{2}{|l|}{ MOS inferior a 40 pontos, $\mathrm{n}(\%)$} & $103(49,8)$ \\
\hline \multicolumn{3}{|l|}{ VARIÁVEIS CLÍNICAS } \\
\hline \multirow{4}{*}{$\begin{array}{l}\text { Ìndice de Multimorbidades de } \\
\text { Charlson }\end{array}$} & 0 ponto, n (\%) & $20(9,7)$ \\
\hline & 1 ponto, n (\%) & $63(30,4)$ \\
\hline & 2 pontos, $\mathrm{n}(\%)$ & $47(22,7)$ \\
\hline & $\geq 3$ pontos, $\mathrm{n}(\%)$ & $77(37,2)$ \\
\hline \multicolumn{2}{|c|}{ Número de medicamentos, média (DP) } & $9,4(3,83)$ \\
\hline \multicolumn{2}{|l|}{ Hiperpolifarmácia, n (\%) } & $74(35,7)$ \\
\hline \multirow{3}{*}{ BOMFAQ } & $\leq 21$ pontos, $\mathrm{n}(\%)$ & $76(36,7)$ \\
\hline & $22-26$ pontos, $\mathrm{n}(\%)$ & $66(31,9)$ \\
\hline & $27-30$ pontos, $n(\%)$ & $65(31,4)$ \\
\hline \multicolumn{2}{|l|}{ GDS-15 > 5 pontos, $n(\%)$} & $81(40)$ \\
\hline \multirow{3}{*}{ MEEM } & $\leq 21$ pontos, $\mathrm{n}(\%)$ & $70(34,1)$ \\
\hline & $22-26$ pontos, n (\%) & $70(34,1)$ \\
\hline & $27-30$ pontos, $n(\%)$ & $65(31,2)$ \\
\hline \multicolumn{2}{|l|}{ SAHLPA $\leq 14, \mathrm{n}(\%)$} & $75(36)$ \\
\hline \multicolumn{2}{|l|}{ Déficit visual, n (\%) } & $36(17,4)$ \\
\hline \multicolumn{2}{|l|}{ Déficit auditivo, n (\%) } & $35(17)$ \\
\hline \multicolumn{2}{|c|}{ Uso recente do sistema de saúde, n (\%) } & $111(53,7)$ \\
\hline \multicolumn{2}{|c|}{ Auxílio para tomada de medicação, n (\%) } & $78(37,6)$ \\
\hline
\end{tabular}

MOS: Medical Outcomes Study; MEEM: Mini Exame do Estado Mental; BOMFAQ: Brazilian OARS Multidimensional Functional Assessment Questionnaire; SAHLPA: Short Assessment of Health Literacy for Portuguese-Speaking

Adults GDS-15: Escala de depressão geriátrica de 15 itens; ICFT: índice de Complexidade Farmacêutica 


\subsection{ASSOCIAÇÃO DAS CARACTERÍSTICAS SOCIODEMOGRÁFICAS E CLINICAS COM AS VARIÁVEIS DE ESTUDO}

\subsubsection{Escala de Morisky}

De acordo com o MMAS-8, apenas $22,2 \%$ dos participantes tinham alta adesão; 37,2\% tinham média adesão e 40,6\% tinham baixa adesão.

A Tabela 3 descreve a associação da adesão medicamentosa de acordo com a escala de Morisky com as características sociodemográficas e clínicas dos participantes. A porcentagem de participantes que obtiveram mais de 5 pontos no GDS-15 foi maior no grupo de baixa adesão (52\%), seguido do grupo de moderada adesão $(35,5 \%)$ e alta adesão $(24,4 \%)$, com diferença estatística significante $(p=0,005)$. 
Tabela 3 - Fatores associados à adesão medicamentosa de acordo com a Escala de Morisky $(\mathrm{n}=207)$

\begin{tabular}{|c|c|c|c|c|c|}
\hline & & $\begin{array}{c}\text { Alta } \\
\text { Adesão } \\
\text { Morisky } 8 \\
(n=46) \\
\end{array}$ & $\begin{array}{c}\text { Moderada } \\
\text { Adesão } \\
\text { Morisky 6-7 } \\
(\mathrm{n}=77) \\
\end{array}$ & $\begin{array}{c}\text { Baixa } \\
\text { Adesão } \\
\text { Morisky 0-5 } \\
(n=84) \\
\end{array}$ & p valor \\
\hline \multicolumn{6}{|c|}{ VARIÁVEIS SOCIODEMOGRÁFICAS } \\
\hline \multicolumn{2}{|c|}{ Idade (anos), média (DP) } & $77,8(7,9)$ & $77,5(8,7)$ & $78,2(7,9)$ & 0,653 \\
\hline \multicolumn{2}{|l|}{ Sexo feminino, $n(\%)$} & $29(36,9)$ & $47(61)$ & $63(75)$ & 0,135 \\
\hline \multicolumn{2}{|l|}{ Com parceiro, n (\%) } & $27(58,7)$ & $43(55,8)$ & $54(64,3)$ & 0,541 \\
\hline \multicolumn{2}{|l|}{ Raça branca, n (\%) } & $27(58,7)$ & $42(54,5)$ & $56(66,7)$ & 0,281 \\
\hline \multicolumn{2}{|l|}{ Morar sozinho, n (\%) } & $14(30,4)$ & $23(29,9)$ & $16(19,0)$ & 0,202 \\
\hline \multirow{3}{*}{$\begin{array}{l}\text { Escolaridade } \\
\text { (anos), média (DP) }\end{array}$} & $0-3$ anos & $15(32,6)$ & $17(22,1)$ & $21(25)$ & \multirow{3}{*}{0,427} \\
\hline & 4-7 anos & $13(28,3)$ & $33(42,9)$ & $33(39,3)$ & \\
\hline & $\geq 8$ anos & $19(41,3)$ & $22(28,6)$ & $19(22,6)$ & \\
\hline \multirow{3}{*}{$\begin{array}{l}\text { Renda familiar per } \\
\text { capita (salários } \\
\text { mínimos), média } \\
\text { (DP) }\end{array}$} & $<1,0$ & $10(21,7)$ & $21(27,3)$ & $22(26,2)$ & \multirow{3}{*}{0,499} \\
\hline & $1,0-1,99$ & $20(43,5)$ & $40(51,9)$ & $43(51,2)$ & \\
\hline & $\geq 2$ & $16(34,8)$ & $16(20,8)$ & $19(22,6)$ & \\
\hline \multicolumn{2}{|c|}{ MOS inferior a 40 pontos, $\mathrm{n}(\%)$} & $22(47,8)$ & $43(55,8)$ & $38(45,2)$ & 0,388 \\
\hline \multicolumn{6}{|c|}{ VARIÁVEIS CLÍNICAS } \\
\hline \multirow{4}{*}{$\begin{array}{l}\text { Índice de } \\
\text { Multimorbidadesde } \\
\text { Charlson, } \\
n(\%)\end{array}$} & 0 ponto, n (\%) & $4(8,7)$ & $6(7,8)$ & $10(11.9)$ & \multirow{4}{*}{0,839} \\
\hline & 1 pontos, $\mathrm{n}(\%)$ & $15(32,6)$ & $27(35,1)$ & $21(25,0)$ & \\
\hline & 2 pontos, $\mathrm{n}(\%)$ & $9(19,6)$ & $17(22,1)$ & $21(25,0)$ & \\
\hline & $\geq 3$ pontos, $\mathrm{n}(\%)$ & $18(39,1)$ & $27(35,1)$ & $32(38,1)$ & \\
\hline \multicolumn{2}{|c|}{ Hiperfolifarmácia, n (\%) } & $20(43,5)$ & $26(33,8)$ & $28(33,3)$ & 0,463 \\
\hline \multicolumn{2}{|l|}{ SAHLPA $\leq 14, n(\%)$} & $16(34,8)$ & $30(39,0)$ & $29(34,5)$ & 0,820 \\
\hline \multirow{3}{*}{$\begin{array}{l}\text { BOMFAQ, média } \\
\text { (DP) }\end{array}$} & $\leq 21$ pontos & $17(37)$ & $29(37,7)$ & $30(35,7)$ & \multirow{3}{*}{0,187} \\
\hline & $22-26$ pontos & $11(23,9)$ & $21(27,3)$ & $34(40,5)$ & \\
\hline & 27-30 pontos & $18(39,1)$ & $27(35,0)$ & $20(23,8)$ & \\
\hline \multicolumn{2}{|c|}{ GDS-15 > 5 pontos, $n(\%)$} & $11(24,4)$ & $27(35,5)$ & $43(52,4)$ & 0,005 \\
\hline \multirow{3}{*}{$\begin{array}{l}\text { MEEM, média } \\
\text { (DP) }\end{array}$} & $\leq 21$ pontos & $11(24,5)$ & $26(33,8)$ & $33(39,8)$ & \multirow{3}{*}{0,320} \\
\hline & $22-26$ pontos & $15(33,3)$ & $26(33,8)$ & $29(34,9)$ & \\
\hline & 27-30 pontos & $19(42,2)$ & $25(32,4)$ & $21(25,3)$ & \\
\hline \multicolumn{2}{|l|}{ Déficit visual, n (\%) } & $5(10,9)$ & $11(14,3)$ & $20(23,9)$ & 0,117 \\
\hline \multicolumn{2}{|c|}{ Déficit auditivo, n (\%) } & $9(19,6)$ & $13(16,9)$ & $13(15,5)$ & 0,838 \\
\hline \multicolumn{2}{|c|}{ Uso recente do sistema de saúde, n (\%) } & $23(50,0)$ & $36(46,7)$ & $52(61,9)$ & 0,134 \\
\hline
\end{tabular}

MOS: Medical Outcomes Study; SAHLPA: Short Assessment of Health Literacy for PortugueseSpeaking Adults; BOMFAQ: Brazilian OARS Multidimensional Functional Assessment Questionnaire; GDS-15: Escala de depressão geriátrica de 15 itens; MEEM: Mini Exame do Estado Mental 
Esta associação foi avaliada através do modelo de regressão logística multivariada em estratégia hierárquica descrito na Tabela 4. No modelo final, o GDS-15, manteve significância estatística. Idosos com GDS-15 > 5 pontos tiveram 2,7 vezes mais chance de estar associado à baixa adesão. 0 SAHLPA não esteve associado à escala de Morisky. Nenhum dos blocos de variáveis melhoraram a predição do modelo de acordo com o teste de Wald.

Tabela 4 - Regressão logística multivariada em estratégia hierárquica dos fatores associados à baixa adesão na Escala de Morisky $(n=207)$

Coeficiente $\beta$ (Intervalo de confiança 95\%)

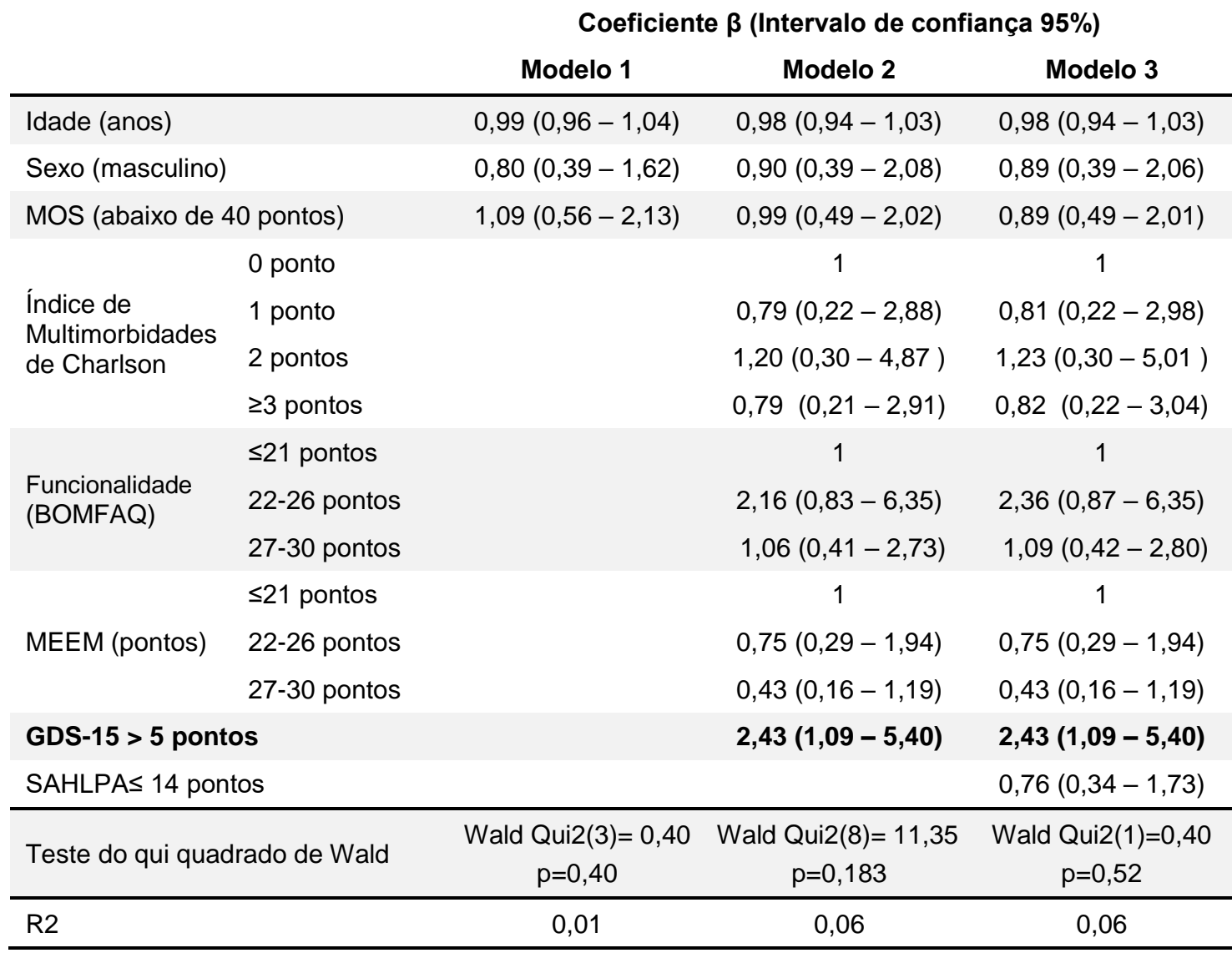

MOS: Medical Outcomes Study; Charlson: índice de multimorbidade de Charlson; MEEM: Mini Exame do Estado Mental; BOMFAQ: Brazilian OARS Multidimensional Functional Assessment Questionnaire; SAHLPA: Short Assessment of Health Literacy for Portuguese-Speaking Adults; GDS-15: Escala de depressão geriátrica de 15 itens 


\subsubsection{Escala do Conhecimento do Regime Terapêutico}

A porcentagem de acertos na escala de conhecimento terapêutico teve uma média de 60,6\% (18,7). Pouco mais de 20\%, 43 idosos, tiveram um percentual de acertos igual ou superior a $80 \%$. E, cerca de um quarto dos participantes, $25,1 \%$ tiveram um desempenho inferior a $50 \%$. A análise individual de cada quesito da escala de conhecimento terapêutico demonstrou que $52 \%$ dos participantes acertaram o nome da medicação, apenas $23 \%$ a dose, $74 \%$ o horário, $75 \%$ a quantidade e $69 \%$ a indicação (Figura 5).

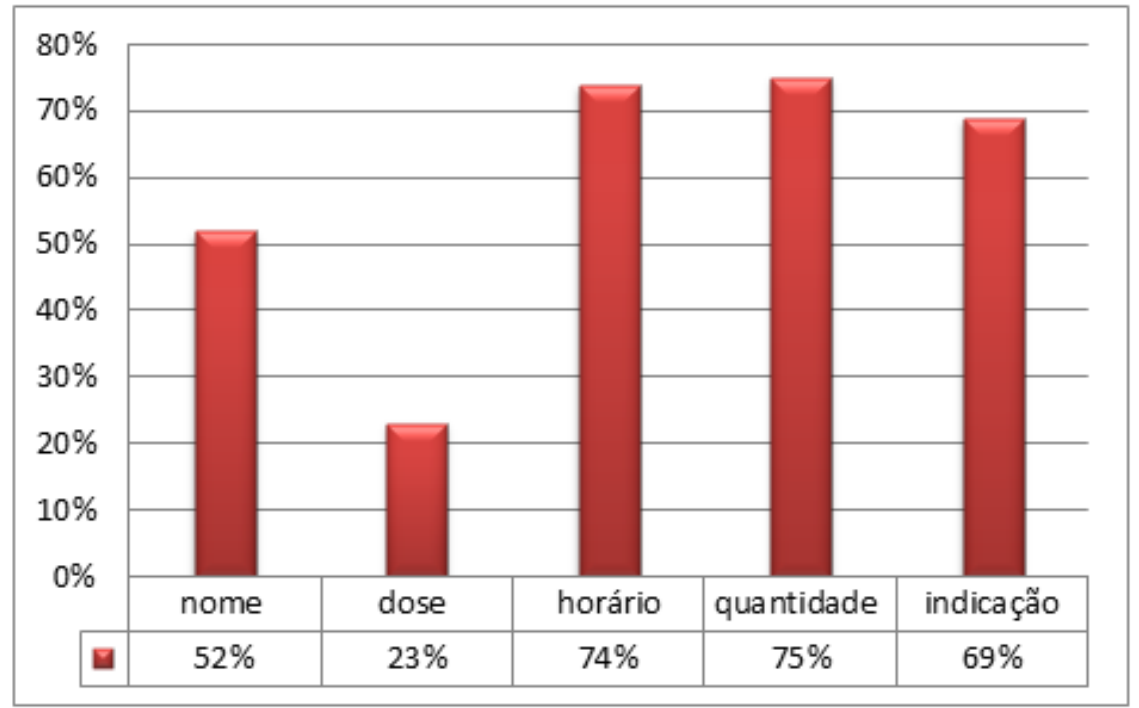

Figura 5 - Percentual médio de acertos de cada etapa da escala de conhecimento terapêutico 
A Tabela 5 descreve associação entre a escala de conhecimento do regime terapêutico dividida em tercis com as características sociodemográficas e clínicas. Os participantes com escala de MOS menor que 40 pontos, mais comorbidades, hiperpolifarmácia, pontuação no SAHLPA menor ou igual a 14, menor funcionalidade, pontuação no GDS-15 superior a 5 pontos e pior pontuação no MEEM estiveram associados ao tercil baixo conhecimento na Escala de Conhecimento Terapêutico. 
Tabela 5 - Fatores associados à Escala de Conhecimento Terapêutico dividida em tercis $(n=203)$

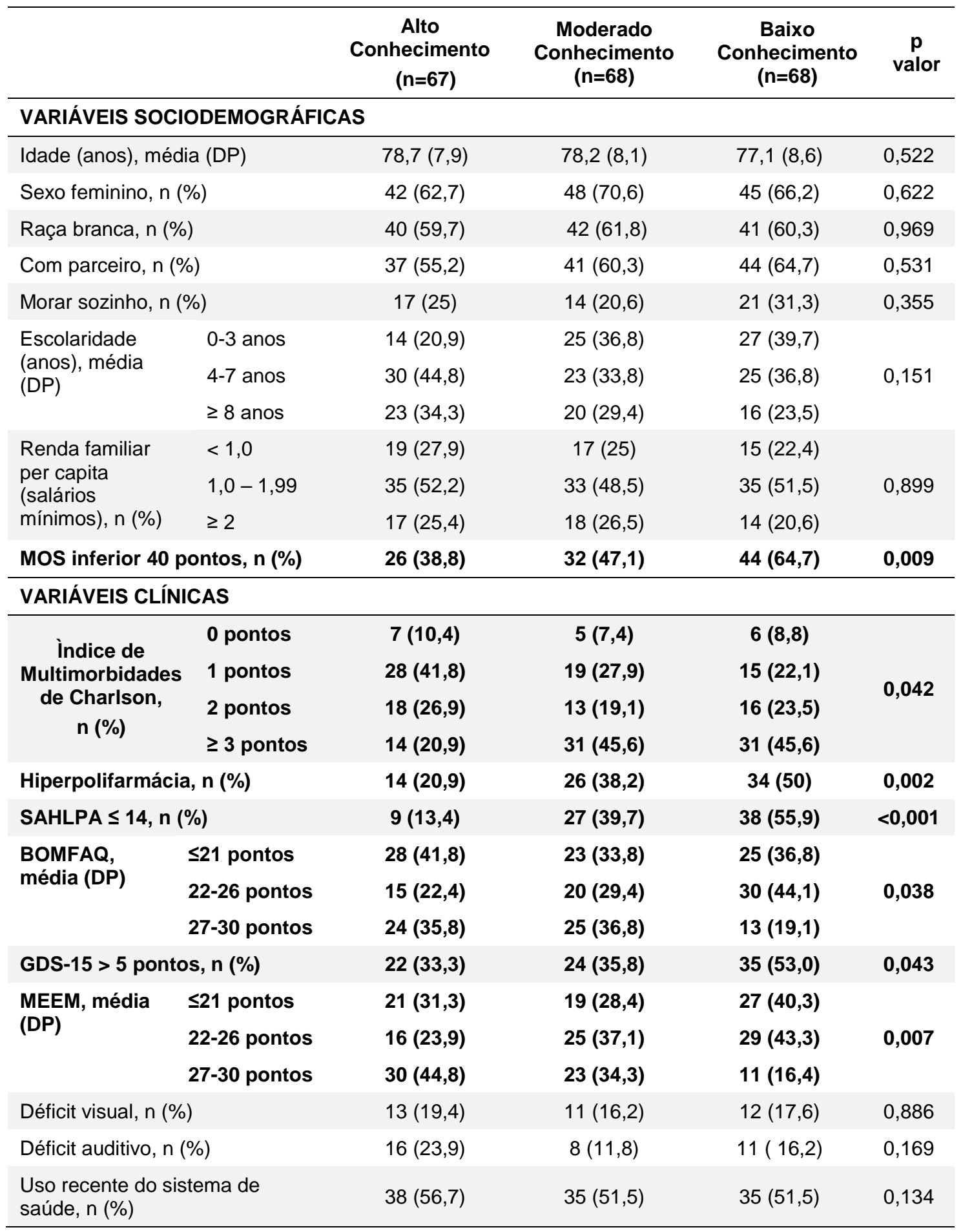

MOS: Medical Outcomes Study; SAHLPA: Short Assessment of Health Literacy for Portuguese-Speaking Adults; BOMFAQ: Brazilian OARS Multidimensional Functional Assessment Questionnaire; GDS-15: Escala de depressão geriátrica de 15 itens; MEEM: Mini Exame do Estado Mental 
O modelo de regressão linear múltiplo em estratégia hierárquica da associação das covariáveis com a escala de conhecimento terapêutico está descrito na Tabela 6. No modelo final, com a inclusão do da escala de alfabetismo em saúde, participantes com SAHLPA menor ou igual a 14 pontos tiveram em média 11,3 pontos a menos na escala de conhecimento terapêutico do que aqueles com pontuação de 15 a 18. Outras duas variáveis independentes foram: a escala de suporte social, MOS e a escala de sintomas depressivos, GDS-15. Participantes com pontuação inferior a 40 pontos tiveram em média 6,2 pontos a menos na escala de conhecimento do que aqueles com 40 pontos e participantes com GDS-15 > 5 pontos tiveram em média 5,3 pontos a menos na escala do conhecimento do que aqueles com pontuação de 0 a 4 . 
Tabela 6 - Regressão linear múltipla em estratégia hierárquica dos fatores associados à Escala de Conhecimento Terapêutico $(n=203)$

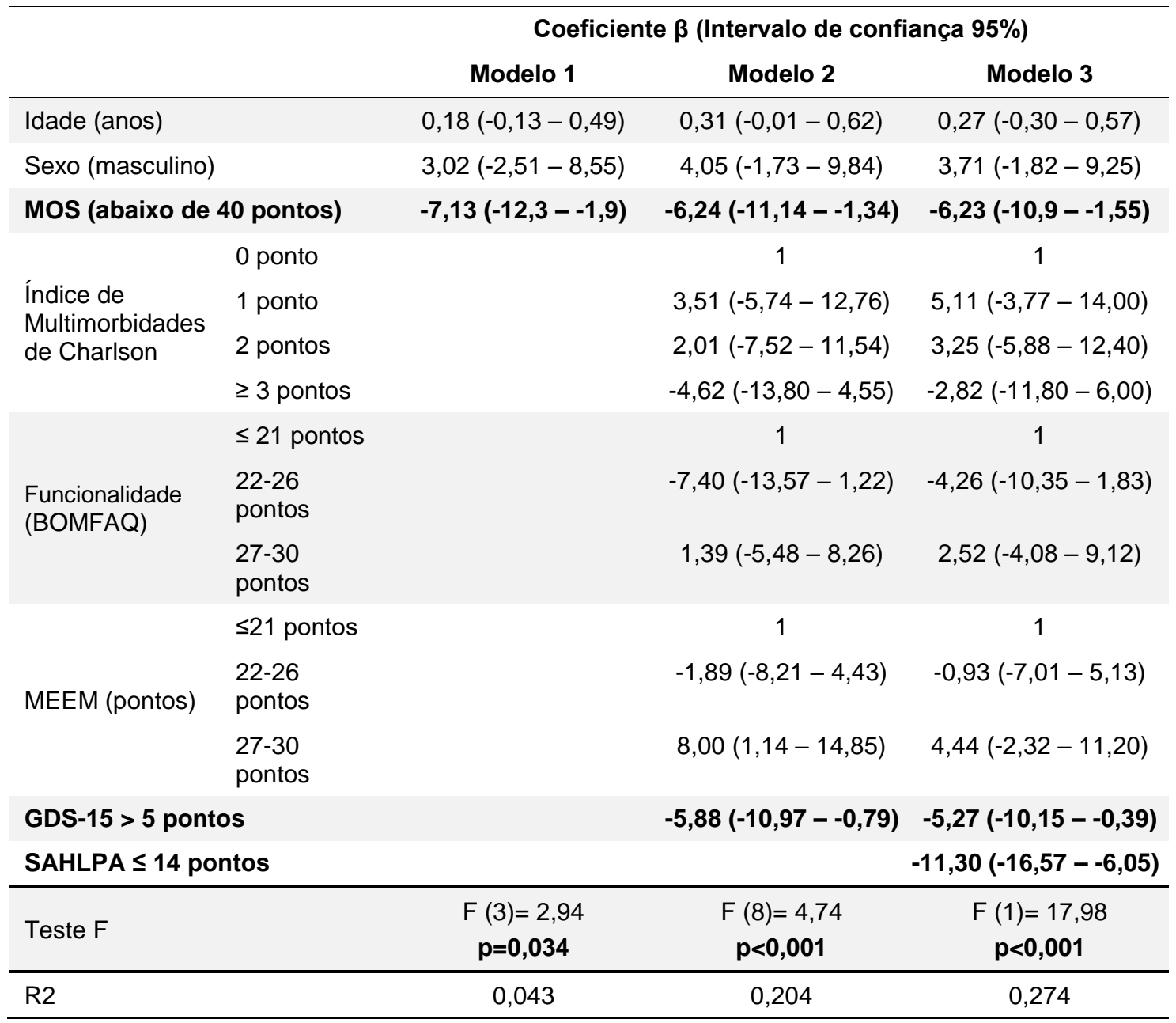

MOS: Medical Outcomes Study; Charlson: índice de multimorbidade de Charlson; MEEM: Mini Exame do Estado Mental; BOMFAQ: Brazilian OARS Multidimensional Functional Assessment Questionnaire; SAHLPA: Short Assessment of Health Literacy for Portuguese-Speaking Adults; GDS-15: Escala de depressão geriátrica de 15 itens

O teste $\mathrm{F}$ demonstrou na estratégia hierárquica que tanto a adição das variáveis clínicas (modelo 2), quanto a adição do SAHLPA (modelo 3) contribuíram significativamente para a melhora do modelo de predição, ambos com $p<0,001$. O R2 ajustado do modelo final foi de 0,27 . O VIF médio do modelo final foi de 1,83 , maior para Charlson $(3,48)$ e MEEM $(1,89)$. 


\subsubsection{Teste da Caixa Organizadora de Medicamentos}

Com relação ao teste da caixa de medicamentos, $45,4 \%$ dos participantes interpretaram corretamente a prescrição médica e conseguiram executar o teste com pontuação máxima. Quando analisamos as cinco tarefas de forma isolada do teste, percebemos que os maiores percentuais de acertos foram com as cápsulas azul 85,7\% (tomar 1 comprimido 1 vez ao dia pela manhã) e laranja 79,8\% (tomar 1 vez ao dia ao deitar) que possuíam posologias mais simples. As porcentagens de acertos com as outras cápsulas foram: vermelha $66 \%$, verde $61,6 \%$ e amarela $59,6 \%$, respectivamente (Figura 6).

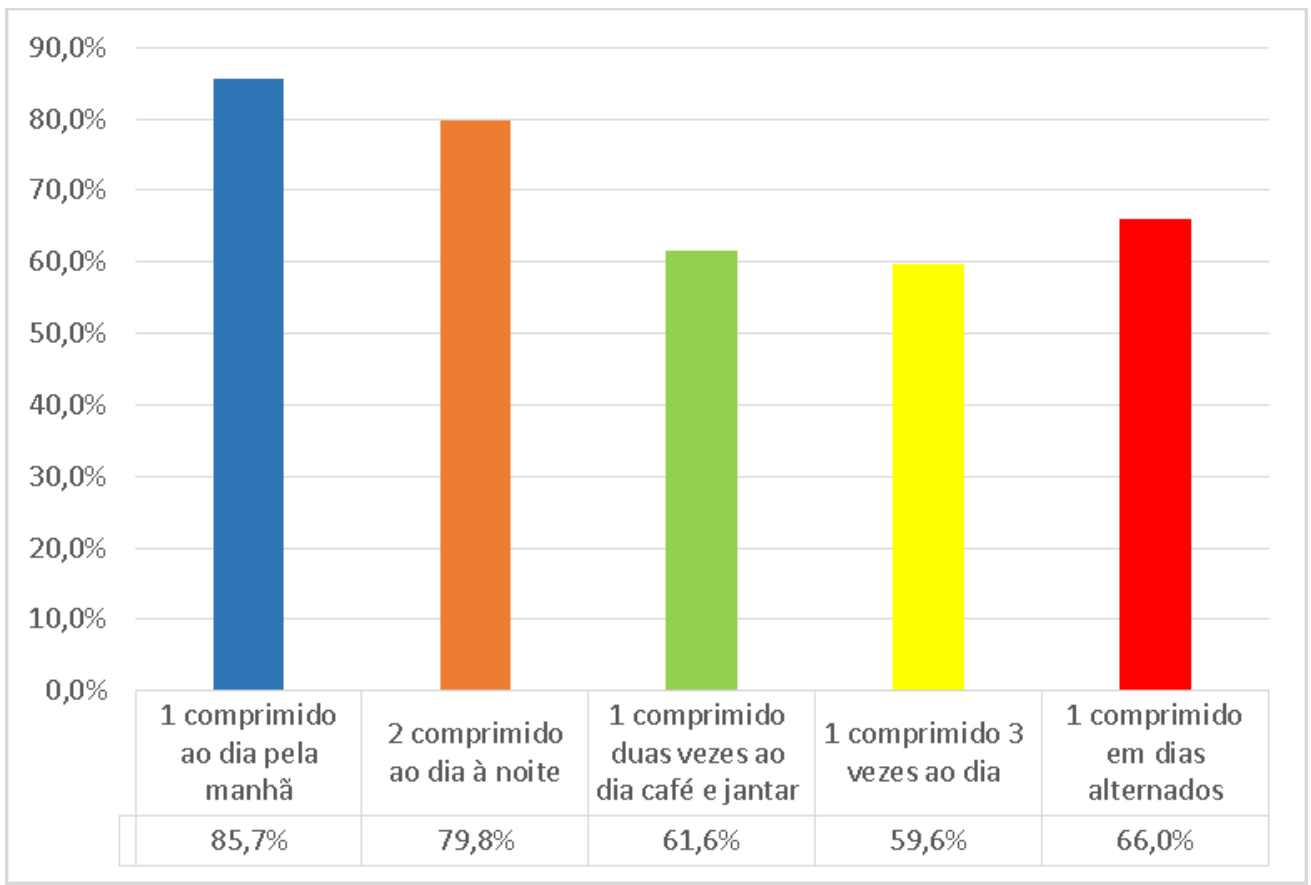

Figura 6 - Percentual de acertos de cada etapa do Teste da Caixa de Medicamentos 
A Tabela 7 descreve a associação do teste da caixa de medicamentos com as características sociodemográficas e clínicas. Participantes do sexo feminino e SAHLPA menor ou igual a 14 pontos e menor pontuação no MEEM estiveram associadas ao desempenho incorreto do teste. 
Tabela 7 - Fatores associados ao Teste da Caixa de Medicamentos ( $n=207$ )

\begin{tabular}{|c|c|c|c|c|}
\hline & & $\begin{array}{c}5 \text { pontos } \\
(n=94)\end{array}$ & $\begin{array}{c}0-4 \text { pontos } \\
(n=113)\end{array}$ & p valor \\
\hline \multicolumn{5}{|c|}{ VARIÁVEIS SOCIODEMOGRÁFICAS } \\
\hline \multicolumn{2}{|c|}{ Idade (anos), média (DP) } & $77,8(9,1)$ & $77,9(7,4)$ & 0,904 \\
\hline \multicolumn{2}{|c|}{ Sexo feminino, $\mathbf{n}(\%)$} & $56(59,6)$ & $83(73,4)$ & 0,034 \\
\hline \multicolumn{2}{|l|}{ Raça branca, n (\%) } & $52(55,3)$ & $73(64,6)$ & 0,174 \\
\hline \multicolumn{2}{|c|}{ Com parceiro, n (\%) } & $54(57,5)$ & $70(62,0)$ & 0,511 \\
\hline \multicolumn{2}{|c|}{ Morar sozinho, n (\%) } & $22(23,4)$ & $31(27,4)$ & 0,508 \\
\hline \multirow{3}{*}{$\begin{array}{l}\text { Escolaridade } \\
\text { (anos), média } \\
\text { (DP) }\end{array}$} & $0-3$ anos & $31(33,0)$ & $37(32,7)$ & \multirow{3}{*}{0,627} \\
\hline & 4-7 anos & $33(35,1)$ & $46(40,7)$ & \\
\hline & $\geq 8$ anos & $30(31,9)$ & $30(26,5)$ & \\
\hline \multirow{3}{*}{$\begin{array}{l}\text { Renda familiar } \\
\text { per capita } \\
\text { (salários } \\
\text { mínimos), média } \\
\text { (DP) }\end{array}$} & $<1,0$ & $28(29,8)$ & $25(22,1)$ & \multirow{3}{*}{0,346} \\
\hline & $1,0-1,99$ & $42(44,7)$ & $61(54,0)$ & \\
\hline & $\geq 2$ & $24(25,5)$ & $27(23,9)$ & \\
\hline \multicolumn{2}{|c|}{ MOS inferior a 40 pontos, $\mathrm{n}(\%)$} & $45(47,87)$ & $58(51,33)$ & 0,621 \\
\hline \multicolumn{5}{|c|}{ VARIÁVEIS CLÍNICAS } \\
\hline \multirow{4}{*}{$\begin{array}{l}\text { Índice de } \\
\text { Multimorbidades } \\
\text { de Charlson }\end{array}$} & 0 ponto, n (\%) & $9(9,6)$ & $11(9,7)$ & \multirow{4}{*}{0,670} \\
\hline & 1 ponto, n (\%) & $30(31,9)$ & $33(29,2)$ & \\
\hline & 2 pontos, $\mathrm{n}(\%)$ & $24(25,5)$ & $23(20,4)$ & \\
\hline & $\geq 3$ pontos, $\mathrm{n}(\%)$ & $31(33,0)$ & $46(40,7)$ & \\
\hline \multicolumn{2}{|c|}{ Hiperpolifarmácia, n (\%) } & $29(30,85)$ & $45(39,8)$ & 0,180 \\
\hline \multicolumn{2}{|c|}{ SAHLPA $\leq 14$ pontos, $n(\%)$} & $15(16,0)$ & $60(53,1)$ & $<0,001$ \\
\hline \multirow{3}{*}{$\begin{array}{l}\text { BOMFAQ, média } \\
\text { (DP) }\end{array}$} & $\leq 21$ pontos & $41(43,6)$ & $35(31,0)$ & \multirow{3}{*}{0,170} \\
\hline & $22-26$ pontos & $27(28,7)$ & $39(34,5)$ & \\
\hline & $27-30$ pontos & $26(27,7)$ & $39(34,5)$ & \\
\hline \multicolumn{2}{|c|}{ GDS-15 > 5 pontos, $n(\%)$} & $34(37,4)$ & $47(42,0)$ & 0,506 \\
\hline \multirow{3}{*}{$\begin{array}{l}\text { MEEM, média } \\
\text { (DP) }\end{array}$} & $\leq 21$ pontos & $30(32,6)$ & $40(35,4)$ & \multirow{3}{*}{0,017} \\
\hline & 22-26 pontos & $24(26,1)$ & $46(40,7)$ & \\
\hline & $27-30$ pontos & $38(41,3)$ & $27(23,9)$ & \\
\hline \multicolumn{2}{|c|}{ Déficit visual, n (\%) } & $19(20,2)$ & $17(15,0)$ & 0,329 \\
\hline \multicolumn{2}{|c|}{ Déficit auditivo, n (\%) } & $19(20,2)$ & $16(14,2)$ & 0,247 \\
\hline \multicolumn{2}{|c|}{ Uso recente do sistema de saúde, $n(\%)$} & $53(56,4)$ & $58(51,3)$ & 0,468 \\
\hline
\end{tabular}

MOS: Medical Outcomes Study; SAHLPA: Short Assessment of Health Literacy for Portuguese-Speaking Adults; BOMFAQ: Brazilian OARS Multidimensional Functional Assessment Questionnaire; GDS-15: Escala de depressão geriátrica de 15 itens; MEEM: Mini Exame do Estado Mental 
A Tabela 8 descreve a análise de regressão logística multivariada em estratégia hierárquica da associação do teste da caixa de medicamentos com as covariáveis. No modelo final, participantes com SAHLPA menor ou igual a 14 pontos tiveram 5,5 vezes mais chance de associação com desempenho incorreto no teste da caixa de medicamentos. O teste de Wald demostrou, na estratégia hierárquica, que a introdução do SAHLPA no modelo 3 contribuiu para a melhora da predição $(p<0,001)$.

Tabela 8 - Regressão logística multivariada em estratégia hierárquica dos fatores associados ao preenchimento inadequado do Teste da Caixa de Medicamentos $(n=207)$

\begin{tabular}{|c|c|c|c|c|}
\hline & & \multicolumn{3}{|c|}{ OR (Intervalo de confiança 95\%) } \\
\hline & & Modelo 1 & Modelo 2 & Modelo 3 \\
\hline \multicolumn{2}{|l|}{ Idade (anos) } & $1,00(0,96-1,03)$ & $1,00(0,96-1,04)$ & $1,01(0,97-1,05)$ \\
\hline \multicolumn{2}{|l|}{ Sexo (masculino) } & $0,53(0,28-0,96)$ & $0,53(0,26-1,07)$ & $0,51(0,24-1,10)$ \\
\hline \multicolumn{2}{|c|}{ MOS (abaixo de 40 pontos) } & $1,11(0,83-1,96)$ & $1,00(0,55-1,81)$ & $0,97(0,51-1,84)$ \\
\hline \multirow{4}{*}{$\begin{array}{l}\text { Índice de } \\
\text { Multimorbidades } \\
\text { de Charlson }\end{array}$} & 0 ponto & & 1 & 1 \\
\hline & 1 ponto & & $1,06(0,34-1,15)$ & $0,78(0,23-2,45)$ \\
\hline & 2 pontos & & $1,04(0,32-3,29)$ & $0,81(0,24-2,75)$ \\
\hline & $\geq 3$ pontos & & $1,93(0,62-5,76)$ & $1,48(0,44-4,71)$ \\
\hline \multirow{3}{*}{$\begin{array}{l}\text { Funcionalidade } \\
\text { (BOMFAQ) }\end{array}$} & $\leq 21$ pontos & & 1 & 1 \\
\hline & $22-26$ pontos & & $2,54(1,21-5,69)$ & $1,73(0,76-4,09)$ \\
\hline & $27-30$ pontos & & $2,47(1,05-5,79)$ & $2,39(0,96-6,26)$ \\
\hline \multirow{3}{*}{ MEEM (pontos) } & $\leq 21$ pontos & & 1 & 1 \\
\hline & $22-26$ pontos & & $1,38(0,66-5,09)$ & $1,24(0,56-2,91)$ \\
\hline & $27-30$ pontos & & $0,49(0,21-1,08)$ & $0,78(0,32-1,88)$ \\
\hline \multicolumn{2}{|c|}{ GDS-15 $>5$ pontos } & & $1,22(0,01-16,64)$ & $1,13(0,59-2,19)$ \\
\hline \multicolumn{2}{|c|}{ SAHLPA $\leq 14$ pontos } & & & $5,49(2,60-11,60)$ \\
\hline \multicolumn{2}{|c|}{ Teste do qui quadrado de Wald } & $\begin{array}{c}\text { Wald Qui2 }(3)=4,42 \\
\qquad p=0,219\end{array}$ & $\begin{array}{l}\text { Wald Qui2 }(8)=14,54 \\
\qquad p=0,068\end{array}$ & $\begin{array}{l}\text { Wald Qui2 }(1)=20,00 \\
\qquad<<0,001\end{array}$ \\
\hline
\end{tabular}

Charlson: índice de multimorbidade de Charlson; MEEM: Mini Exame do Estado Mental; BOMFAQ: Brazilian OARS Multidimensional Functional Assessment Questionnaire; SAHLPA: Short Assessment of Health Literacy for Portuguese-

Speaking Adults; GDS-15: Escala de depressão geriátrica de 15 itens 


\subsection{4 Índice de Complexidade do Regime Terapêutico}

Sobre o índice de complexidade da farmacoterapia, a média da pontuação foi de 29,3 e o desvio padrão de 12,8. Quando analisamos separadamente cada parte do índice, temos a seguinte distribuição em média e desvio padrão, respectivamente:

- Parte A: 4,9 (DP 13,1)

- Parte B: 16,2 (DP 6,9)

- Parte C 8,1 (DP 4,9)

Na tabela 9 está descrita a associação do índice de complexidade farmacêutica em tercis e as variáveis sociodemográficas e clínicas. Participantes com maior pontuação no índice de Charlson, hiperpolifarmácia e GDS-15 maior que 5 pontos estiveram associados a maior complexidade do regime terapêutico. 
Tabela 9 - Fatores associados ao Índice de Complexidade Farmacêutica dividido em tercis $(n=203)$

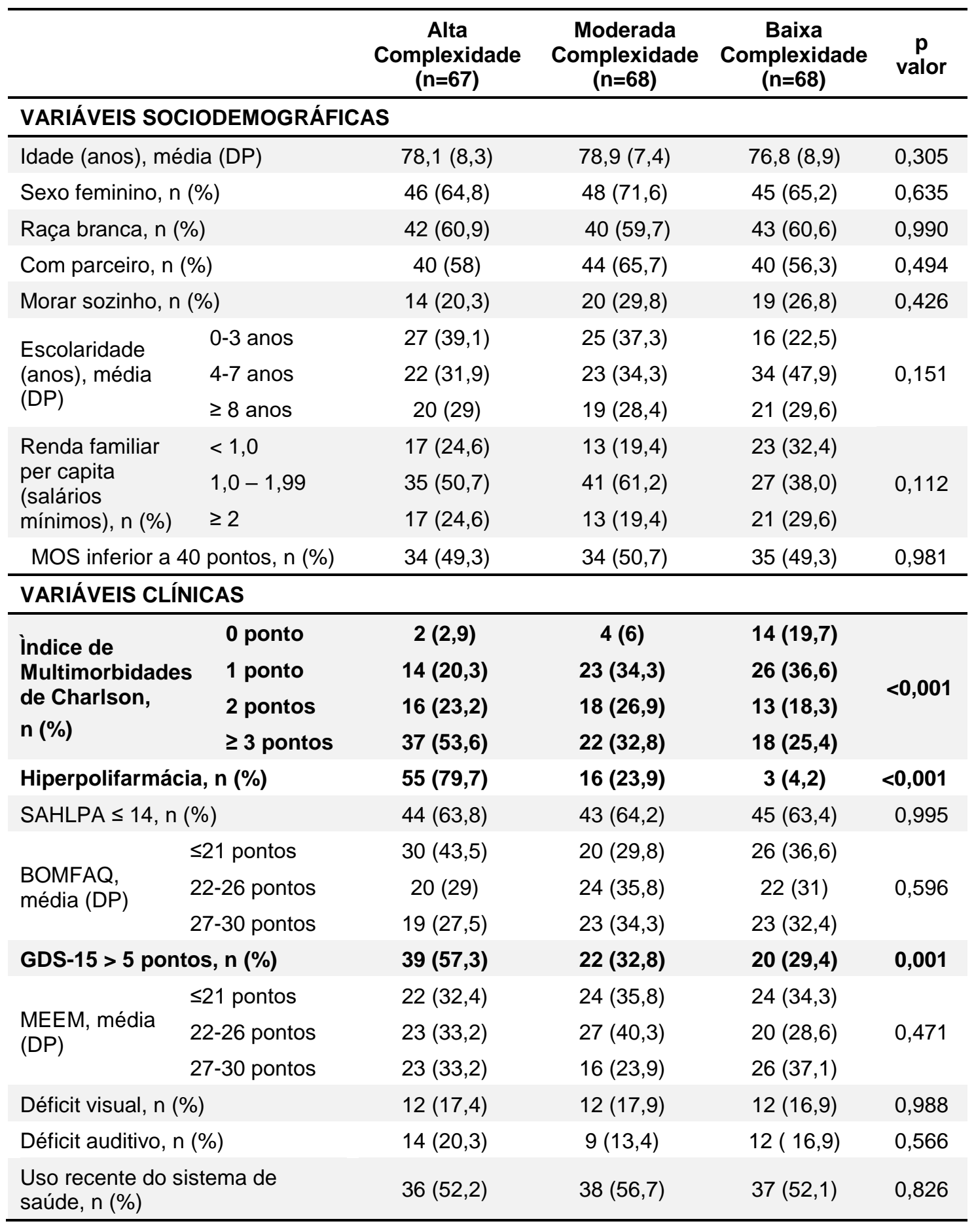

MOS: Medical Outcomes Study; SAHLPA: Short Assessment of Health Literacy for Portuguese-Speaking Adults; BOMFAQ: Brazilian OARS Multidimensional Functional Assessment Questionnaire; GDS-15: Escala de depressão geriátrica de 15 itens; MEEM: Mini Exame do Estado Mental 
A Tabela 10 descreve a regressão linear múltipla em estratégia hierárquica para a associação do índice de complexidade farmacêutica e as covariáveis. No modelo final, participantes com GDS-15 > 5 pontos tiverem em média 6,1 pontos a mais no índice de complexidade farmacêutica. 0 SAHLPA não teve associação com o ICFT. Outra variável independente foi o índice de multimorbidades de Charlson. O VIF do Charlson com o ICFT no modelo final foi de 3,2 .

Tabela 10 - Regressão linear múltipla em estratégia hierárquica dos fatores associados ao Índice de Complexidade Farmacêutica $(n=203)$

\begin{tabular}{|c|c|c|c|c|}
\hline & & \multicolumn{3}{|c|}{ Coeficiente $\beta$ (Intervalo de confiança $95 \%$ ) } \\
\hline & & Modelo 1 & Modelo 2 & Modelo 3 \\
\hline \multicolumn{2}{|l|}{ Idade (anos) } & $0,17(-0,04-0,38)$ & $0,18(-0,03-0,40)$ & $0,16(-0,04-0,39)$ \\
\hline \multicolumn{2}{|l|}{ Sexo (masculino) } & $-1,02(-4,80-2,75)$ & $-2,81(-6,78-1,14)$ & $-2,69(-6,68-1,44)$ \\
\hline \multicolumn{2}{|c|}{ MOS (abaixo de 40 pontos) } & $1,75(-1,87-5,38)$ & $2,02(-1,37-5,42)$ & $-1,08(-4,57-2,82)$ \\
\hline \multirow{4}{*}{$\begin{array}{l}\text { Índice de } \\
\text { Multimorbidades } \\
\text { de Charlson }\end{array}$} & 0 ponto & & 1 & 1 \\
\hline & 1 ponto & & $6,88(0,79-12,98)$ & $7,04(0,87-13,20)$ \\
\hline & 2 pontos & & $9,67(3,34-15,99)$ & $9,94(3,53-16,35)$ \\
\hline & $\geq 3$ pontos & & $13,40(-13,80-4,55)$ & $13,60(7,44-19,74)$ \\
\hline \multirow{3}{*}{$\begin{array}{l}\text { Funcionalidade } \\
\text { (BOMFAQ) }\end{array}$} & $\leq 21$ pontos & & 1 & 1 \\
\hline & $22-26$ pontos & & $0,20(-4,03-4,45)$ & $0,61(-3,38-3,35)$ \\
\hline & 27-30 pontos & & $0,45(-4,21-5,12)$ & $0,82(-3,90-5,50)$ \\
\hline \multirow{3}{*}{ MEEM (pontos) } & $\leq 21$ pontos & & 1 & 1 \\
\hline & $22-26$ pontos & & $2,14(-2,11-6,40)$ & $2,23(-2,05-6,53)$ \\
\hline & 27-30 pontos & & $3,74(-0,84-8,34)$ & $3,21(-1,57-8,00)$ \\
\hline \multicolumn{2}{|c|}{ GDS- $15>5$ pontos } & & $5,98(2,49-9,46)$ & $6,13(2,61-9,63)$ \\
\hline \multicolumn{2}{|c|}{ SAHLPA $\leq 14$ pontos } & & & $-0,91(-4,70-2,87)$ \\
\hline \multirow{2}{*}{\multicolumn{2}{|c|}{ Teste F }} & $F(3)=0,87$ & $F(8)=4,76$ & $F(1)=0,23$ \\
\hline & & $p=0,87$ & $\mathrm{p}<0,001$ & $p=0,634$ \\
\hline \multicolumn{2}{|l|}{$\mathrm{R} 2$} & 0,013 & 0,177 & 0,178 \\
\hline
\end{tabular}

MEEM: Mini Exame do Estado Mental; BOMFAQ: Brazilian OARS Multidimensional Functional Assessment Questionnaire; SAHLPA: Short Assessment of Health Literacy for Portuguese-Speaking Adults; GDS-15: Escala de depressão geriátrica de 15 itens 
$\mathrm{O}$ teste $\mathrm{F}$ demonstrou na estratégia hierárquica que a adição das variáveis clínicas no modelo 2 contribuiu significativamente para a melhora do modelo de predição $(p<0,001)$.

\subsubsection{Interação entre o Conhecimento do Regime Terapêutico e} alfabetismo em saúde através do ICFT

Nas análises de interação, o efeito do alfabetismo em saúde na escala de conhecimento terapêutico não foi modificado pela idade $(p=0,211)$, pelo suporte social $(p=0,728)$, pela escala de depressão $(p=0,553)$ e pelo MEEM $(p=0,189)$. No entanto, o índice de complexidade da farmacoterapia modificou significativamente o efeito do alfabetismo em saúde na escala do conhecimento terapêutico $(p=0,003)$ (Figura 7). De fato, os participantes com bom desempenho na avaliação do alfabetismo em saúde e baixa complexidade do regime terapêutico apresentaram um conhecimento do regime terapêutico melhor do que aqueles com bom desempenho na avaliação do alfabetismo em saúde e alta complexidade terapêutica. No entanto, a complexidade do regime terapêutico não influenciou no conhecimento terapêutico daqueles com alfabetismo em saúde inadequado. 


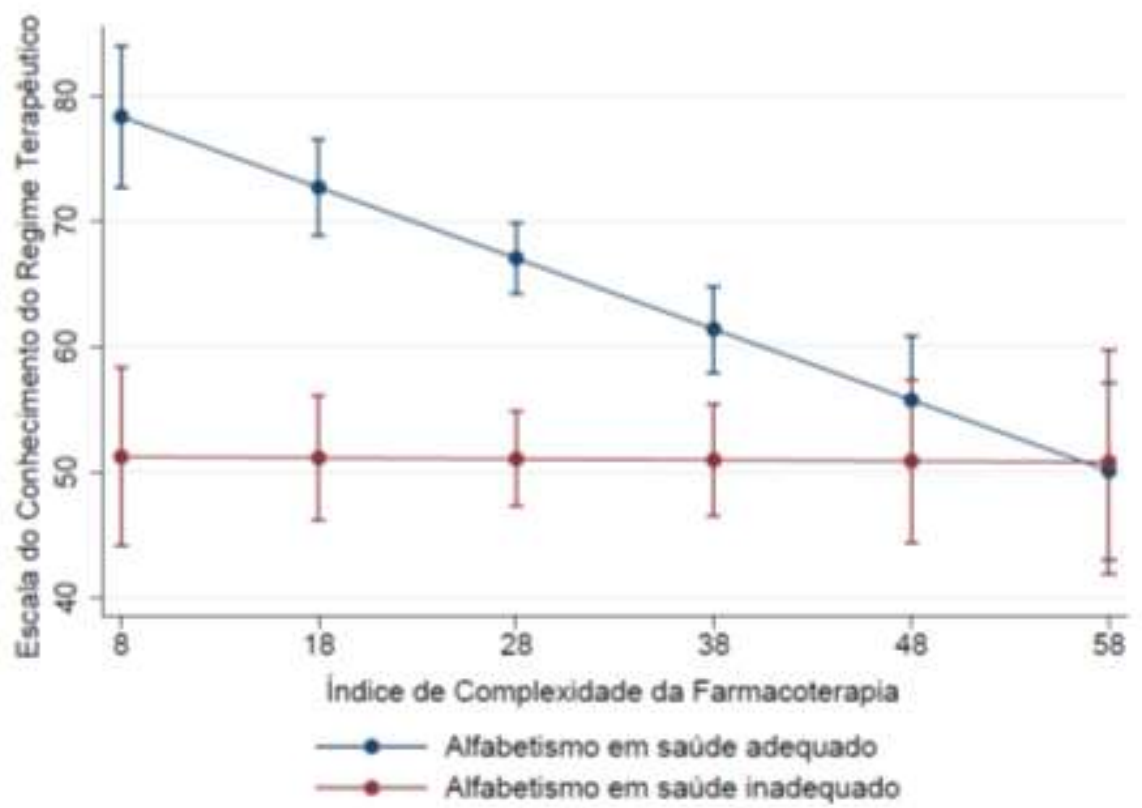

Figura 7 - Predição Linear Ajustada e IC95\% usando o índice de Complexidade do Regime Terapêutico como fator que modula o efeito do Alfabetismo em Saúde na Escala do Conhecimento do Regime Terapêutico

\subsubsection{Interação entre a escala de Morisky e o GDS-15}

O efeito do GDS-15 na Escala de Morisky de oito itens não foi modificado pelas variáveis: idade $(p=0,803)$, suporte social $(p=0,751)$, MEEM $(p=0,159)$ e SAHLPA $(p=0,924)$, após a realização das análises de interação.

\subsubsection{Interação entre o Teste da Caixa de Medicamentos e SAHLPA}

Nas análises de interação, o efeito do SAHLPA no teste da caixa de medicamentos não foi modificado pelas seguintes variáveis: idade $(p=0,910)$, sexo $(p=0,752)$, MEEM $(p=0,159)$, suporte social $(p=0,736)$ e GDS-15 $(\mathrm{p}=0,8)$. 


\subsection{PREDIÇÃO DAS VARIÁVEIS DE ESTUDO PARA HOSPITALIZAÇÃO}

Durante o período de seis meses, 57 idosos $(27,4 \%)$ preencheram os critérios para o desfecho hospitalização.

\subsubsection{Escala de Morisky e Hospitalização}

Com relação à adesão medida pela escala de Morisky, a frequência de hospitalizações foi a seguinte: 26 idosos $(30,9 \%)$ com baixa adesão, 18 idosos $(23,4 \%)$ com média adesão e $13(28,3 \%)$ com alta adesão. Não houve diferença significativamente estatística entre os grupos, $p=0,557$.

A Figura 8 descreve as curvas de Kaplan-Meier para hospitalização em 6 meses de acordo com as categorias da escala de Morisky. Observa-se que as linhas de dos grupos se separam por volta do centésimo dia de seguimento, contudo, o teste de log-rank não revela diferença estatística para hospitalização entre os grupos $(p=0,494)$.

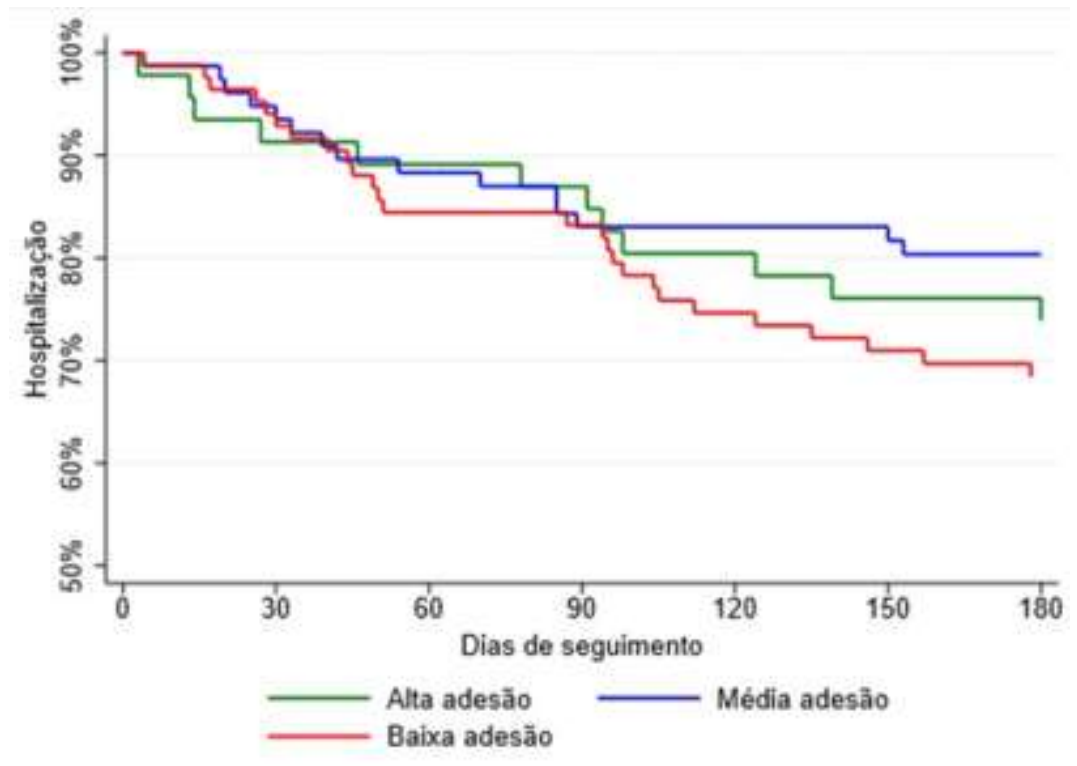

Figura 8 - Curvas de Kaplan-Meier para Hospitalização em 6 meses de acordo com a Escala de Morisky 
A Regressão de Cox em estratégia hierárquica para descrever a adição da escala de Morisky na predição de hospitalização está na Tabela 11. No modelo final, não houve associação da escala de Morisky com hospitalização. O teste de Wald demostrou que a adição da escala de Morsky não contribuiu para a melhora de predição do modelo com $p=0,620$.

Tabela 11 - Modelo de regressão de Cox em estratégia hierárquica para descrever a adição da escala de Morisky na predição de hospitalização $(n=207)$

\begin{tabular}{|c|c|c|c|c|}
\hline & \multicolumn{3}{|c|}{ Hazard Ratio (Intervalo de confiança 95\%) } \\
\hline & & Modelo 1 & Modelo 2 & Modelo 3 \\
\hline \multicolumn{2}{|l|}{ Idade (anos) } & $0,97(0,94-1,0)$ & $0,96(0,92-0,99)$ & $0,95(0,92-0,99)$ \\
\hline \multicolumn{2}{|l|}{ Sexo (masculino) } & $1,15(0,67-1,97)$ & $1,02(0,58-1,82)$ & $1,05(0,59-1,87)$ \\
\hline \multicolumn{2}{|c|}{ MOS (inferior a 40 pontos) } & $1,06(0,63-1,79)$ & $1,05(0,62-1,77)$ & $1,07(0,63-1,81)$ \\
\hline \multirow{4}{*}{$\begin{array}{l}\text { Índice de } \\
\text { Multimorbidades } \\
\text { de Charlson }\end{array}$} & 0 ponto & & 1 & 1 \\
\hline & 1 ponto & & $0,68(0,27-1,75)$ & $0,69(0,27-1,75)$ \\
\hline & 2 pontos & & $0,88(0,35-2,22)$ & $0,88(0,35-2,22)$ \\
\hline & $\geq 3$ pontos & & $0,67(0,27-1,68)$ & $0,67(0,27-1,63)$ \\
\hline \multirow{3}{*}{$\begin{array}{l}\text { Funcionalidade } \\
\text { (BOMFAQ) }\end{array}$} & $\leq 21$ pontos & & 1 & 1 \\
\hline & $22-26$ pontos & & $0,60(0,03-1,12)$ & $0,58(0,31-1,10)$ \\
\hline & 27-30 pontos & & $0,30(0,14-0,64)$ & $0,30(0,14-0,65)$ \\
\hline \multirow{3}{*}{$\begin{array}{l}\text { Escala de } \\
\text { Morisky }\end{array}$} & Alta Adesão & & & 1 \\
\hline & Média Adesão & & & $0,76(0,37-1,57)$ \\
\hline & Baixa Adesão & & & $1,11(0,56-2,21)$ \\
\hline \multicolumn{2}{|c|}{ Teste do qui quadrado de Wald } & $\begin{array}{l}\text { Wald Q2 }(3)=2,46 \\
\qquad p=0,483\end{array}$ & $\begin{array}{l}\text { Wald Q2(5) }=10,85 \\
\qquad p=0,054\end{array}$ & $\begin{array}{c}\text { Wald } Q 2(1)=1,42 \\
p=0,491\end{array}$ \\
\hline
\end{tabular}

MOS: Medical Outcomes Study;; BOMFAQ: Brazilian OARS Multidimensional Functional Assessment Questionnaire 


\subsubsection{Conhecimento do regime terapêutico e hospitalização}

A frequência de hospitalizações de acordo com a escala do conhecimento do regime terapêutico categorizado em tercis foi a seguinte: baixo conhecimento do regime terapêutico 20 idosos (29,4\%); médio conhecimento do regime terapêutico, 17 idosos (25\%) e alto conhecimento do regime terapêutico 19 idosos (28,4\%). Para esse resultado não foi evidenciada significância estatística, $p=0,835$.

A Figura 9 apresenta as curvas de Kaplan-Meier para hospitalização em 6 meses de acordo com as categorias do conhecimento terapêutico. Observa-se que as linhas de dos grupos de alto, médio e baixo conhecimento do regime terapêutico não se distinguem. $O$ teste de log-rank não revela diferença estatística para hospitalização entre os grupos $(p=0,835)$.

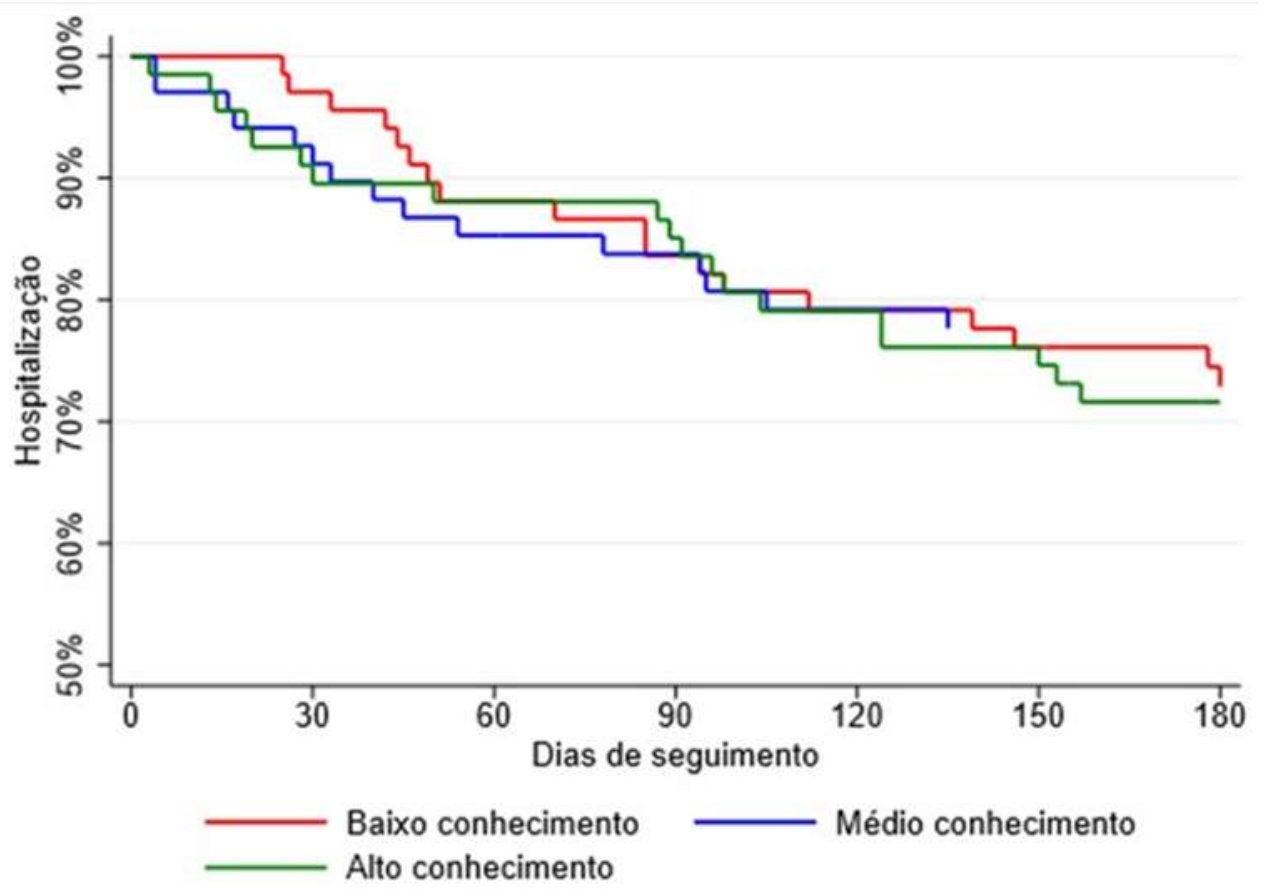

Figura 9 - Curvas de Kaplan-Meier para Hospitalização em 6 meses de acordo com a Escala do Conhecimento do Regime Terapêutico 
O modelo de Regressão de Cox em estratégia hierárquica para descrever a adição da escala do conhecimento do regime terapêutico na predição de hospitalização está descrito na Tabela 12. No modelo final, não houve associação da escala do conhecimento do regime terapêutico com hospitalização. O teste de Wald demostrou que tanto a adição de variáveis clínicas quanto a adição da escala do conhecimento do regime terapêutico não contribuiu significativamente para a melhora de predição com $p=0,659$.

Tabela 12 - Modelo de regressão de Cox em estratégia hierárquica para descrever a adição do conhecimento do regime terapêutico na predição de hospitalização $(n=203)$

\begin{tabular}{|c|c|c|c|c|}
\hline & & \multicolumn{3}{|c|}{ Hazard Ratio (Intervalo de confiança 95\%) } \\
\hline & & Modelo 1 & Modelo 2 & Modelo 3 \\
\hline \multicolumn{2}{|l|}{ Idade (anos) } & $0,98(0,95-1,01)$ & $0,96(0,93-0,99)$ & $0,96(0,93-0,99)$ \\
\hline \multicolumn{2}{|l|}{ Sexo (masculino) } & $1,15(0,67-1,99)$ & $1,04(0,58-1,84)$ & $1,02(0,57-1,82)$ \\
\hline \multicolumn{2}{|c|}{ MOS (inferior a 40 pontos) } & $1,08(0,63-1,84)$ & $1,07(0,63-1,82)$ & $1,11(0,64-1,93)$ \\
\hline \multirow{4}{*}{$\begin{array}{l}\text { Índice de } \\
\text { Multimorbidades } \\
\text { de Charlson }\end{array}$} & 0 ponto & & 1 & 1 \\
\hline & 1 ponto & & $0,62(0,24-1,59)$ & $0,61(0,24-1,57)$ \\
\hline & 2 pontos & & $0,79(0,31-2,0)$ & $0,79(0,31-1,98)$ \\
\hline & $\geq 3$ pontos & & $0,57(0,23-1,40)$ & $0,59(0,24-1,44)$ \\
\hline \multirow{3}{*}{$\begin{array}{l}\text { Funcionalidade } \\
\text { (BOMFAQ) }\end{array}$} & $\leq 21$ pontos & & 1 & 1 \\
\hline & $22-26$ pontos & & $0,60(0,32-1,13)$ & $0,62(0,32-1,18)$ \\
\hline & $27-30$ pontos & & $0,28(0,13-0,62)$ & $0,28(0,01-0,61)$ \\
\hline \multirow{3}{*}{$\begin{array}{l}\text { Conhecimento } \\
\text { do Regime } \\
\text { Terapêutico }\end{array}$} & Baixo & & & 1 \\
\hline & Médio & & & $1,07(0,54-2,12)$ \\
\hline & Alto & & & $1,19(0,59-2,39)$ \\
\hline \multicolumn{2}{|c|}{ Teste do qui quadrado de Wald } & $\begin{array}{l}\text { Wald } Q 2(3)=2,46 \\
\quad p=0,483\end{array}$ & $\begin{array}{l}\text { Wald Q2(5) }=10,85 \\
\qquad p=0,054\end{array}$ & $\begin{array}{l}\text { Wald } Q 2(1)=0,19 \\
\qquad p=0,659\end{array}$ \\
\hline
\end{tabular}

MOS: Medical Outcomes Study; BOMFAQ: Brazilian OARS Multidimensional Functional Assessment Questionnaire 


\subsubsection{Teste da Caixa de Medicamentos e Hospitalização}

A incidência de hospitalização nos idosos que concluíram de maneira correta o teste foi de $27,7 \%$ (26 participantes) e aqueles que não conseguiram completar o teste corretamente de 27,4\% (31 participantes). Não houve diferença estatisticamente significativa entre os dois grupos, $p=0,971$.

As curvas de Kaplan-Meier para hospitalização em 6 meses de acordo com o teste da caixa de medicamentos estão descritas na Figura 10. Observa-se que as linhas dos dois grupos não se distinguem durante 0 tempo de seguimento de 180 dias. O teste de log-rank não revela diferença estatística para hospitalização entre os dois grupos $(p=0,969)$.

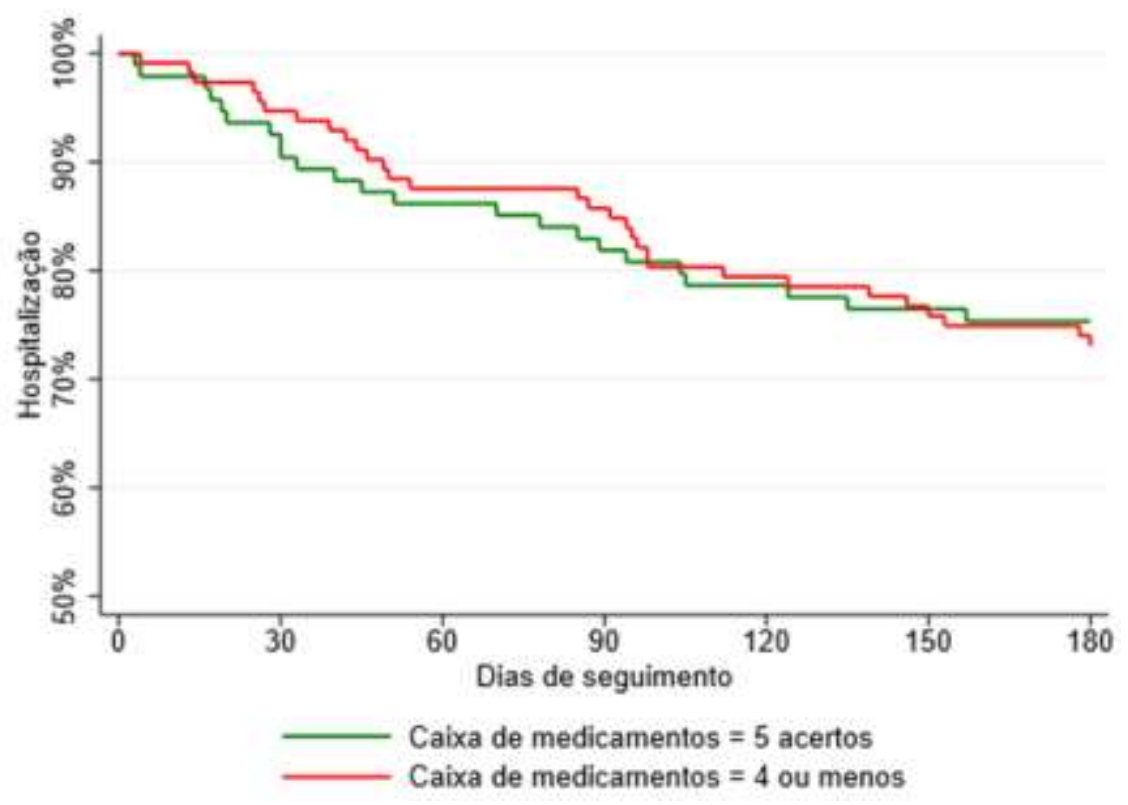

Figura 10 - Curvas de Kaplan-Meier para Hospitalização em 6 meses de acordo com o Teste da Caixa de Medicamentos 
A Tabela 13 descreve a adição do teste da caixa de medicamentos na predição de hospitalização pelo modelo de Regressão de Cox em estratégia hierárquica. No modelo final, não houve associação do teste da caixa de medicamentos com hospitalização. O teste de Wald demostrou na estratégia hierárquica que a adição do teste da caixa de medicamentos não contribuiu para a melhora de predição do modelo $(p=0,659)$.

Tabela 13 - Modelo de regressão de Cox em estratégia hierárquica para descrever a adição do Teste da Caixa de Medicamentos na predição de hospitalização $(\mathrm{n}=207)$

\begin{tabular}{|c|c|c|c|c|}
\hline & & \multicolumn{3}{|c|}{ Hazard Ratio (Intervalo de confiança 95\%) } \\
\hline & & Modelo 1 & Modelo 2 & Modelo 3 \\
\hline \multicolumn{2}{|l|}{ Idade (anos) } & $0,97(0,94-1,0)$ & $0,96(0,92-0,99)$ & $0,96(0,92-0,99)$ \\
\hline \multicolumn{2}{|l|}{ Sexo (masculino) } & $1,15(0,67-1,97)$ & $1,02(0,58-1,82)$ & $1,05(0,58-1,90)$ \\
\hline \multicolumn{2}{|c|}{ MOS (inferior a 40 pontos) } & $1,06(0,63-1,79)$ & $1,05(0,62-1,77)$ & $1,04(0,62-1,77)$ \\
\hline \multirow{4}{*}{$\begin{array}{l}\text { Indice de } \\
\text { Multimorbidades } \\
\text { de Charlson }\end{array}$} & 0 ponto & & 1 & 1 \\
\hline & 1 ponto & & $0,68(0,27-1,75)$ & $0,69(0,27-1,75)$ \\
\hline & 2 pontos & & $0,89(0,35-2,22)$ & $0,88(0,35-2,22)$ \\
\hline & $\geq 3$ pontos & & $0,67(0,27-1,64)$ & $0,66(0,27-1,61)$ \\
\hline \multirow{3}{*}{$\begin{array}{l}\text { Funcionalidade } \\
\text { (BOMFAQ) }\end{array}$} & $\leq 21$ pontos & & 1 & 1 \\
\hline & $22-26$ pontos & & $0,60(0,32-1,12)$ & $0,60(0,31-1,11)$ \\
\hline & $27-30$ pontos & & $0,30(0,14-0,64)$ & $0,30(0,14-0,06)$ \\
\hline $\begin{array}{l}\text { Teste da Caixa } \\
\text { de Medicamentos }\end{array}$ & $0-4$ acertos & & & $1,12(0,06-1,93)$ \\
\hline \multicolumn{2}{|c|}{ Teste do qui quadrado de Wald } & $\begin{array}{l}\text { Wald } Q 2(3)=2,46 \\
\qquad p=0,483\end{array}$ & $\begin{array}{l}\text { Wald Q2(5) }=10,85 \\
\qquad p=0,054\end{array}$ & $\begin{array}{c}\text { Wald Q2(1)=0,19 } \\
\qquad p=0,659\end{array}$ \\
\hline
\end{tabular}

MOS: Medical Outcomes Study; BOMFAQ: Brazilian OARS Multidimensional Functional Assessment Questionnaire 


\subsubsection{Complexidade do Regime Terapêutico e Hospitalização}

A incidência de hospitalizações de acordo com o ICFT em tercis foi a seguinte: 23 idosos (32,4\%) no grupo de baixo ICFT; 25 idosos $(37,3 \%)$ no grupo de médio ICFT e 9 idosos $(13,1 \%)$ no grupo de alto ICFT, com significância estatística $(p=0,003)$.

A Figura 11 apresenta as curvas de Kaplan-Meier para hospitalização em 6 meses de acordo com as categorias do ICFT. A curva de alta complexidade se separa das outras duas desde o início do seguimento. $\mathrm{O}$ teste de log-rank revela a diferença estatística crescente de hospitalização entre os três grupos $(p=0,005)$.

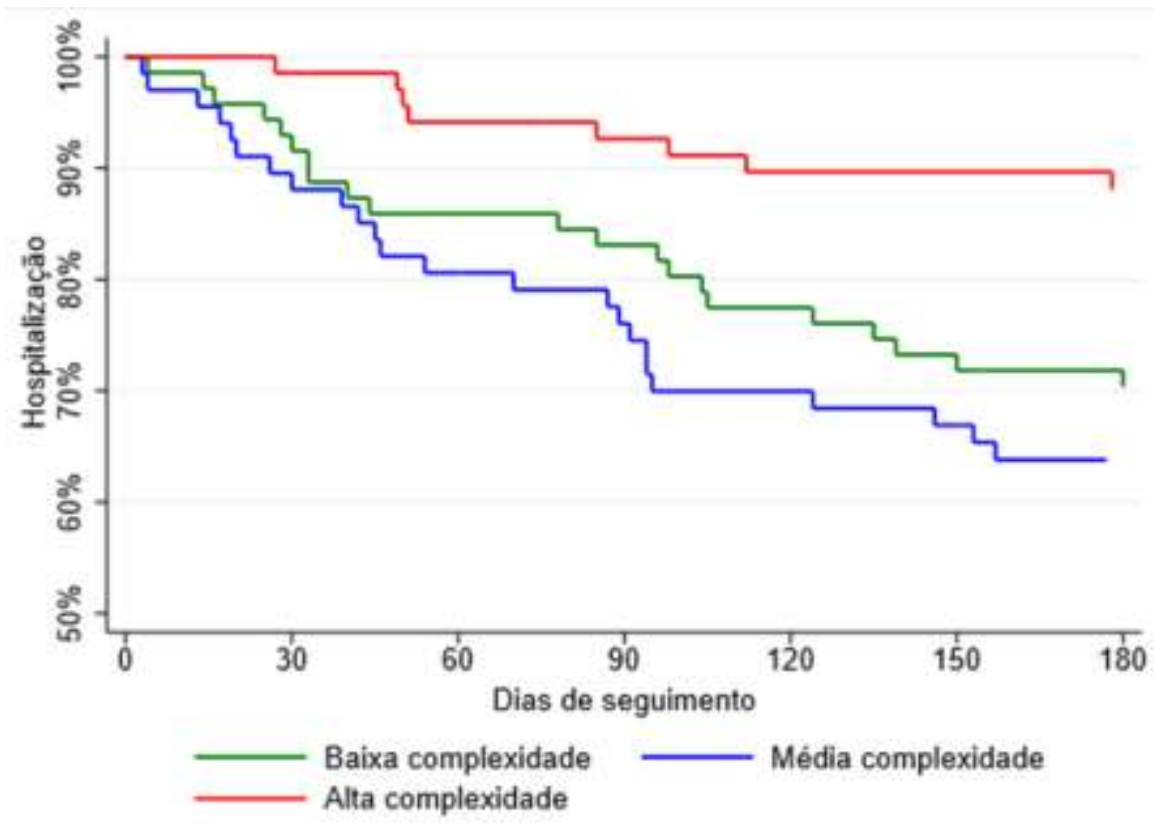

Figura 11 - Curvas de Kaplan-Meier para Hospitalização em 6 meses de acordo com o Índice de Complexidade do Regime Terapêutico (ICFT) 
O modelo de Regressão de Cox em estratégia hierárquica para descrever a adição do ICFT na predição de hospitalização está descrito na Tabela 14. No modelo final, participantes com alta complexidade do regime terapêutico apresentaram um fator de proteção para hospitalização $(p=0,01)$. Esta associação se manteve mesmo após ajuste para cognição e sintomas depressivos, HR 0,27 (IC95\% 0,11-0,63; p=0,003) ou utilizando o ICFT como variável contínua, HR 0,64 (IC95\% 0,45-0,90; p=0,012).

Tabela 14 - Modelo de regressão de Cox em estratégia hierárquica para descrever a adição do ICFT na predição de hospitalização $(n=203)$

\begin{tabular}{|c|c|c|c|c|}
\hline & & \multicolumn{3}{|c|}{ Hazard Ratio (Intervalo de confiança 95\%) } \\
\hline & & Modelo 1 & Modelo 2 & Modelo 3 \\
\hline \multicolumn{2}{|l|}{ Idade (anos) } & $0,97(0,94-1,0)$ & $0,96(0,92-0,99)$ & $0,95(0,92-0,99)$ \\
\hline \multicolumn{2}{|l|}{ Sexo (masculino) } & $1,15(0,67-1,97)$ & $1,02(0,58-1,82)$ & $1,0(0,56-1,79)$ \\
\hline \multicolumn{2}{|c|}{ MOS (inferior a 40 pontos) } & $1,06(0,63-1,79)$ & $1,05(0,62-1,77)$ & $1,03(0,60-1,77)$ \\
\hline \multirow{4}{*}{$\begin{array}{l}\text { Indice de } \\
\text { Multimorbidades } \\
\text { de Charlson }\end{array}$} & 0 ponto & & 1 & 1 \\
\hline & 1 ponto & & $0,68(0,27-1,75)$ & $0,71(0,27-1,84)$ \\
\hline & 2 pontos & & $0,88(0,35-2,22)$ & $1,08(0,41-2,86)$ \\
\hline & $\geq 3$ pontos & & $0,67(0,27-1,64)$ & $0,88(0,34-2,29)$ \\
\hline \multirow{3}{*}{$\begin{array}{l}\text { Funcionalidade } \\
\text { (BOMFAQ) }\end{array}$} & $\leq 21$ pontos & & 1 & 1 \\
\hline & $22-26$ pontos & & $0,60(0,03-1,12)$ & $0,56(0,29-1,04)$ \\
\hline & $27-30$ pontos & & $0,30(0,14-0,64)$ & $0,26(0,12-0,57)$ \\
\hline \multirow{3}{*}{ ICFT tercis } & Baixa & & & 1 \\
\hline & Média & & & $1,40(0,75-2,63)$ \\
\hline & Alta & & & $0,33(0,14-0,77)$ \\
\hline \multicolumn{2}{|c|}{ Teste do qui quadrado de Wald } & $\begin{array}{l}\text { Wald } Q 2(3)=2,46 \\
\qquad p=0,483\end{array}$ & $\begin{array}{l}\text { Wald Q2(5)=10,85 } \\
\qquad p=0,054\end{array}$ & $\begin{array}{l}\text { Wald Qui2 }(2)=12,87 \\
\qquad \mathbf{p}=\mathbf{0 , 0 0 1}\end{array}$ \\
\hline
\end{tabular}

ICFT: Índice de Complexidade Farmacêutica; MOS: Medical Outcomes Study; BOMFAQ: Brazilian OARS Multidimensional Functional Assessment Questionnaire

O teste de Wald demostrou na estratégia hierárquica que a adição do ICFT em tercis (modelo 3 ) contribuiu significativamente para a melhora de predição com $p=0,001$. 


\subsection{PREDIÇÃO DAS VARIÁVEIS DE ESTUdO PARA VISITA AO PRONTO SOCORRO}

Durante o período de seis meses, 101 idosos $(48,8 \%)$ preencheram os critérios para o desfecho visita ao PS.

\subsubsection{Escala de Morisky e Visita ao PS}

A incidência de visitas ao PS nos idosos com baixa adesão de acordo com a escala de Morisky foi de 47,6\% (40 participantes), o grupo com média adesão teve $46,7 \%$ (36 participantes) e o grupo de alta adesão 54,3\% (25 participantes). Esse achado não teve significância estatística, p=0,690.

A Figura 12 descreve as curvas de Kaplan-Meier para visita ao PS de acordo com as categorias da escala de Morisky. Não houve diferença estatística para este desfecho entre os grupos $(p=0,937)$.

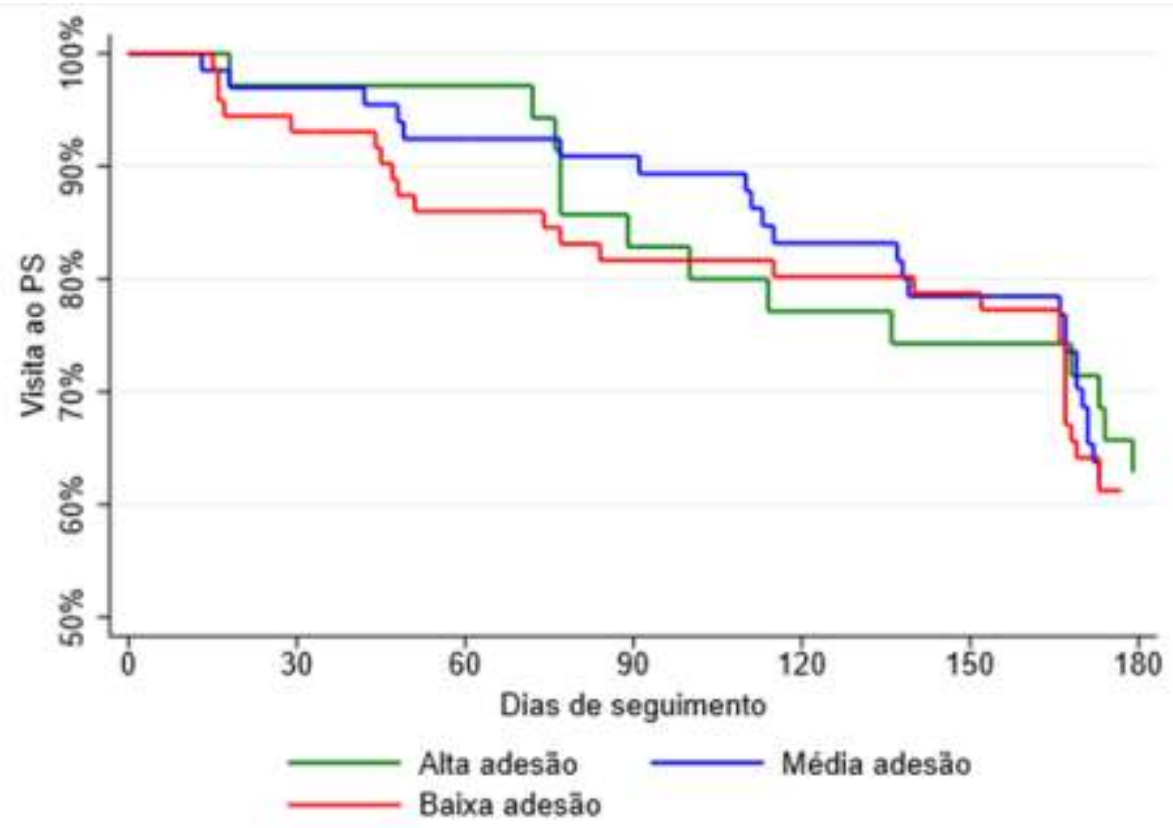

Figura 12 - Curvas de Kaplan-Meier para Visitas ao Pronto Socorro em 6 meses de acordo com a Escala de Morisky 
O modelo de Regressão de Cox em estratégia hierárquica para descrever a adição da escala de Morisky na predição de visitas ao PS está descrito na Tabela 15. Os modelos 1 e 2 não revelaram variáveis preditoras. No modelo final, não houve associação da escala de Morisky com visita ao PS. O teste de Wald demostrou que a adição das variáveis clínicas trouxe melhora para a predição do desfecho $(p=0,009)$. Já a adição da Escala de Morisky não melhorou o modelo final $(p=0,884)$.

Tabela 15 - Modelo de regressão de Cox em estratégia hierárquica para descrever a adição da escala de Morisky na predição de visitas ao PS $(n=207)$

\begin{tabular}{|c|c|c|c|c|}
\hline & & \multicolumn{3}{|c|}{ Hazard Ratio (Intervalo de confiança 95\%) } \\
\hline & & Modelo 1 & Modelo 2 & Modelo 3 \\
\hline \multicolumn{2}{|l|}{ Idade (anos) } & $1,02(0,99-1,05)$ & $1,02(0,98-1,05)$ & $1,02(0,98-1,05)$ \\
\hline \multicolumn{2}{|l|}{ Sexo (masculino) } & $1,64(1,01-2,68)$ & $1,16(0,69-1,94)$ & $1,16(0,69-1,94)$ \\
\hline \multicolumn{2}{|c|}{ MOS (inferior a 40 pontos) } & $0,67(0,41-1,10)$ & $0,69(0,42-1,13)$ & $0,69(0,41-1,13)$ \\
\hline \multirow{4}{*}{$\begin{array}{l}\text { Índice de } \\
\text { Multimorbidadesde } \\
\text { Charlson }\end{array}$} & 0 ponto & & 1 & 1 \\
\hline & 1 ponto & & $1,53(0,50-4,65)$ & $1,52(0,49-4,64)$ \\
\hline & 2 pontos & & $1,28(0,38-4,20)$ & $1,28(0,38-4,20)$ \\
\hline & $\geq 3$ pontos & & $2,53(0,87-7,35)$ & $2,52(0,87-7,33)$ \\
\hline \multirow{3}{*}{$\begin{array}{l}\text { Funcionalidade } \\
\text { (BOMFAQ) }\end{array}$} & $\leq 21$ pontos & & 1 & 1 \\
\hline & $22-26$ pontos & & $1,12(0,64-1,96)$ & $1,13(0,63-2,02)$ \\
\hline & $27-30$ pontos & & $0,42(0,20-0,87)$ & $0,41(0,20-0,87)$ \\
\hline \multicolumn{2}{|l|}{ Escala de Morisky } & & & $0,97(0,70-1,35)$ \\
\hline \multicolumn{2}{|c|}{ Teste do qui quadrado de Wald } & $\begin{array}{l}\text { Wald } Q 2(3)=8,18 \\
\qquad p=0,042\end{array}$ & $\begin{array}{l}\text { Wald Q2(5)=15,21 } \\
\qquad p=0,009\end{array}$ & $\begin{array}{c}\text { Wald Q2(1)=0,02 } \\
\qquad p=0,884\end{array}$ \\
\hline
\end{tabular}

MOS: Medical Outcomes Study; BOMFAQ: Brazilian OARS Multidimensional Functional Assessment Questionnaire 


\subsubsection{Conhecimento do Regime Terapêutico e Visita ao PS}

Com relação ao conhecimento do regime terapêutico categorizado em tercis, os idosos que tiveram maior frequência de visita ao PS foram àqueles com baixo conhecimento do regime terapêutico, 37 idosos (54,4\%); seguidos dos idosos com alto conhecimento do regime terapêutico $32(47,8 \%)$ e médio conhecimento do regime terapêutico 31 (45,6\%), $p=0,563$.

A Figura 13 apresenta as curvas de Kaplan-Meier para visitas ao PS em 6 meses de acordo com as categorias do conhecimento terapêutico. Observa-se que não há uma separação clara dos grupos de alto, médio e baixo conhecimento do regime terapêutico. $O$ teste de log-rank não revela diferença estatística para este desfecho entre os grupos $(p=0,723)$.

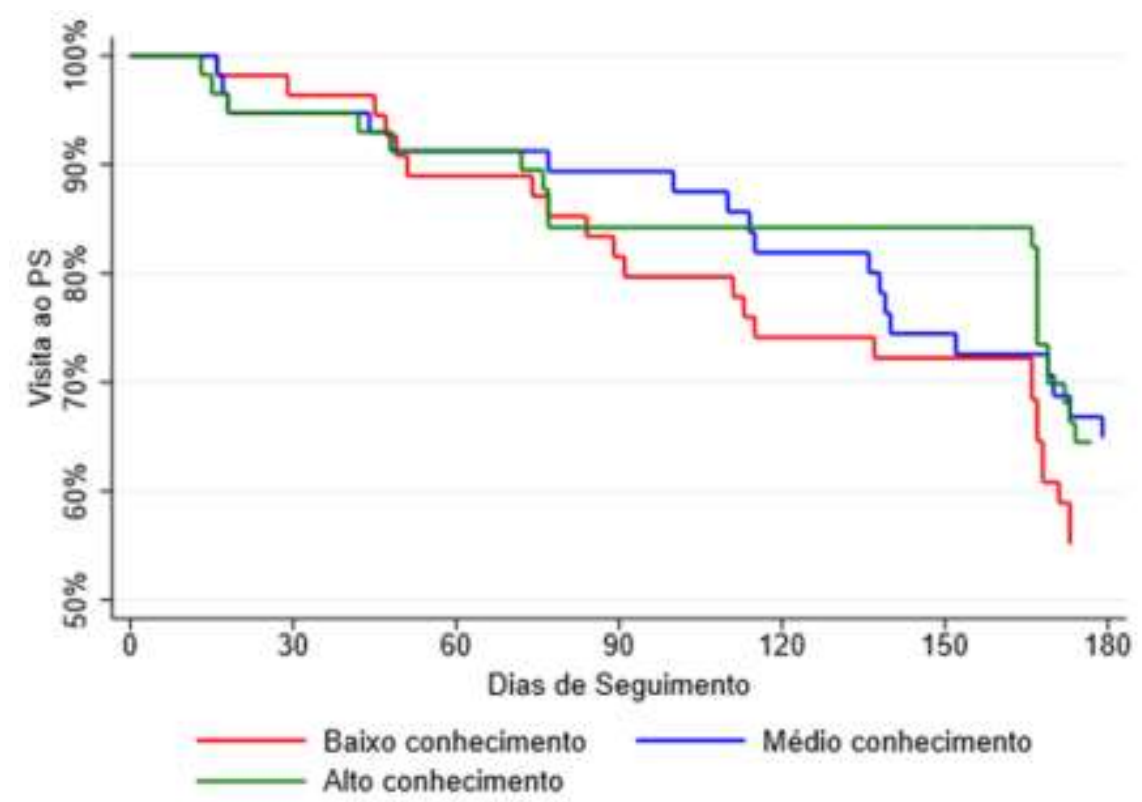

Figura 13 - Curvas de Kaplan-Meier para Visitas ao Pronto Socorro em 6 meses de acordo com a Escala de Conhecimento do Regime Terapêutico 
O modelo de Regressão de Cox em estratégia hierárquica para descrever a adição do conhecimento terapêutico na predição de visitas ao PS está descrito na Tabela 16. No modelo final, não houve associação da escala do conhecimento do regime terapêutico com visita ao PS. O teste de Wald demostrou que a adição das variáveis clínicas melhorou a predição do modelo $(p=0,013)$. Já a adição da escala do conhecimento do regime terapêutico não contribuiu significativamente para a melhora de predição $(p=0,963)$.

Tabela 16 - Modelo de regressão de Cox em estratégia hierárquica para descrever a adição do conhecimento do regime terapêutico na predição de visitas ao PS ( $\mathrm{n}=203)$

\begin{tabular}{|c|c|c|c|c|}
\hline & & \multicolumn{3}{|c|}{ Hazard Ratio (Intervalo de confiança 95\%) } \\
\hline & & Modelo 1 & Modelo 2 & Modelo 3 \\
\hline \multicolumn{2}{|l|}{ Idade (anos) } & $1,02(0,99-1,05)$ & $1,02(0,99-1,05)$ & $1,02(0,99-1,05)$ \\
\hline \multicolumn{2}{|l|}{ Sexo (masculino) } & $1,60(0,98-2,61)$ & $1,14(0,68-1,91)$ & $1,14(0,68-1,92)$ \\
\hline \multicolumn{2}{|c|}{ MOS (inferior a 40 pontos) } & $0,66(0,40-1,09)$ & $0,68(0,41-1,13)$ & $0,68(0,40-1,13)$ \\
\hline \multirow{4}{*}{$\begin{array}{l}\text { Indice de } \\
\text { Multimorbidades } \\
\text { de Charlson }\end{array}$} & 0 ponto & & 1 & 1 \\
\hline & 1 ponto & & $1,19(0,39-3,60)$ & $1,19(0,39-3,60)$ \\
\hline & 2 pontos & & $0,99(0,30-3,23)$ & $0,99(0,30-3,23)$ \\
\hline & $\geq 3$ pontos & & $1,92(0,67-5,50)$ & $1,92(0,66-5,56)$ \\
\hline \multirow{3}{*}{$\begin{array}{l}\text { Funcionalidade } \\
\text { (BOMFAQ) }\end{array}$} & $\leq 21$ pontos & & 1 & 1 \\
\hline & $22-26$ pontos & & $1,17(0,67-2,05)$ & $1,17(0,67-2,05)$ \\
\hline & $27-30$ pontos & & $0,39(0,18-0,85)$ & $0,40(0,18-0,85)$ \\
\hline \multirow{3}{*}{$\begin{array}{l}\text { Conhecimento } \\
\text { do Regime } \\
\text { Terapêutico }\end{array}$} & Baixo & & & 1 \\
\hline & Médio & & & $0,86(0,46-1,58)$ \\
\hline & Alto & & & $0,99(0,52-1,86)$ \\
\hline \multicolumn{2}{|c|}{ Teste do qui quadrado de Wald } & $\begin{array}{l}\text { Wald Q2(3)=8,26 } \\
\qquad p=0,040\end{array}$ & $\begin{array}{l}\text { Wald Q2(5) }=14,35 \\
\qquad p=0,013\end{array}$ & $\begin{array}{l}\text { Wald Q2(1)=0 } \\
\qquad p=0,963\end{array}$ \\
\hline
\end{tabular}

MOS: Medical Outcomes Study; Charlson: BOMFAQ: Brazilian OARS Multidimensional Functional Assessment Questionnaire 


\subsubsection{Teste da Caixa de Medicamentos e Visitas ao PS}

Quando analisamos o Teste da Caixa de Medicamentos, a incidência de visita ao PS nos idosos que não conseguiram completá-lo corretamente foi de $52,2 \%$ (59 participantes) e naqueles que completaram de maneira correta, 44,7\% (42 participantes) $(p=0,280)$.

As curvas de Kaplan-Meier para visita ao PS em 6 meses de acordo com o teste da caixa de medicamentos estão descritas na Figura 14. O teste de log-rank não revela diferença estatística para visita ao PS entre os dois grupos $(p=0,480)$.

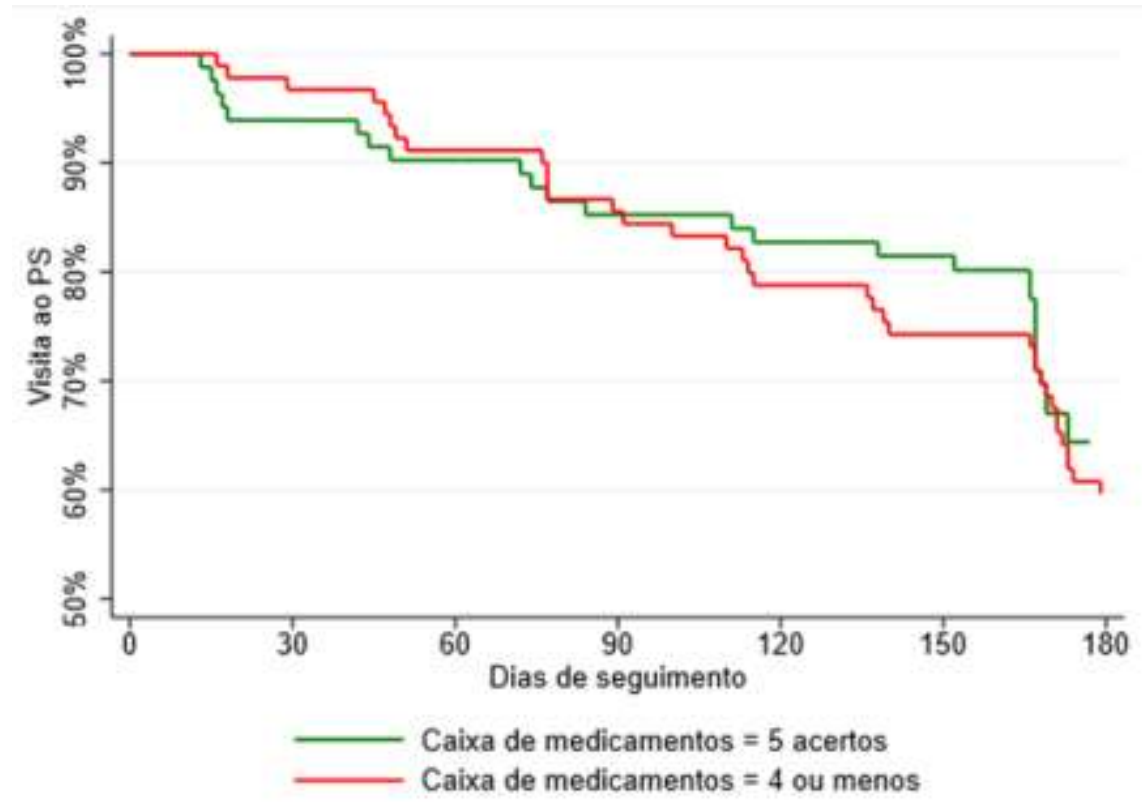

Figura 14 - Curvas de Kaplan-Meier para Visitas ao Pronto Socorro em 6 meses de acordo com o Teste da Caixa de Medicamentos 
O modelo de Regressão de Cox em estratégia hierárquica para descrever a adição do teste da caixa de medicamentos na predição de visitas ao PS está descrito na Tabela 17. No modelo final, não houve associação do teste com visita ao PS. O teste de Wald demostrou que a adição do bloco 2 trouxe melhora para a predição do desfecho $(p=0,009)$. Já a adição do teste da caixa de medicamentos não contribuiu significativamente para a melhora de predição $(p=0,280)$.

Tabela 17 - Modelo de regressão de Cox em estratégia hierárquica para descrever a adição do Teste da Caixa de Medicamentos na predição de visitas ao PS ( $\mathrm{n}=207)$

\begin{tabular}{|c|c|c|c|c|}
\hline & & \multicolumn{3}{|c|}{ Hazard Ratio (Intervalo de confiança 95\%) } \\
\hline & & Modelo 1 & Modelo 2 & Modelo 3 \\
\hline \multicolumn{2}{|l|}{ Idade (anos) } & $1,02(0,99-1,05)$ & $1,02(0,98-1,05)$ & $1,02(0,98-1,05)$ \\
\hline \multicolumn{2}{|l|}{ Sexo (masculino) } & $1,64(1,01-2,68)$ & $1,64(0,69-1,94)$ & $1,20(0,71-2,02)$ \\
\hline \multicolumn{2}{|c|}{ MOS (inferior a 40 pontos) } & $0,67(0,41-1,10)$ & $0,69(0,42-1,13)$ & $0,67(0,41-1,11)$ \\
\hline \multirow{4}{*}{$\begin{array}{l}\text { Indice de } \\
\text { Multimorbidades } \\
\text { de Charlson }\end{array}$} & 0 ponto & & 1 & 1 \\
\hline & 1 ponto & & $1,53(0,50-4,50)$ & $1,56(0,51-4,73)$ \\
\hline & 2 pontos & & $1,28(0,38-4,20)$ & $1,31(0,40-4,32)$ \\
\hline & $\geq 3$ pontos & & $2,53(0,87-7,35)$ & $2,46(0,85-7,12)$ \\
\hline \multirow{3}{*}{$\begin{array}{l}\text { Funcionalidade } \\
\text { (BOMFAQ) }\end{array}$} & $\leq 21$ pontos & & 1 & 1 \\
\hline & $22-26$ pontos & & $1,12(0,64-1,96)$ & $1,07(0,60-1,89)$ \\
\hline & 27-30 pontos & & $0,42(0,20-0,87)$ & $0,39(0,18-0,82)$ \\
\hline \multicolumn{2}{|c|}{$\begin{array}{l}\text { Teste da Caixa de } \\
\text { Medicamentos }\end{array}$} & & & $1,32(0,79-2,21)$ \\
\hline \multicolumn{2}{|c|}{ Teste do qui quadrado de Wald } & $\begin{array}{l}\text { Wald } Q 2(3)=8,18 \\
\quad p=0,004\end{array}$ & $\begin{array}{l}\text { Wald Q2(5) }=15,21 \\
\qquad p=0,009\end{array}$ & $\begin{array}{c}\text { Wald Q2(1) }=1,16 \\
p=0,280\end{array}$ \\
\hline
\end{tabular}

MOS: Medical Outcomes Study; Charlson: índice de multimorbidade de Charlson; BOMFAQ: Brazilian OARS Multidimensional Functional Assessment Questionnaire 


\subsubsection{Complexidade do Regime Terapêutico e Visita ao PS}

Dentre os indivíduos que apresentaram o desfecho visita ao PS, 34 idosos $(47,9 \%)$ tinham baixa complexidade farmacêutica, 39 (58,2\%) tinham média complexidade farmacêutica e 28 (40,6\%) tinham alta complexidade farmacêutica, $p=0,119$.

A Figura 15 apresenta as curvas de Kaplan-Meier para visita ao PS de acordo com as categorias do ICFT. Não houve diferença estatística entre os grupos ( $p=0,340)$.

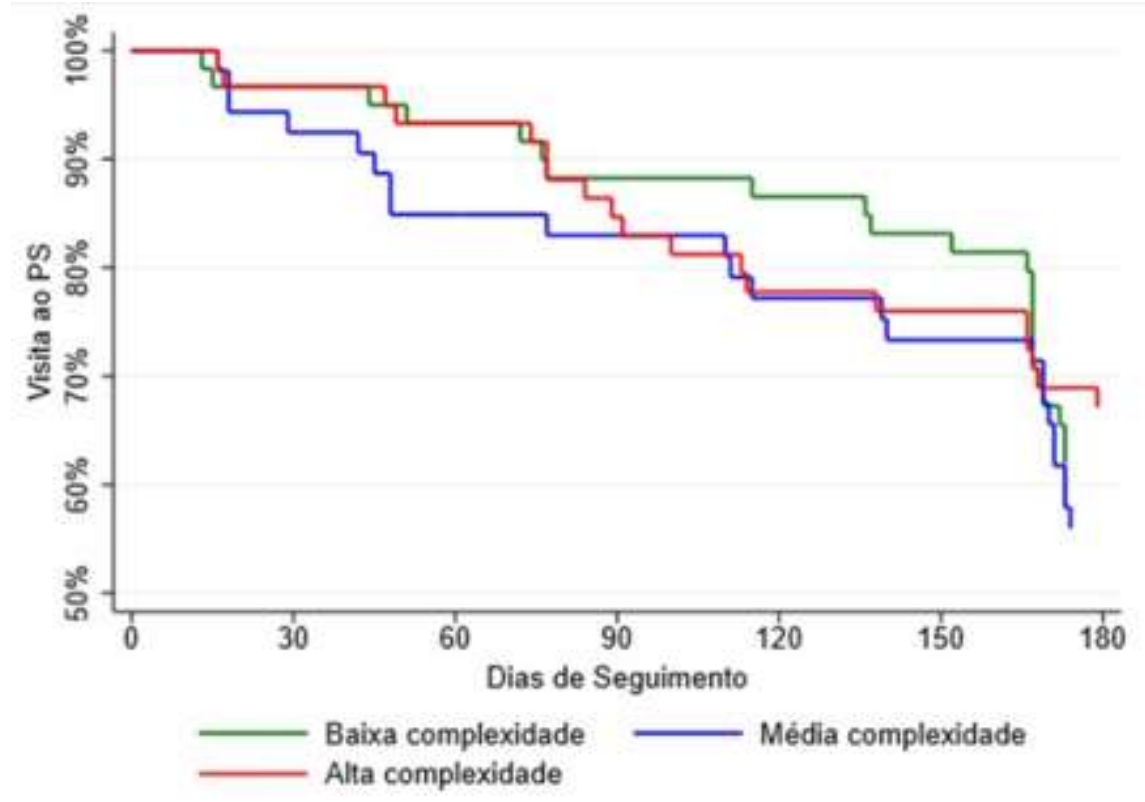

Figura 15 - Curvas de Kaplan- Meier para visitas ao Pronto Socorro em 6 meses de acordo com o Índice de Complexidade do Regime Terapêutico 
A Tabela 18 descreve a predição de visitas ao PS de acordo com o ICFT. No modelo final, não houve associação do ICFT com visita ao PS. O teste de Wald demostrou que a adição do bloco 2 trouxe melhora para a predição do desfecho $(p=0,009)$. Já a adição do ICFT não contribuiu significativamente para a melhora de predição $(p=0,280)$.

Tabela 18 - Modelo de regressão de Cox em estratégia hierárquica para descrever a adição do ICFT na predição de visitas ao PS $(n=203)$

\begin{tabular}{|c|c|c|c|c|}
\hline & & \multicolumn{3}{|c|}{ Hazard Ratio (Intervalo de confiança 95\%) } \\
\hline & & Modelo 1 & Modelo 2 & Modelo 3 \\
\hline \multicolumn{2}{|l|}{ Idade (anos) } & $1,02(0,99-1,05)$ & $1,02(0,98-1,05)$ & $1,02(0,98-1,05)$ \\
\hline \multicolumn{2}{|l|}{ Sexo (masculino) } & $1,64(1,01-2,68)$ & $1,16(0,69-1,94)$ & $1,15(0,68-1,92)$ \\
\hline \multicolumn{2}{|c|}{ MOS (inferior a 40 pontos) } & $0,67(0,41-1,10)$ & $0,69(0,42-1,13)$ & $0,64(0,38-1,07)$ \\
\hline \multirow{4}{*}{$\begin{array}{l}\text { Índice de } \\
\text { Multimorbidades } \\
\text { de Charlson }\end{array}$} & 0 ponto & & 1 & 1 \\
\hline & 1 ponto & & $1,53(0,50-4,65)$ & $1,44(0,46-4,48)$ \\
\hline & 2 pontos & & $1,28(0,38-4,20)$ & $1,31(0,38-4,56)$ \\
\hline & $\geq 3$ pontos & & $2,53(0,87-7,35)$ & $2,76(0,90-8,43)$ \\
\hline \multirow{3}{*}{$\begin{array}{l}\text { Funcionalidade } \\
\text { (BOMFAQ) }\end{array}$} & $\leq 21$ pontos & & 1 & 1 \\
\hline & $22-26$ pontos & & $1,12(0,64-1,96)$ & $1,08(0,61-1,89)$ \\
\hline & $27-30$ pontos & & $0,42(0,20-0,87)$ & $0,38(0,18-0,81)$ \\
\hline \multirow{3}{*}{ ICFT } & Baixa & & & 1 \\
\hline & Média & & & $1,36(0,75-2,49)$ \\
\hline & Alta & & & $0,67(0,35-1,28)$ \\
\hline \multicolumn{2}{|c|}{ Teste do qui quadrado de Wald } & $\begin{array}{l}\text { Wald } Q 2(3)=8,18 \\
\qquad p=0,042\end{array}$ & $\begin{array}{l}\text { Wald } Q 2(5)=15,21 \\
\quad p=0,009\end{array}$ & $\begin{array}{c}\text { Wald Q2(2) }=5,13 \\
\qquad p=0,077\end{array}$ \\
\hline
\end{tabular}

ICFT: Índice de Complexidade Farmacêutica; MOS: Medical Outcomes Study; BOMFAQ: Brazilian OARS Multidimensional Functional Assessment Questionnaire 


\subsection{INTERAÇÃO DOS TESTES DE ADESÃO TERAPÊUTICA E O ÍNDICE DE COMPLEXIDADE DO REGIME TERAPÊUTICO NA PREDIÇÃO DE HOSPITALIZAÇÃO E VISITA AO PS}

\subsubsection{Interação da Escala de Morisky na predição de hospitalização e visita ao PS}

Não houve modificação do resultado da pontuação obtida na escala de Morisky para o desfecho hospitalização pelas seguintes variáveis: idade $(p=0,775)$, sexo $(p=0,956)$, GDS-15 $(p=0,963)$, MOS $(p=0,893)$, SAHLPA $(p=0,942)$, MEEM $(p=0,938)$, hiperpolifarmácia $(p=0,309)$ e dependência para tomada de medicações $(p=0,271)$.

Não houve modificação do resultado da pontuação obtida na escala de Morisky para o desfecho visita ao PS pelas seguintes variáveis: idade $(p=$ $0,078)$, sexo $(p=0,740)$, GDS-15 $(p=0,342)$, MOS $(p=0,579)$, SAHLPA $(p=$ $0,420)$, MEEM $(p=0,938)$, hiperpolifarmácia $(p=0,765)$ e dependência para tomada de medicações $(p=0,416)$. 


\subsubsection{Interação da escala do conhecimento do Regime Terapêutico na predição de hospitalização e visita ao PS}

$\mathrm{Na}$ análise de interação, o resultado da pontuação obtida na escala de conhecimento do regime terapêutico em tercis para o desfecho hospitalização não foi modificado por: idade $(p=0,668 ; p=0,152)$, sexo $(p=0,097 ; p=0,024)$, GDS-15 $(p=0,113 ; p=0,787)$, MOS $(p=0,469 ; p=$ $0,454)$, SAHLPA $(p=0,164 ; p=0,625), \operatorname{MEEM}(p=0,096 ; p=0,325)$ e dependência para tomada de medicações $(p=0,360 ; p=0,603)$.

$\mathrm{Na}$ análise de interação, o resultado da pontuação obtida na escala do conhecimento do regime terapêutico em tercis para o desfecho visita ao PS não foi modificado por: idade $(p=0,837 ; p=0,128)$, sexo $(p=0,134 ; p=$ $0,180)$, GDS-15 $(p=0,356 ; p=0,451)$, MOS $(p=0,451 ; p=0,312)$, SAHLPA $(p=0,618 ; p=0,818)$, MEEM $(p=0,362 ; p=0,125)$, hiperpolifarmácia $(p=$ $0,441 ; p=0,408)$ e dependência para tomada de medicações $(p=0,518 ; p=$ $0,390)$. 


\subsubsection{Interação do Teste da Caixa de Medicamentos na predição de hospitalização e visita ao PS}

Não houve modificação do resultado da pontuação obtida no teste da caixa de medicamentos para o desfecho hospitalização pelas seguintes variáveis: idade $(p=0,277)$, sexo $(p=0,378)$, GDS-15 $(p=0,876)$, MOS $(p=$ $0,851)$, SAHLPA $(p=0,260)$, MEEM $(p=0,152)$, hiperpolifarmácia $(p=0,100)$ e dependência para tomada de medicações $(p=0,638)$.

Não houve modificação do resultado da pontuação obtida no teste da caixa de medicamentos para o desfecho visita ao PS pelas seguintes variáveis: idade $(p=0,440)$, sexo $(p=0,620)$, GDS-15 $(p=0,881)$, MOS $(p=$ $0,239)$, SAHLPA $(p=0,212)$, MEEM $(p=0,005)$, hiperpolifarmácia $(p=0,618)$ e dependência para tomada de medicações $(p=0,450)$. 


\subsubsection{Interação do Índice de Complexidade do Regime Terapêutico na predição de hospitalização e visita ao PS}

O resultado da pontuação obtida na escala de complexidade do regime farmacêutico em tercis para o desfecho hospitalização não foi modificado por: idade ( $p=0,040 ; p=0,038)$, sexo $(p=0,971 ; p=0,041)$, GDS-15 $(p=0,029 ; p=0,801)$, MOS $(p=0,650 ; p=0,416)$, SAHLPA $(p=0,560 ; p=$ $0,372)$, MEEM $(p=0,991 ; p=0,228)$, hiperpolifamárcia $(p=0,454 ; p=0,751)$ e dependência para tomada de medicações $(p=0,423 ; p=0,672)$.

O resultado da pontuação obtida na escala de complexidade do regime terapêutico em tercis para o desfecho visita ao PS não foi modificado por: idade $(p=0,096 ; p=0,707)$, sexo $(p=0,534 ; p=0,407)$, GDS-15 $(p=0,264$; $p=0,056)$, MOS $(p=0,383 ; p=0,838)$, SAHLPA $(p=0,626 ; p=0,900)$, MEEM $(p=0,483 ; p=0,095)$, hiperpolifamárcia $(p=0,983 ; p=0,831)$, BOMFAQ $(p=$ $0,325 ; 0,358)$ e dependência para tomada de medicações $(p=0,505 ; p=$ $0,316)$. 
6 DISCUSSÃO 


\section{DISCUSSÃO}

Neste estudo tivemos o objetivo de avaliar adesão medicamentosa e complexidade do regime terapêutico como preditores de hospitalização e visita ao PS em idosos atendidos com doenças agudas ou descompensações de doenças crônicas. Demonstramos que alta complexidade do regime terapêutico foi fator protetor para hospitalização. As medidas de adesão medicamentosa não foram preditoras de hospitalização ou visita ao serviço de emergência.

O número de participantes incluídos na pesquisa, 207, foi o esperado de acordo com o cálculo amostral realizado previamente, sem nenhuma perda de seguimento ao longo dos seis meses. $O$ número de hospitalizações, desfecho primário da coorte, também ficou dentro do estimado, $27,5 \%$. No entanto, a diferença entre os grupos de risco (adesão versus não adesão) foi bem abaixo do previsto, $20 \%$ versus $40 \%$, respectivamente. Nos três testes propostos relacionados a avaliação de adesão, a diferença de hospitalização entre os grupos foi mínima. No teste da caixa de medicamentos, o grupo de 5 acertos teve $27,6 \%$ de hospitalização contra $27,4 \%$ naquele com 4 acertos ou menos; na escala de Morisky, o grupo alta adesão teve $28,26 \%$ de desfecho primário contra $30,95 \%$ no grupo de baixa adesão; nos tercis da escala de conhecimento, também houve semelhança nas hospitalizações: $29,4 \%, 25 \%$ e $28,36 \%$. Para que houvesse poder suficiente para detectar diferença entre os grupos, 
estimamos que o número de participantes teria que ser em torno de 7.000. Isso sugere que, embora seja possível encontrar a adesão medicamentosa como um fator preditor de hospitalização e visitas a emergência, valendo-se de uma amostra substancialmente maior, o efeito preditor da adesão a medicações sobre os desfechos deverá ser relativamente pequeno.

Desta forma, a discussão dos dados foi pautada, principalmente, nos resultados proporcionados tanto pela análise descritiva dos testes quanto pela análise transversal que revelou os fatores associados ao desempenho dos testes de adesão e do índice de complexidade do regime terapêutico.

Nessa pesquisa, tivemos uma população com baixa escolaridade, baixa renda per capita e alto índice de multimorbidades quando comparado com outros estudos sobre adesão. Esses fatores a tornam uma pesquisa diferenciada, pois, reflete com maior fidelidade a população brasileira e de países em desenvolvimento atendida em serviços secundários e terciários de saúde.

Verificamos que $88,2 \%$ dos idosos encaminhados ao HDG do Serviço de Geriatria da FMUSP apresentavam polifarmácia. Outro dado interessante foi a média de medicações de uso contínuo desta população incluída no estudo: 9,4 (DP 3,83). Hiperpolifarmácia foi encontrada em 35,7\% dos idosos. Esses dados são importantes porque reforçam o perfil de complexidade da população estudada dentro de um serviço de atenção terciária, assim como a vulnerabilidade de desenvolver doenças agudas ou descompensar doenças crônicas. 


\section{- Escala de Morisky}

Com relação à adesão medicamentosa medida pela escala MMAS-8, encontramos uma prevalência de $22,2 \%$ de alta adesão. Esse dado é inferior àqueles encontrados na literatura internacional na qual a prevalência de alta adesão em idosos da comunidade atendidos na atenção primária varia entre 39 a 65,7\% (Cárdenas-Valladolid et al., 2010; Moral et al., 2015).

Contudo, quando analisamos estudos nacionais, a prevalência encontrada de alta adesão foi semelhante à nossa, mesmo em idosos acompanhados na atenção primária. Um estudo transversal, realizado numa cidade do interior de São Paulo, avaliou a adesão através da escala MMAS8 em 102 idosos de Unidades Básicas de Saúde e encontrou uma prevalência de $14,7 \%$ de alta adesão (Obreli-Neto et al., 2010). Prevalência similar de adesão foi encontrada em outro estudo transversal brasileiro realizado no Piauí com idosos acompanhados em um programa de hipertensão e diabetes em 2012: $26,75 \%$ de alta adesão pelo MMAS-4 (Menezes Carvalho et al., 2012).

Quanto aos fatores associados à baixa adesão, encontramos uma prevalência maior de idosos com GDS-15 > 5 pontos no grupo de baixa adesão (52\%) com significância estatística $(p=0,005)$. Esse dado foi confirmado na regressão logística multivariada: idosos com GDS > 5 pontos tiveram 2,4 vezes mais chance de associação com o grupo de baixa adesão

pela MMAS-8. Associação entre sintomas depressivos e baixa adesão também foi encontrada num estudo de coorte envolvendo quase 2.000 idosos hipertensos que analisou os preditores de não adesão ao tratamento 
anti-hipertensivo através da escala de Morisky de 8 itens. Após análise multivariada, sintomas depressivos (OR: 1,84 [IC 95\%: 1,20-2,82]) e níveis elevaods de estresse (OR: 1,68 [IC 95\%: 1,19-2,38]) foram identificados como fatores de risco elevados para declínio na adesão (Krousel-Wood et al., 2011).

Outros fatores que não tiveram associação em nosso trabalho, porém são descritos na literatura são: satisfação com o atendimento prestado, ICFT, número de medicamentos consumidos e número de doenças crônicas relatadas (Obreli-Neto et al., 2010).

\section{- Escala do Conhecimento do Regime Terapêutico}

Quando analisamos dados referentes à escala do conhecimento do regime terapêutico, encontramos que cerca de $20 \%$ da amostra teve um percentual de acertos $\geq 80 \%$. A análise individual de cada quesito da escala de conhecimento terapêutico demonstrou que 52\% dos participantes acertaram o nome da medicação, apenas $23 \%$ a dose, $74 \%$ o horário, $75 \%$ a quantidade e $69 \%$ a indicação.

Apesar de demonstrar uma grande falta do conhecimento do regime prescrito por parte dos idosos, nossos dados são semelhantes àqueles encontrados num grande estudo transversal espanhol realizado recentemente. Nesse estudo, 71,9\% (IC 95\%: 70,9\%-73,0\%) dos participantes pesquisados tinham conhecimento inadequado acerca da medicação que estavam tomando. Os itens "frequência" (75,4\%), "dosagem" 
$(74,5 \%)$ e "indicação" (70,5\%) tiveram o maior percentual de acertos (Romero-Sanchez et al., 2016).

Ainda analisando este tema, também os dados obtidos em nosso estudo são semelhantes aos dados de um estudo transversal brasileiro que avaliou o grau de conhecimento de idosos da atenção primária sobre o tratamento medicamentoso. Nesse estudo, 223 participantes (55,75\%) desconheciam o nome do medicamento usado, 291 (72,75\%) a dose administrada, 26 (6,5\%) o intervalo e 293 participantes (73,25\%) não sabiam por quanto tempo o tratamento deveria ser realizado (Menezes Carvalho et al., 2012).

Pouco mais de um quarto da nossa amostra sabia a dose da medicação prescrita, apenas metade conhecia o nome e dois terços relatou de forma correta a indicação para a medicação de uso contínuo. Esses são dados preocupantes para a segurança do paciente e controle adequado de doenças crônicas. Na população estudada, todos os participantes recebiam uma prescrição eletrônica e retiravam medicação de forma gratuita na farmácia do HCFMUSP. Isso pode ter minimizado alguns danos. Contudo, desconhecer o nome da medicação e dose prescrita pode acarretar diversos problemas, como por exemplo:

- Consultas médicas fora do ambiente do HCFMUSP: mesmo no SUS, não há um sistema integrado de prescrições médicas o que pode ocasionar duplicidade de medicamentos ou uso de mesmo medicamento com dosagens diferentes, por exemplo; 
- Admissões em serviços de emergência e/ou hospitalizações: o paciente que não sabe relatar nome, dose e indicação de suas medicações de uso contínuo pode causar dificuldades no atendimento de urgência/emergência se considerarmos, por exemplo, que dois terços das internações são relacionadas a efeitos colaterais;

- Em caso de falta de medicação na farmácia do HCFMUSP e necessidade de compra: muitas medicações são vendidas sem que seja necessária apresentação da receita médica no Brasil, o que pode gerar erros com dosagens;

- A falta de conhecimento da indicação da medicação: esse fato muitas vezes pode contribuir para a não adesão medicamentosa e descompensação de doenças crônicas.

Essas são informações relevantes que exemplificam a necessidade de identificar quais os fatores que influenciam no conhecimento do regime terapêutico para que medidas de intervenção sejam propostas. No nosso estudo, encontramos que baixo suporte social, alfabetismo em saúde inadequado, hiperpolifarmácia, índice de multimorbidades de Charlson, escala BOMFAQ, pior desempenho no MEEM e presença de sintomas depressivos foram associados ao pior desempenho na escala do conhecimento do regime terapêutico. Escolaridade $\geq 8$ anos foi correlacionada com melhor desempenho na escala.

Outros trabalhos publicados recentemente corroboram com nossos achados. Romero-Sanchez et al (2016) evidenciaram polifamácia como 
preditor de conhecimento inadequado (OR: 1,14; IC 95\%: 1,00-1,31; $p=$ 0,050). Já Quinlan et al. (2013), após ajuste para covariáveis, concluíram que alfabetismo em saúde adequado foi um preditor significativo de conhecimento em saúde. Num estudo transversal envolvendo idosos ambulatoriais e hospitalizados, maior nível de escolaridade se correlacionou com os aspectos do conhecimento sobre medicação ( $p<0,05)$ : 35,8-56,9\% dos participantes com menor nível de escolaridade demonstraram boa/excelente reconhecimento dos medicamentos, suas indicações e esquema de dosagem em comparação com 76,2-90,5\% dos participantes com maior nível de escolaridade (Alkatheri et al., 2013).

Déficit cognitivo e perda funcional também foram encontrados no nosso estudo como fatores associados à pior conhecimento do regime terapêutico. Essa relação também foi descrita por outros autores (Menezes Carvalho et al., 2012; Sears et al., 2016).

\section{- Índice de Complexidade do Regime Terapêutico}

Sobre o ICFT, a média da pontuação foi de 29,28 (DP 12,79). Essa média é mais alta do que a encontrada em outros estudos, inclusive no estudo de validação da escala para o português onde o ICFT obteve média de 15,7 pontos (DP 8,36) (Melchiors et al., 2007). Isso pode ser justificado pela complexidade dos pacientes atendidos no HDG do Serviço de Geriatria da FMUSP (alto grau de multimorbidades e não adesão ao tratamento medicamentoso) e ainda pelo nosso critério de inclusão ter sido a presença 
de polifarmácia elevando a média de medicações dos participantes para quase 10.

Quando analisamos separadamente cada parte do índice, observamos que a maior pontuação dos idosos ocorreu na Parte B com 16,18 pontos; seguidas da parte C com 8,15 pontos e Parte A com 4,94 pontos. A Parte B é aquela que traduz a frequência da dose na prescrição médica. Foi muito comum encontrar prescrições com posologias consideradas mais complexas pelo índice como, por exemplo, "12/12h" ao invés de "2 vezes ao dia" ou mesmo várias prescrições com medicações "se necessário". A Parte C teve a segunda média mais alta. Isso já era esperado, pois, nessa sessão são fornecidas as orientações específicas para a tomada de medicação. Nesse item foi frequente a prescrição de comprimidos partidos ao meio, múltiplas unidades ao mesmo tempo ou mesmo tomadas em horários específicos. A Parte A, apesar de ter tido a menor média, também representa uma complexidade mais alta uma vez que os pacientes tinham, na maioria das vezes, mais de uma forma de apresentação de medicação (comprimidos + líquidos ou comprimidos + ampola, por exemplo).

No nosso estudo, os fatores que se correlacionaram com maior complexidade do regime terapêutico foram: GDS-15 maior que 5 pontos, hiperpolifarmácia e índice de Charlson. Esses achados são consistentes com outros estudos publicados.

Para idosos brasileiros de um município de Minas Gerais: maior número de medicamentos, menor escolaridade, pior percepção de saúde e 
menor renda foram associados positivamente à maior complexidade do regime terapêutico $(p<0,05)$ (Acurcio et al., 2009). Com relação à depressão, uma coorte publicada recentemente concluiu que idosos com depressão possuem maior complexidade do regime simplesmente pelo fato de tomarem um número maior de medicações e terem menor adesão ao tratamento medicamentoso global (Linnebur et al., 2014).

$\mathrm{Na}$ análise de sobrevida do nosso estudo, o ICFT, dividido em tercis, foi uma variável com predição estatisticamente significativa para o desfecho de hospitalização. Os pacientes com maior complexidade do regime terapêutico tiveram maior tempo livre de hospitalização quando comparados com os pacientes com baixa complexidade. Essa relação entre ICFT e hospitalização, que ainda não tinha sido estudada de forma mais aprofundada, foi publicada recentemente num estudo de coorte em idosos institucionalizados. Ao contrário do que encontramos, Lalic et al. demonstraram relação entre complexidade do regime e o aumento no número de hospitalizações (HR 1,17; IC95\% 1,06-1,29) (Lalic et al., 2016). Devemos considerar a diferença entre as populações estudadas bem como o tempo de seguimento para justificar a divergência entre os achados. Uma hipótese para explicar nossos resultados é que idosos com maior complexidade do regime terapêutico estejam com suas prescrições otimizadas e, portanto, apresentem menor taxa de descompensação de doenças crônicas e, consequentemente, menor número de hospitalizações.

Outro dado interessante que merece discussão foi o encontrado na análise de interação entre a escala do conhecimento do regime terapêutico e 
o alfabetismo em saúde. Nesta análise, verificamos que o ICFT modificou significativamente o efeito do alfabetismo em saúde sobre a escala do conhecimento do regime terapêutico $(p=0,003)$. Os participantes com bom desempenho na avaliação do alfabetismo em saúde e baixa complexidade do regime terapêutico apresentaram um conhecimento melhor do regime terapêutico do que aqueles com bom desempenho na avaliação do alfabetismo em saúde e alta complexidade terapêutica. No entanto, a complexidade do regime terapêutico não influenciou no conhecimento terapêutico daqueles com alfabetismo em saúde inadequado. Poucos trabalhos discutem esse tema e os dados apontam que intervenções de alfabetismo de saúde apresentem maior efeito sobre a adesão apenas em amostras de menor renda e em minorias étnico-raciais (Geboers et al., 2015; Miller, 2016). Ou seja, é necessário educar a população para melhorar o alfabetismo em saúde ao mesmo tempo em que se promove uma redução da complexidade farmacêutica com o objetivo final de melhorar a adesão.

\section{- Teste da Caixa Organizadora de Medicamentos}

Uma grande confirmação daquilo que se percebe no cotidiano do atendimento de idosos foi demonstrada através da execução do teste da caixa de medicamentos, no qual, apenas $45,41 \%$ dos participantes interpretaram corretamente a prescrição médica e conseguiram executar o teste com pontuação máxima.

Isso proporciona rica discussão sobre os possíveis motivos desse achado. Alfabetismo em saúde inadequado, baixa escolaridade, baixo 
suporte social e déficit visual são algumas das possibilidades. $\mathrm{Na}$ análise multivariada do nosso estudo, idosos com inadequado alfabetismo em saúde tiveram maior associação com pior desempenho no teste da caixa de medicamentos. Esse foi um dos resultados esperados já que há dados na literatura que corroboravam com esta hipótese (Miller et al., 2016).

Quando analisamos as cinco tarefas de forma isolada do teste, percebemos que os maiores percentuais de acertos foram com as cápsulas azul $85,7 \%$ (tomar 1 comprimido 1 vez ao dia pela manhã) e laranja $79,8 \%$ (tomar 1 vez ao dia ao deitar) associadas as posologias mais simples. As porcentagens de acertos com as outras cápsulas foram: vermelha $66 \%$, verde $61,6 \%$ e amarela $59,6 \%$, respectivamente.

Outro ponto que merece discussão: comprovamos que os pacientes conseguem entender de forma mais adequada prescrições que incluam posologias simplificadas como aquelas com apenas uma tomada diária. Esse dado permite estimular a simplificação das prescrições médicas como uma estratégia para melhorar a adesão medicamentosa. 
7 PONTOS FORTES

EM RELAÇÃo À LITERATURA 


\section{PONTOS FORTES EM RELAÇÃO À LITERATURA}

Este foi um estudo que expande o conhecimento na área em relação à literatura internacional. Analisamos um tema pouco estudado, mas de fundamental importância para a prática clínica. Por ter sido um estudo de coorte, apresenta as vantagens inerentes a este desenho. Outro ponto que merece destaque é o fato de termos utilizado mais de um método para avaliar a adesão medicamentosa o que diferencia este estudo com relação aos outros estudos publicados na área. Além disso, expandimos o conhecimento anterior, ao analisamos uma população de idosos com condições agudas atendidos em um Hospital Dia Geriátrico, população que não havia sido estudada anteriormente. Por fim, avaliamos uma miriade de covariáveis, buscando demonstrar os fatores que se associam com complexidade do regime terapêutico e adesão medicamentosa, incluindo a avaliação de alfabestismo em saúde. 
8 LIMITAÇÕES 


\section{LIMITAÇÕES}

Uma das limitações do nosso estudo foi o tamanho amostral que não foi suficiente para avaliar as associações entre os métodos de adesão com os desfechos. No entanto, o estudo demonstrou que a magnitude de efeito das medidas de adesão sobre os desfechos estudados deve ser reduzida, requerendo milhares de participantes para que este efeito seja verificado. $A$ exclusão de idosos analfabetos e/ou que não apresentaram polifarmácia pode ter influenciado no tamanho amostral bem como na heterogeneidade da amostra. É válido ressaltar que o cálculo amostral não foi baseado em trabalhos anteriores, pois não existiam trabalhos semelhantes na literatura no início do estudo. Além disso, os idosos atendidos no HDG do HC-FMUSP constituíram uma população muito grave e que, muito provavelmente, iria apresentar altas taxas de hospitalização e visitas ao PS, independentemente da adesão medicamentosa e da complexidade do regime terapêutico.

Outro ponto que pode ser considerado uma limitação, foi a não utilização de métodos diretos para aferir adesão. Apesar de serem considerados mais eficazes, envolvem custos elevados para serem aplicados o que não seria viável nesse estudo.

Outra limitação que pode ter interferido nos resultados é o número grande de variáveis que podem ter influência nos desfechos hospitalização e visitas ao PS. Em virtude da complexidade dos casos, outros fatores que não foram contemplados nessa coorte podem ter tido interferência direta nos 
desfechos como, por exemplo, a ausência de recursos financeiros para o transporte até o hospital, dificuldade de deslocamento do idoso por questões físicas até o ambiente hospitalar, ou mesmo experiências negativas prévias em visitas ao PS.

Por fim, a avaliação dos idosos apenas ocorreu no início da coleta dos dados. Não houve reavaliação dos participantes após a intervenção multidisciplinar do HDG. Esse fato pode ter influenciado os resultados, uma vez que, tanto a adesão medicamentosa quanto a complexidade do regime terapêutico podem ter sido modificados após a intervenção do HDG durante o período de observação. 
9 CONCLUSÕES 


\section{CONCLUSÕES}

Adesão Medicamentosa e Complexidade do Regime Terapêutico não foram preditores de hospitalização ou visita ao pronto socorro na população estudada.

Os fatores associados a não adesão medicamentosa foram: alfabetismo em saúde inadequado, baixo suporte social e presença de sintomas depressivos. Complexidade do regime terapêutico foi associada à presença de sintomas depressivos e índice de multimorbidades de Charlson. 


\section{ANEXOS}




\section{ANEXO A - ÍNDICE DE COMPLEXIDADE DA FARMACOTERAPIA (ICFT)}

\section{PARTE A}

\begin{tabular}{|c|c|c|}
\hline Formas de dosagem & & Peso \\
\hline \multirow[t]{6}{*}{ Oral } & Cápsulas/comprimidos & 1 \\
\hline & Gargarejos/colutórios & 2 \\
\hline & Gomas/pastilhas & 2 \\
\hline & Líquidos & 2 \\
\hline & Pós/grânulos & 2 \\
\hline & Spray/comprimidos sublinguais & 2 \\
\hline \multirow[t]{6}{*}{ Tópico } & Cremes/géis/pomadas & 2 \\
\hline & Emplastros & 3 \\
\hline & Tinturas/soluções de uso tópico & 2 \\
\hline & Pastas & 3 \\
\hline & Adesivos transdérmicos/patches & 2 \\
\hline & Spray de uso tópico & 1 \\
\hline \multirow[t]{5}{*}{ Ouvido, olhos e Nariz } & Gotas/cremes/pomadas para o ouvido & 3 \\
\hline & Colírios/gotas para os olhos & 3 \\
\hline & Géis/pomadas para os olhos & 3 \\
\hline & Gotas/cremes/pomadas nasais & 3 \\
\hline & Spray nasal & 2 \\
\hline \multirow[t]{7}{*}{ Inalação } & Accuhalers (pó seco para inalação/diskus) & 3 \\
\hline & Aerolizers (cápsulas para inalação) & 3 \\
\hline & Inaladores de dose medida (bombinha) & 4 \\
\hline & Nebulizador (ar comprimido/ultra-sônico) & 5 \\
\hline & Oxigênio/concentrador & 3 \\
\hline & Turbuhalers (pó seco para inalação) & 3 \\
\hline & Outros inaladores de pó seco & 3 \\
\hline \multirow[t]{9}{*}{ Outros } & Fluido para diálise & 5 \\
\hline & Enemas & 2 \\
\hline & Injeções: & \\
\hline & - Pré-carregadas & 3 \\
\hline & - Ampolas/frascos-ampolas & 4 \\
\hline & Supositórios/óvulos vaginais & 3 \\
\hline & Analgesia controlada pelo paciente & 2 \\
\hline & Supositório & 2 \\
\hline & Cremes vaginais & 2 \\
\hline
\end{tabular}

TOTAL PARTE A 


\section{PARTE B}

\begin{tabular}{|c|c|c|c|c|}
\hline Frequência de Dose & Medicações & Total & Peso & Total $\times$ Peso \\
\hline $1 \times \mathrm{dia}$ & & & 1 & \\
\hline $1 \mathrm{x}$ dia $S / N$ & & & 0,5 & \\
\hline $2 x$ dia & & & 2 & \\
\hline $2 x$ dia $S / N$ & & & 1 & \\
\hline $3 x$ dia & & & 3 & \\
\hline $3 x$ dia $S / N$ & & & 1,5 & \\
\hline $4 \mathrm{x}$ dia & & & 4 & \\
\hline $4 x \operatorname{dia} S / N$ & & & 2 & \\
\hline $12 / 12 \mathrm{~h}$ & & & 2,5 & \\
\hline $12 / 12$ h S/N & & & 1,5 & \\
\hline $8 / 8 \mathrm{~h}$ & & & 3,5 & \\
\hline $8 / 8$ h S/N & & & 2 & \\
\hline $6 / 6 \mathrm{~h}$ & & & 4,5 & \\
\hline $6 / 6$ h S/N & & & 2,5 & \\
\hline $4 / 4 \mathrm{~h}$ & & & 6,5 & \\
\hline $4 / 4 \mathrm{~h} \mathrm{~S} / \mathrm{N}$ & & & 3,5 & \\
\hline $2 / 2 \mathrm{~h}$ & & & 12,5 & \\
\hline $2 / 2$ h S/N & & & 6,5 & \\
\hline $\mathrm{S} / \mathrm{N}$ & & & 0,5 & \\
\hline $\begin{array}{l}\text { Dias alternados ou menor } \\
\text { frequência }\end{array}$ & & & 2 & \\
\hline Oxigênio $S / N$ & & & 1 & \\
\hline Oxigênio < $5 \mathrm{~h}$ & & & 2 & \\
\hline Oxigênio > $15 \mathrm{~h}$ & & & 3 & \\
\hline TOTAL PARTE B & & & & \\
\hline
\end{tabular}


PARTE C

\begin{tabular}{|c|c|c|c|c|}
\hline Instruções adicionais & Medicações & Total & Peso & $\begin{array}{l}\text { Peso } x \\
\text { Número de } \\
\text { medicações }\end{array}$ \\
\hline Partir ou triturar o comprimido & & & 1 & \\
\hline Dissolver o comprimido/pó & & & 1 & \\
\hline $\begin{array}{l}\text { Múltiplas unidades ao mesmo tempo } \\
\text { (p. ex., } 2 \text { comprimidos, } 2 \text { jatos) }\end{array}$ & & & 1 & \\
\hline $\begin{array}{l}\text { Dose variável } \\
\text { (p. ex., 1-2 cápsulas, } 2-3 \text { jatos) }\end{array}$ & & & 1 & \\
\hline $\begin{array}{l}\text { Tomar/usar em horário específico ( } p \text {. } \\
\text { ex., manhã, noite, } 8 \text { AM) }\end{array}$ & & & 1 & \\
\hline $\begin{array}{l}\text { Relação com alimento } \\
\text { (p. ex., com alimento, antes das } \\
\text { refeições, depois das refeições) }\end{array}$ & & & 1 & \\
\hline Tomar com líquido específico & & & 1 & \\
\hline Tomar/usar conforme indicado & & & 2 & \\
\hline $\begin{array}{l}\text { Reduzir ou aumentar a dose } \\
\text { progressivamente }\end{array}$ & & & 2 & \\
\hline $\begin{array}{l}\text { Doses alternadas } \\
\text { (p. ex., } 1 \text { manhã e } 2 \text { noite, } 1 / 2 \text { em dias } \\
\text { alternados) }\end{array}$ & & & 2 & \\
\hline
\end{tabular}

\section{TOTAL PARTE C}

Total da complexidade da farmacoterapia $=$ 


\section{ANEXO B - FICHA DE SEGUIMENTO TELEFÔNICO}

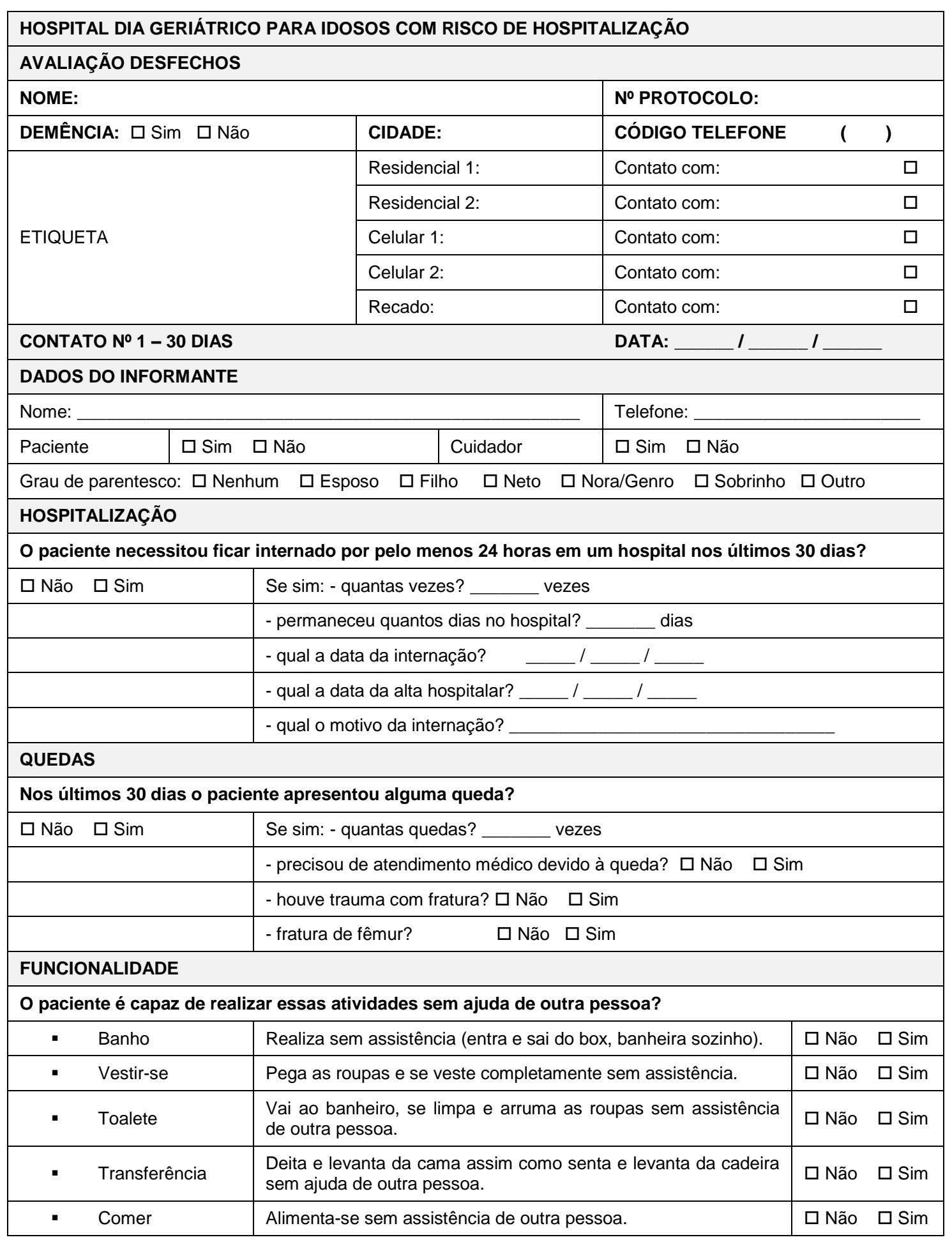




\begin{tabular}{|c|c|c|c|}
\hline \multicolumn{4}{|l|}{ MORTALIDADE } \\
\hline \multicolumn{4}{|c|}{ Ocorreu óbito nos últimos 30 dias? } \\
\hline \multirow[t]{2}{*}{$\square$ Não $\square \operatorname{Sim}$} & \multicolumn{3}{|c|}{ Se sim, qual a data? ___ } \\
\hline & \multicolumn{3}{|l|}{ Qual a causa? } \\
\hline \multicolumn{4}{|c|}{ CONTATO TELEFÔNICO } \\
\hline \multicolumn{4}{|c|}{ Há alguma previsão de mudança de telefone para contato no próximo mês? } \\
\hline$\square$ Não $\square \operatorname{Sim}$ & Se sim, para qual contato devo ligar? & Tel.: & Contato: \\
\hline \multicolumn{4}{|c|}{ Foi possível responder todas as perguntas deste questionário? } \\
\hline \multirow[t]{4}{*}{$\square$ Não $\square \operatorname{Sim}$} & \multicolumn{3}{|l|}{ Se não, qual foi o motivo? } \\
\hline & \multicolumn{3}{|c|}{$\checkmark$ Perda do contato (ex: mudança de telefone do paciente sem aviso prévio) } \\
\hline & \multicolumn{3}{|c|}{$\square$ Desistência do paciente ou familiar de participar da pesquisa } \\
\hline & $\square$ Outro motivo: & & \\
\hline
\end{tabular}


ANEXO C - TERMO DE CONSENTIMENTO LIVRE E ESCLARECIDO

HOSPITAL DAS CLÍNICAS DA FACULDADE DE MEDICINA DA UNIVERSIDADE DE

SÃO PAULO-HCFMUSP

TERMO DE CONSENTIMENTO LIVRE E ESCLARECIDO

DADOS DE IDENTIFICAÇÃO DO SUJEITO DA PESQUISA OU RESPONSÁVEL LEGAL

1. NOME:

DOCUMENTO DE IDENTIDADE N ${ }^{\circ}$ : SEXO :.$M \square F \square$

DATA NASCIMENTO: $. / \ldots \ldots . . . . . . .$.

№ APTO:

ENDEREÇO CIDADE

BAIRRO: TELEFONE: DDD ..)

CEP:

2.RESPONSÁVEL LEGAL

NATUREZA (grau de parentesco, tutor, curador etc.)

DOCUMENTO DE IDENTIDADE SEXO: $M \square F \square$

DATA NASCIMENTO.: ............

ENDEREÇO: № APTO:

BAIRRO: CIDADE:

CEP: TELEFONE: DDD

\section{DADOS SOBRE A PESQUISA}

TÍTULO DO PROTOCOLO DE PESQUISA:

Hospital Dia para idosos com risco de hospitalização. PESQUISADOR: Wilson Jacob Filho CARGO/FUNÇÃO: Professor Titular do Serviço de Geriatria UNIDADE DO HCFMUSP: Hospital Dia Geriátrico

3. AVALIAÇÃO DO RISCO DA PESQUISA:

$\begin{array}{lll}\text { RISCO MÍNIMO } & \text { RISCO MÉDIO } \square \\ \text { RISCO BAIXO } & \square & \text { RISCO MAIOR } \square\end{array}$

4. DURAÇÃO DA PESQUISA: 48 meses. 


\title{
HOSPITAL DAS CLÍNICAS DA FACULDADE DE MEDICINA DA UNIVERSIDADE DE SÃO PAULO-HCFMUSP
}

\author{
Prezado(a) $\operatorname{Sr}(a)$
}

Gostaríamos de contar com a sua participação em uma pesquisa aqui do hospital. Trata-se de um estudo do Hospital Dia sobre idosos com risco de internação e dependência de outras pessoas. Para isto faremos algumas perguntas aqui mesmo durante o seu atendimento médico. As perguntas dizem respeito a sua saúde geral. Além de responder a essas perguntas, você será convidado a fazer algumas tarefas simples como caminhar alguns passos e levantar da cadeira. Não será feita nenhuma medicação para esse estudo e os exames de sangue utilizados serão apenas os do seu prontuário médico aqui do hospital.

1- Caso o $\operatorname{Sr}(a)$ aceite participar, faremos também ligações de cinco minutos para o telefone da sua preferência. Essas chamadas são para saber como o $\operatorname{Sr}(a)$ tem passado e se precisou de alguma internação no hospital. Ligaremos uma vez por mês, por 12 meses seguidos.

2- Essas entrevistas podem trazer algum aborrecimento ou cansaço, apesar do nosso esforço para que isso não aconteça em nenhum momento. O benefício dessa avaliação é a possibilidade dos médicos que o atendem descobrirem algum problema que possa vir a prejudicar a sua saúde nos próximos meses, bem como auxiliar outros pacientes.

3- Caso decida não participar desse estudo, você continuará com o seu atendimento aqui no Hospital Dia normalmente sem nenhuma perda. Você pode também recusar-se a responder qualquer pergunta ou retirar-se do estudo a qualquer momento, sem nenhum prejuízo ao seu atendimento aqui no hospital.

4- Os principais médicos desse estudo são Dr. Márlon Aliberti e Dra. Juliana de Araújo Melo, que podem ser encontrados de segunda a sexta-feira das 8 às $18 \mathrm{~h}$ aqui no Hospital Dia que fica no Prédio dos Ambulatórios, 5ํandar, tel.2661-7168 ou por email: marlon.aliberti@hc.fm.usp.br; juliana.melo@hc.fm.usp.br.

5- Se você tiver alguma consideração ou dúvida sobre a ética desse estudo, poderá entrar em contato com o Comitê de Ética em Pesquisa (CEP) - Rua Ovídio Pires de Campos, 225 - 5o andar - tel: 2661-6442 ramais 16, 17, 18 ou 20, FAX: 2661-6442 ramal 26 - e-mail: cappesq.adm@hc.fm.usp.br.

6- Solicitamos a sua autorização para uso e reprodução de informações que constam nas suas fichas médicas e prontuários aqui do hospital. Pedimos ainda a permissão para que seus dados sejam usados nos estudos atuais e futuros desta pesquisa. Lembramos que, em nenhum momento sua identidade será revelada. Caso depois, o Sr(a) resolva retirar esta permissão, seus dados não serão mais usados a partir de então.

7- Caso deseje, você será atualizado sobre os resultados gerais desse estudo e a qualquer momento poderá pedir esclarecimentos sobre os dados relativos à sua própria avaliação.

8- Não há despesas pessoais nesse estudo. Você receberá apenas uma ajuda para transporte igual ao valor do metro e ônibus gasto (ida e volta) de sua casa para o hospital para você e seu acompanhante.

9- Não há outros benefícios financeiros previstos. Porém, não haverá qualquer prejuízo a seus direitos legais de questionamento, indenização ou outros garantidos pela Constituição brasileira. 


\section{HOSPITAL DAS CLÍNICAS DA FACULDADE DE MEDICINA DA UNIVERSIDADE DE SÃO PAULO-HCFMUSP}

Acredito ter recebido os esclarecimentos necessários a respeito das informações que li ou que foram lidas para mim. Ficaram claros para mim quais são os propósitos desse estudo, os procedimentos a serem realizados, seus desconfortos e riscos, as garantias de confidencialidade e de esclarecimentos permanentes. Ficou claro também que minha participação é isenta de despesas e não inclui remuneração. Concordo voluntariamente em participar deste estudo e poderei retirar o meu consentimento a qualquer momento, sem prejuízo ou perda de qualquer benefício que eu possa ter adquirido no meu atendimento neste Serviço.

Assinatura do paciente/representante legal

Data

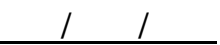

Assinatura da testemunha

Data

(para casos de pacientes menores de 18 anos, analfabetos, semi-analfabetos ou portadores de deficiência auditiva ou visual.)

\section{(Somente para o responsável do projeto)}

Declaro que obtive de forma apropriada e voluntária o Consentimento Livre e Esclarecido deste paciente ou representante legal para a participação neste estudo.

Assinatura do responsável pelo estudo

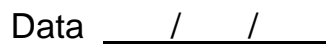


11 REFERÊNCIAS 


\section{REFERÊNCIAS}

Acurcio FA, Silva AL, Rlbelro AQ, Rocha NP. Complexldade do reglme terapêutlco prescrlto para Idosos. Rev Assoc Med Bras. 2009; 55 (4): 46874.

Aliberti MJ, Suemoto CK, Fortes-Filho SQ, Melo JA, Trindade CB, Kasai JY, Altona M, Apolinario D, Jacob-Filho W. The Geriatric Day Hospital: preliminary data on an innovative model of care in Brazil for older adults at risk of hospitalization. J Am Geriatr Soc. 2016; 64(10):2149-53.

Alkatheri AM, Albekairy AM. Does the patients educational level and previous counseling affect their medication knowledge. Ann Thorac Med. 2013;8(2): 105-8.

Almeida OP, Almeida SA. Short versions of the Geriatric Depression Scale: a study of their validity for the diagnosis of a major depressive episode according to ICD-10 and DSM-IV. Int J Geriatr Psychiatry. 1999;14:858-65.

Apolinario D, Braga Rde C, Magaldi RM, Busse AL, Campora F, Brucki S, Lee SY. Short assessment of health literacy for Portuguese-speaking adults. Rev Saude Publica. 2012;46(4):702-11.

Ascione FJ, Kirscht JP, Shimp LA. An assessment of different components of patient medication knowledge. Med Care. 1986;24(11):1018-28.

Baker DW, Williams MV, Parker RM, Gazmararian JA, Nurss J. Development of a brief test to measure functional health literacy. Patient Educ Couns. 1999;38(1):33-42. 
Ben AJ, Neumann CR, Mengue SS. The Brief Medication Questionnaire and MoriskyGreen test to evaluate medication adherence. Rev Saude Publica. 2012; 46 (2): 279-89.

Beynon $\mathrm{JH}$, Padiachy $\mathrm{D}$. The past and future of geriatric day hospitals. Reviews in Clinical Gerontology. 2009; 19: 45-51.

Bosch-Lenders D, Maessen DW, Stoffers HE, Knottnerus JA, Winkens B, van den Akker M. Factors associated with appropriate knowledge of the indications for prescribed drugs among community-dwelling older patients with polypharmacy. Age Ageing. 2016;45(3):402-8.

Brown L, Forster A, Young J, Crocker T, Benham A, Langhorne P; DayHospital Group. Medical day hospital care for older people versus alternative forms of care. Cochrane Database Syst Rev. 2015; 23(6):CD001730.

Brucki SMD, Nitrini R, Caramelli P, Bertolucci PHF, Okamoto IH. Sugestões para o uso do mini-exame do estado mental no Brasil. Arq Neuropsiquiatr. 2003;61(3B):777-81.

Burge S, White D, Bajorek E, Bazaldua O, Trevino J, Albright T, Wright F, Cigarroa L. Correlates of medication knowledge and adherence: findings from the residency research network of South Texas. Fam Med. 2005;37(10):712-8.

Camarano AA, Kanso S. Perspectivas de crescimento para a população brasileira: velhos e novos resultados. Texto para discussão no 1426 , Rio de Janeiro: lepa, 2009. 
Cardenas-Valladolid J, Martin-Madrazo C, Salinero-Fort MA, Carrillo deSanta Pau E, Abanades-Herranz JC, de Burgos-Lunar C. Prevalence of adherence to treatment in homebound elderly people in primary health care: a descriptive, cross-sectional, multicentre study. Drugs Aging. 2010;27(8):641-51.

Carvalho AL, Leopoldino RW, da Silva JE, da Cunha CP. Adherence to drug treatment among registered users in the "HIPERDIA" Program in Teresina in the State of Piauí. Cien Saude Colet. 2012;17:1885-92.

Carvalho MF, Romano-Lieber NS, Bergsten-Mendes G, Secoli SR, Ribeiro E, Lebrão ML, Duarte YA. Polypharmacy among the elderly in the city of São Paulo, Brazil -SABE Study. Rev Bras Epidemiol. 2012;15(4):817-27.

Charlson ME, Pompei P, Ales KL, MacKenzie CR. A new method of classifying prognostic comorbidity in longitudinal studies: development and validation. J Chronic Dis. 1987;40:373-83.

Cohen MJ, Shaykevich S, Cawthon C, Kripalani S, Paasche-Orlow MK, Schnipper JL. Predictors of medication adherence postdischarge: the impact of patient age, insurance status, and prior adherence. J Hosp Med. 2012;7(6):470-5.

Costa SC, Pedroso ERP. A prescrição de medicamentos para idosos internados em serviço de clínica médica: atualização. Rev Med Minas Gerais. 2011;21(2):201-14.

DATASUS. Informações de Saúde Demográficas e Socioeconômicas. Disponível:http://tabnet.datasus.gov.br/cgi/deftohtm.exe?sih/cnv/nruf.def.

Davis TC, Crouch MA, Long SW, Jackson RH, Bates P, George RB, Bairnsfather LE. Rapid assessment of literacy levels of adult primary care patients. Fam Med. 1991;23(6):433-5. 
Dean AG, Sullivan KM, Soe MM. OpenEpi: Open Source Epidemiologic Statistics for Public Health, 2006.

Desrosiers J, Hébert R, Payette H, Roy PM, Tousignant M, Côté S, Trottier L. A Geriatric Day Hospital: who improves the most? Can J Aging. 2004;23:21729.

Eichler K, Wieser S, Brügger U. The costs of limited health literacy: a systematic review. Int J Public Health. 2009;54(5):313-24.

Forster A, Young J, Langhorne P. Medical day hospital care for the elderly versus alternative forms of care. Cochrane Database Syst Rev. 2000;(2): CD001730.

Franchi C, Marcucci M, Mannucci PM, Tettamanti M, Pasina L, Fortino I, Bortolotti A, Merlino L, Nobili A.Changes in clinical outcomes for communitydwelling older people exposed to incident chronic polypharmacy: a comparison between 2001 and 2009. Pharmacoepidemiol Drug Saf. 2016;25(2):204-11.

García Delgado P, Gastelurrutia Garralda MA, Baena Parejo MI, Fisac Lozano F, Martínez Martínez F. Validation of a questionnaire to assess patient knowledge of their medicines. Aten Primaria. 2009;41(12):661-8.

Geboers B, Brainard JS, Loke YK, Jansen CJ, Salter C, Reijneveld SA, de Winter AF. The association of health literacy with adherence in older adults, and its role in interventions: a systematic meta-review. BMC Public Health. 2015;15:903.

George J, Phun YT, Bailey MJ, Kong DC, Stewart K. Development and validation of the medication regimen complexity index. Ann Pharmacother. 2004;38(9):1369-76. 
Giardini A, Martin MT, Cahir C, Lehane E, Menditto E, Strano M, Pecorelli S, Monaco A, Marengoni A. Toward appropriate criteria in medication adherence assessment in older persons: Position Paper. Aging Clin Exp Res. 2016;28(3):371-81.

Gnjidic D, Hilmer SN, Blyth FM, Naganathan V, Waite L, Seibel MJ, McLachlan AJ, Cumming RG, Handelsman DJ, Le Couteur DG. Polypharmacy cutoff and outcomes: five or more medicines were used to identify community-dwelling older men at risk of different adverse outcomes. J Clin Epidemiol. 2012;65(9):989-95.

Hayes KS. Adding medications in the emergency department: effect on knowl-edge of medications in older adults. J Emerg Nurs. 1999;25:178-82.

Hope CJ, Wu J, Tu W, Young J, Murray MD. Association of medication adherence, knowledge, and skills with emergency department visits by adults 50 years or older with congestive heart failure. Am J Health Syst Pharm. 2004;61(19):2043-9.

IBGE 2010 - Instituto Brasileiro de Geografia e Estatística. Censo demográfico. Rio de Janeiro: IBGE, 2010.

Instituto Brasileiro de Geografia e Estatística - IBGE, 2013. Disponível em: www.ibge.gov.br/home

Jovic-Vranes A, Bjegovic-Mikanovic V, Marinkovic J, Kocev N. Health literacy in a population of primary health-care patients in Belgrade, Serbia. Int $J$ Public Health. 2011;56(2):201-7.

Kaufman DW, Kelly JP, Rosenberg L, Anderson TE, Michell AA. Recent patterns of medication use in the ambulatory adult population of the United States. JAMA. 2002;287:337-44. 
Krousel-Wood M, Joyce C, Holt E, Muntner P, Webber LS, Morisky DE, Frohlich ED, Re RN. Predictors of decline in medication adherence: results from the cohort study of medication adherence among older adults. Hypertension. 2011;58(5):804-10.

Kwan B, Frankish J, Rootman I, Zumbo B, Kelly K, Begoray D, et al. Thedevelopment and validation of measures of "health literacy" in diferente populations. Vancouver: University of British Columbia, Institute of Health Promotion Research \& University of Victoria Centre for Community Health Promotion Research; 2006.

Lalic S, Sluggett JK, Ilomäki J, Wimmer BC, Tan EC, Robson L, Emery T, Bell JS. Polypharmacy and medication regimen complexity as risk factors for hospitalization among residents of long-term care facilities: a Prospective Cohort Study. J Am Med Dir Assoc. 2016;17(11):1067.

Lee SY, Bender DE, Ruiz RE, Cho YI. Development of an easy-to-use Spanish Health Literacy test. Health Serv Res. 2006;41:1392-412.

Linnebur SA, Vande Griend JP, Metz KR, Hosokawa PW, Hirsch JD, Libby AM. Patient-level medication regimen complexity in older adults with depression. Clin Ther. 2014;36(11):1538-46.

Lyles A, Culver N, Ivester J, Potter T. Effects of health literacy and polypharmacy on medication adherence. Consult Pharm. 2013;28(12):793-9.

MacFarlane JP, Collings T, Graham K, Maclntosh JC. Day hospitals in modern clinical practice--cost benefit. Age Ageing. 1979;(suppl 20):80-6.

Martins MAP, Costa JM, Mambrini JVM, Ribeiro ALP, Benjamin EJ, Brant LCC, Paasche-Orlow MK, Magnani JW. Health literacy and warfarin therapy at two anticoagulation clinics in Brazil. Heart. 2017;103(14):1089-95. 
Mathes T, Pieper D, Antoine SL, Eikermann M. 50\% adherence of patients suffering chronic conditions - where is the evidence. Ger Med Sci. 2013;10:1612-3174.

Melchiors AC, Correr CJ, Fernández-Llimos F. Translation and validation into Portuguese language of the medication regimen complexity index. Arq Bras Cardiol. 2007;89(4):210-8.

Menezes Carvalho AL, Duarte Leopoldino RW, Silva JG, Cunha CP. Adesão ao tratamento medicamentoso em usuários cadastrados no Programa Hiperdia no município de Teresina (PI). Ciênc Saúde Coletiva. 2012;17(7):1885-92.

Miller TA. Health literacy and adherence to medical treatment in chronic and acute illness: A meta-analysis. Patient Educ Couns. 2016;99(7):1079-86.

Ministério da Saúde. Manual de Hipertensão Arterial e Diabetes Mellitus. Brasília: Ministério da Saúde; 2002.

Ministério da Saúde. Portaria $\mathrm{n}^{\circ} 249$ de 16 de abril de 2002. Disponível em: <http://dtr2001.saude.gov.br/sas/PORTARIAS/PORT2002/PT-249.htm>

Moral RR, Torres LA, Ortega LP, Larumbe MC, Villalobos AR, Garcia JA. Effectiveness of motivational interviewing to improve therapeutic adherence in patients over 65 years old with chronic diseases: A cluster randomized clinical trial in primary care. Patient Educ Couns. 2015;98(8):977-83.

Morisky DE, Ang A, Krousel-Wood M, Ward HJ. Predictive validity of a medication adherence measure in an outpatient setting. $J$ Clin Hypertens. 2008;10(5):348-54. 
Moser A, Stuck AE, Silliman RA, Ganz PA, Clough-Gorr KM. The eight-item modified Medical Outcomes Study Social Support Survey: psychometric evaluation showed excellent performance. J Clin Epidemiol. 2012;65(10): 1107.

Najjar A, Amro Y, Kitaneh I, Abu-Sharar S, Sawalha M, Jamous A, Qiq M, Makharzeh E, Subb Laban B, Amro W, Amro A. Knowledge and adherence to medications among Palestinian geriatrics living with chronic diseases in the West Bank and East Jerusalem. PLoS One. 2015;10(6):e0129240.

Ngoh LN. Health literacy: a barrier to pharmacist-patient communication and medication adherence. J Am Pharm Assoc. 2009;49(5):132-46.

Núñez Montenegro AJ, Montiel Luque A, Martín Aurioles E, Torres Verdú B, Lara Moreno C, González Correa JA. Adherence to treatment, by active ingredient, in patients over 65 years on multiple medication. Aten Primaria. 2014;46(5):238-45.

Obreli-Neto PR, Prado MF, Vieira JC, Fachini FC, Pelloso SM, Marcon SS, Cuman RKN. Fatores interferentes na taxa de adesão à farmacoterapia em idosos atendidos na rede pública de saúde do Município de Salto Grande SP, Brasil. Rev Ciênc Farm Básica Apl. 2010;31(3):229-233.

Okuyan B, Sancar M, Izzettin FV. Assessment of medication knowledge and adherence among patients under oral chronic medication treatment in community pharmacy settings. Pharmacoepidemiol Drug Saf. 2013;22(2):209-14.

Oliveira-Filho AD, Morisky DE, Costa FA, Pacheco ST, Neves SF, Lyra-Jr DP. Otimização da adesão terapêutica pós-alta hospitalar de pacientes com DCV: ensaio clínico randomizado - estudo piloto. Arq Bras Cardiol. 2014; [online]. 
Oliveira-Filho AD, Morisky DE, Neves SJ, Costa FA, de Lyra DP Jr. The 8item Morisky Medication Adherence Scale: validation of a BrazilianPortuguese version in hypertensive adults. Res Social Adm Pharm. 2014;10(3):554-61.

OMS: Organização Mundial da Saúde. Adherence to long-term therapiesevidence for action, 2003. Disponível em: http:// www.who.int/chp/knowledge/publications/adherence_report/ en/

Osterberg L, Blaschke T. Adherence to medication. $N$ Engl $J$ Med. 2005;353(5):487-97.

Ostini R, Kairuz T. Investigating the association between health literacy and non-adherence. Int J Clin Pharm. 2014;36(1):36-44.

Parker RM, Baker DW, Williams MV, Nurss JR. The test of functional health literacy in adults: a new instrument for measuring patients' literacy skills. J Gen Intern Med. 1995;10(10):537-41.

Quinlan P, Price KO, Magid SK, Lyman S, Mandl LA, Stone PW. The relationship among health literacy, health knowledge, and adherence to treatment in patients with rheumatoid arthritis. HSS J. 2013;9(1):42-9.

Ramos LR, Rosa TEC, Oliveira ZM. Perfil do idoso em área metropolitana na região sudeste do Brasil: resultados de inquérito domiciliar. Rev Saúde Pública. 1993;27(2):87-94.

Rocha $\mathrm{CH}$, Oliveira $\mathrm{AP}$, Ferreira $\mathrm{C}$, et al. Adesão à prescrição médica em idosos de Porto Alegre, RS. Ciência e Saúde Coletiva. 2008;13 (suppl):70310. 
Romero-Sanchez J, Garcia-Cardenas V, Abaurre R, Martínez-Martínez F, Garcia-Delgado P. Prevalence and predictors of inadequate patient medication knowledge. J Eval Clin Pract. 2016;22(5):808-15.

Roth MT, Ivey JL. Self-reported medication use in community-residing older adults: A pilot study. Am J Geriatr Pharmacother. 2005;3(3):196-204.

Ruppar TM, Cooper PS, Mehr DR, Delgado JM, Dunbar-Jacob JM. Medication adherence interventions improve heart failure mortality and readmission rates: systematic review and meta-analysis of controlled trials. $J$ Am Heart Assoc. 2016;17:5-6.

Safran DG, Neuman P, Schoen C, Kitchman MS, Wilson IB, Cooper. Prescription drug coverage and seniors: findings from a 2003 national survey. Health Aff (Millwood). 2005;suppl:152-66.

Salvi F, Rossi L, Lattanzio F, Cherubini A. Is polypharmacy an independent risk factor for adverse outcomes after an emergency department visit? Intern Emerg Med. 2016; online.

Santos TR, Lima DM, Nakatani AY, Pereira LV, Leal GS, Amaral RG. Medicine use by the elderly in Goiania, Midwestern Brazil. Rev Saude Publica. 2013;47(1):94-103.

Sears K, Woo KY, Almost J, Wilson R, Frymire E, Whitehead M, Van Den Kerkhof E. Medication knowledge among older adults admitted to home care in Ontario during 2012-2013. J Healthc Qual. 2016; online.

Sganga F, Landi F, Ruggiero C, Corsonello A, Vetrano DL, Lattanzio F, Cherubini A, Bernabei R, Onder G. Polypharmacy and health outcomes among older adults discharged from hospital: results from the CRIME study. Geriatr Gerontol Int. 2015;15(2):141-6. 
Sherbourne CD, Stewart AL. The MOS social support survey. Soc Sci Med. 1991;32(6):705-14.

Souza JG, Apolinario D, Magaldi RM, Busse AL, Campora F, Jacob-Filho W. Functional health literacy and glycaemic control in older adults with type 2 diabetes: a cross-sectional study. BMJ Open. 2014;4(2):e004180.

Sundararajan V, Henderson T, Perry C, Muggivan A, Quan H, Ghali WA. New ICD-10 version of the Charlson comorbidity index predicted in-hospital mortality. J Clin Epidemiol. 2004;57(12):1288-94.

Svarstad BL, Chewning BA, Sleath BL, Claesson C. The Brief Medication Questionnaire: a tool for screening patient adherence and barriers to adherence. Patient Educ Couns. 1999;37(2):113-24.

Thomas EJ, Brennan TA. Incidence and types of preventable adverse events in elderly patients: population based review of medical records. BMJ. 2000; 320(7237):741-4.

Turra CM, Rios-Neto E. Intergenerational accounting and economic consenquences of aging in Brazil. Trabalho apresentado no XXIV IUSSP General Population. Conference, Salvador, Brasil, 2001.

Voils CI, Hoyle RH, Thorpe CT, Maciejewski ML, Yancy WS Jr. Improving the measurement of self-reported medication nonadherence. J Clin Epidemiol. 2011;64(3):250-4.

Wimmer BC, Bell JS, Fastbom J, Wiese MD, Johnell K. Medication regimen complexity and polypharmacy as factors associated with all-cause mortality in older people: A Population-Based Cohort Study. Ann Pharmacother. 2016;50(2):89-95. 
Wimmer BC, Dent E, Bell JS, Wiese MD, Chapman I, Johnell K, Visvanathan R. Medication regimen complexity and unplanned hospital readmissions in older people. Ann Pharmacother. 2014;48(9):1120-8.

Wimmer BC, Johnell K, Fastbom J, Wiese MD, Bell JS. Factors associated with medication regimen complexity in older people: a cross-sectional population-based study. Eur J Clin Pharmacol. 2015;71(9):1099-108.

Yam FK, Lew T, Eraly SA, Lin HW, Hirsch JD, Devor M. Changes in medication regimen complexity and the risk for 90-day hospital readmission and/or emergency department visits in U.S. Veterans with heart failure. Res Social Adm Pharm. 2016;12(5):713-21.

Yesavage JA, Brink TL, Rose TL, Lum O, Huang V, Adey M, Leirer VO. Development and validation of a geriatric depression screening scale: a preliminary report. J Psychiat Res. 1982;17:37-49.

Zartman AL, Hilsabeck RC, Guarnaccia CA, Houtz A. The Pillbox Test: an ecological measure of executive functioning and estimate of medication management abilities. Arch Clin Neuropsychol. 2013;28(4):307-19. 